\title{
WestVirginiaUniversity
}

THE RESEARCH REPOSITORY @ WVU

Graduate Theses, Dissertations, and Problem Reports

2004

\section{West Virginia coal fly ash sorption of BTEX}

Jerome C. Wentz

West Virginia University

Follow this and additional works at: https://researchrepository.wvu.edu/etd

\section{Recommended Citation}

Wentz, Jerome C., "West Virginia coal fly ash sorption of BTEX" (2004). Graduate Theses, Dissertations, and Problem Reports. 2052.

https://researchrepository.wvu.edu/etd/2052

This Thesis is protected by copyright and/or related rights. It has been brought to you by the The Research Repository @ WVU with permission from the rights-holder(s). You are free to use this Thesis in any way that is permitted by the copyright and related rights legislation that applies to your use. For other uses you must obtain permission from the rights-holder(s) directly, unless additional rights are indicated by a Creative Commons license in the record and/ or on the work itself. This Thesis has been accepted for inclusion in WVU Graduate Theses, Dissertations, and Problem Reports collection by an authorized administrator of The Research Repository @ WVU. For more information, please contact researchrepository@mail.wvu.edu. 


\title{
WEST VIRGINIA COAL FLY ASH SORPTION OF BTEX
}

\author{
Jerome C. Wentz
}

Thesis submitted to the Eberly College of Arts and Sciences at West Virginia University

in partial fulfillment of the requirements for the degree of

\section{Master of Science}

in

Geology

John J. Renton, Ph.D., Chair Louis M. McDonald, Ph.D.

Joseph J. Donovan, Ph.D.

Department of Geology and Geography

\author{
Morgantown, West Virginia
}

2004

Keywords: Sorption, Fly Ash, BTEX 


\section{ABSTRACT \\ West Virginia Coal Fly Ash Sorption of BTEX}

\section{Jerome C. Wentz}

Sorption is a term used in the environmental field to describe how chemical contaminants in soil and groundwater adhere to solid particles such as: clay, peat and activated carbon for the purposes of remediation, fate and transport. A potential surrogate for sorption of chemical contaminants in groundwater is coal fly ash. Batch test experiments have demonstrated coal fly ash's ability to remove hydrophobic, organic petroleum contaminants including: benzene, toluene, ethylbenzene and xylenes (BTEX) in groundwater through the processes of sorption. Coal fly ash is a byproduct material of coal fired power plants that is often disposed of on-site or at landfills. A beneficial use of coal fly ash is for the sorption of BTEX in groundwater. 


\section{ACKNOWLEDGMENTS}

I'd like to thank the many people who contributed to this research, including:

- Louis McDonald in the WVU College of Agriculture, Forestry and Consumer Science, for use of the Plant and Soil Sciences Division's laboratory and materials

- Dr. John Renton and Harry(Duke)Brown in the WVU Department of Geology and Geography for XRF chemical composition analysis of coal fly ash samples using the Phillips 1480 XRF Wavelength Spectrometer

- Dr. John Sencindiver and Brian Cooley in the WVU College of Agriculture, Forestry and Consumer Science, for use of Plant and Soil Sciences Division's LECO CNS-2000 to determine percent carbon of coal fly ash samples

- Dr. Sven Verlinden in the WVU college of Agriculture, Forestry and Consumer Science, for use of the Plant and Soil Science Division's Spectronic 20®, Genesys 5, single wavelength Spectrophotmeter

- Bob Romanofski and Don Floyd, DOE, National Energy Technology Laboratories (NETL), Morgantown, WV for determining surface areas of coal fly ash samples using Multipoint BET Quantachrome ${ }^{\circledR}$ Autosorb gas sorption system analysis. 


\section{TABLE OF CONTENTS}

ABSTRACT ….......................................................................................................................ii

ACKNOWLEDGMENTS...................................................................................ii

TABLE OF CONTENTS .................................................................................................iv

LIST OF TABLES ……............................................................................................................ v

LIST OF FIGURES ................................................................................................................ vi

Chapter 1: Introduction ....................................................................................................... 1

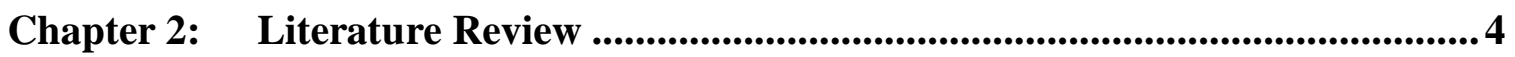

Chapter 3: $\quad$ Materials and Methods ................................................................................. 23

3.1 Chemical Composition: ........................................................................ 23

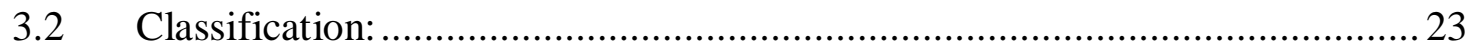

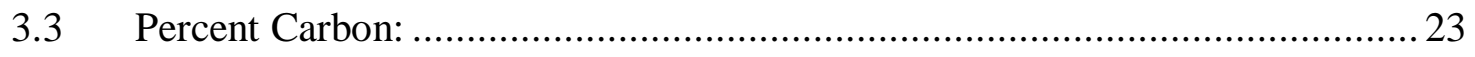

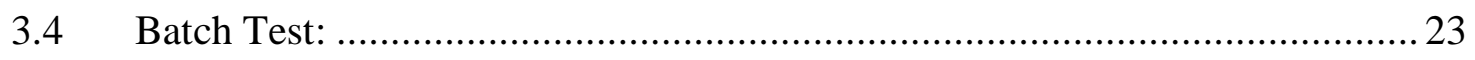

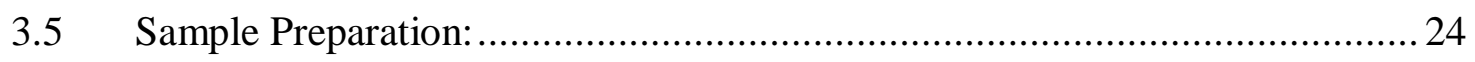

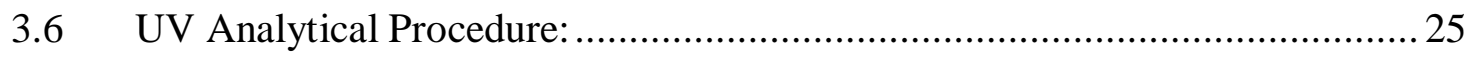

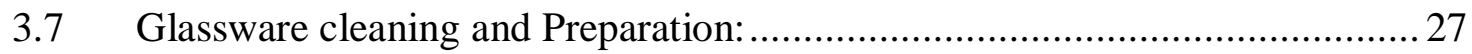

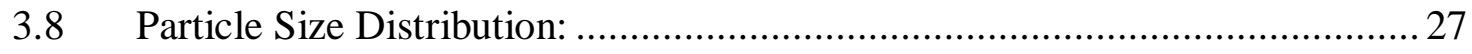

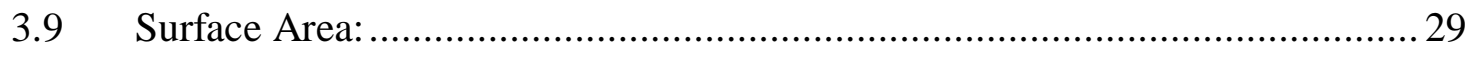

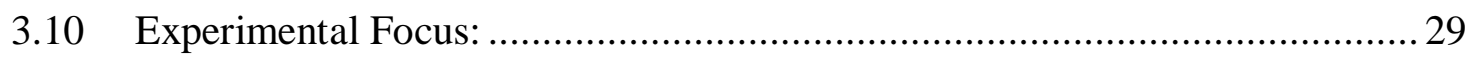

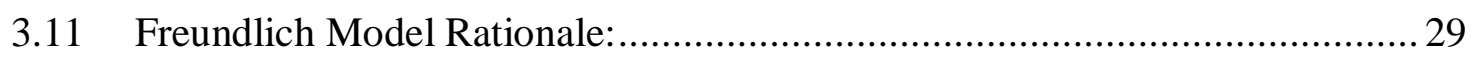

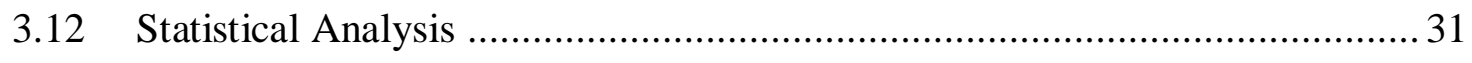

Chapter 4: Results .................................................................................................... 32

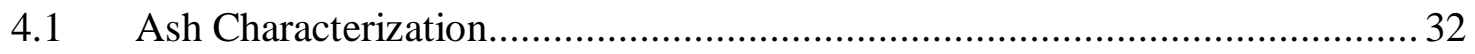

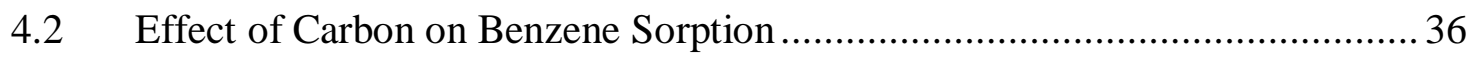

4.3 Effects of analyte and temperature on two low carbon ashes ............................ 38

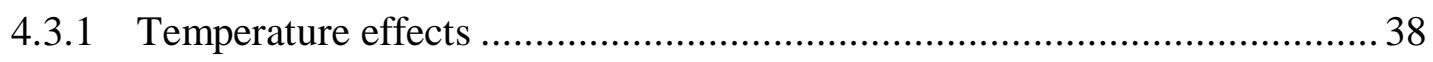

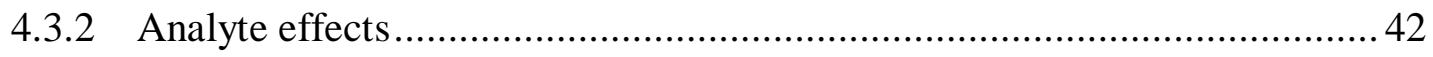


Chapter 5: Conclusion and Discussion................................................................4 44

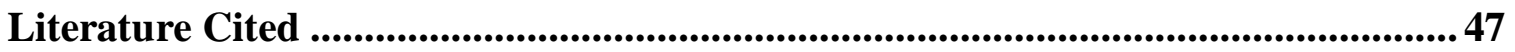

Appendix I. Batch Test Experimental Data ........................................................................55

Appendix II. UV Analytical Curves ....................................................................................6 67

\section{LIST OF TABLES}

Table 1. Chemical Composition (\% by weight) of ash from various coal power plants....7

Table 2. Typical composition of Class F and C ashes as defined by ASTM (1997),.........8

Table 3. Comparative Surface Areas of Various Sorbents............................................ 8

Table 4. Average carbon content and $\mathrm{K}_{\mathrm{f}}$ values of threeMichigan fly ashes (modified

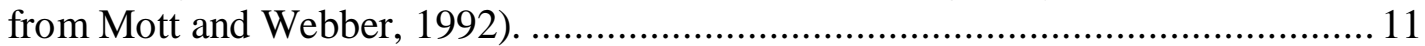

Table 5. Summary of pre- and post-CCP application water quality at the Chaplin Hill Mine, Morgantown WV. (The data are for samples taken and analyzed by Anker Energy Corporation and reported to the state of West Virginia. All values in $\mathrm{mg} / \mathrm{L}$ ).

Table 6. Comparison of West Virginia and Pennsylvania standards for CCP leachate concentrations (taken from Ziemkiewicz and Skousen, 2000)............................... 15

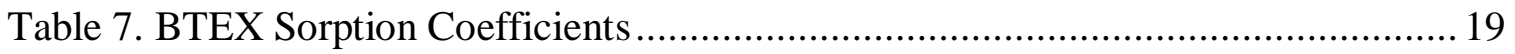

Table 8. Organic matter normalized sorption coefficients ............................................. 19

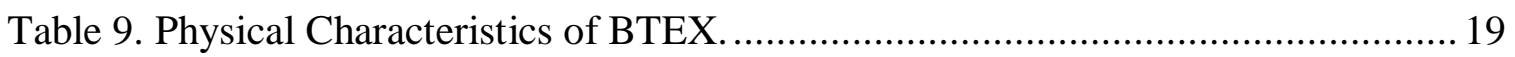

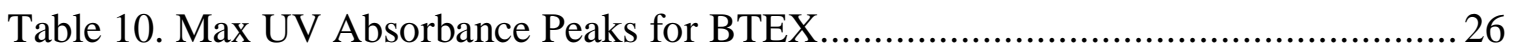

Table 11. XRF Chemical Composition \% by weight........................................................ 33

Table 12. Coal Flyash Physical Characteristics............................................................... 33

Table 13. Effects of temperature and ash source on average (standard deviation) percent

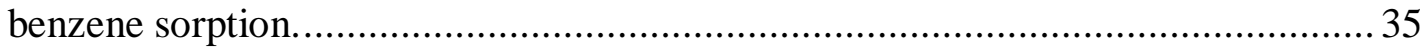

Table 14.The SAS System, GLM Procedure: Duncan's Multiple Range Test for Percent

Sorption 


\section{LIST OF FIGURES}

Figure 1. Percentage of Leading Coal Fly Ash Uses, 1998 (Source: American Coal Ash Association; Taken From: Kalyoncu, 1998) ..........................................................5

Figure 2. Microscopic Fly Ash Structure (From Western Fly Ash Company) .................. 6

Figure 3. Microscopic Fly Ash (Courtesy of U. of Québec) …………............................. 6

Figure 4. Schematic representation of sorption processes. (Dan Ferrante, 1996, Virginia

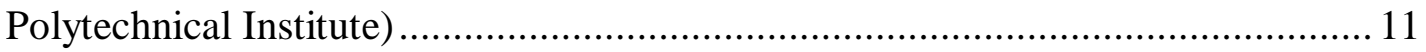

Figure 5. BTEX Molecular Organic Structures (taken from Sax and Lewis, Hawley's Condensed Chemical Dictionary. $11^{\text {th }}$ ed., 1987)............................................. 21

Figure 6. Benzene sorption onto three different coal fly ashes: Alb-dark, Ald-light, and

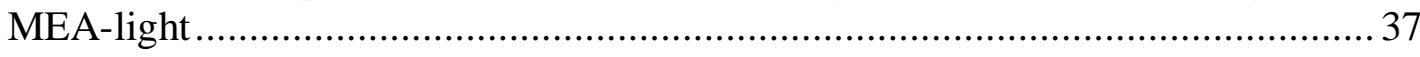

Figure 7. Equilibrium concentration vs adsorbed concentration of benzene and toluene on ashes Alb-L and MEA-L at $25^{\circ} \mathrm{C}$

Figure 8. Equilibrium concentration vs adsorbed concentration of ethylbenzene and xylene on ashes Alb-L and MEA-L at $25^{\circ} \mathrm{C}$. 40 


\section{Chapter 1: Introduction}

More than 2000 chemical contaminants have been found in wastewater, while 750 of these chemical contaminants have been identified in drinking water. More than 600 of these drinking water contaminants are of organic origin (Singh, 1994). Petroleum hydrocarbon products are found as contaminants in soils, ground water aquifers and surface waters. This is the result of leaking underground gasoline and diesel storage tanks, surface and marine transportation spills (Krumholz et al., 1996). In 1996, underground storage tanks were reported to Congress as the leading source of groundwater contamination in the nation according to the 1996 National Water Quality Inventory Report, section 305(b) (Anzzolin and Siedlecki, 2001). In 1998, more than 85,000 underground storage tanks (USTs) were reported from hydrogeologic settings in 22 states with $57 \%$ of these USTs having had confirmed contaminant releases and $60 \%$ of these settings reported volatile organic chemicals (VOCs) and petroleum compounds as contaminants of concern (Anzzolin and Siedlecki, 2001). The BTEX organic chemicals (benzene, toluene, ethylbenzene and xylene) are very common in the petroleum and chemical industry, which makes them ubiquitous and presents great risks to public health and the environment. Benzene is a carcinogen. Toluene is currently the most produced chemical in the United States (All American Environmental Services, 2002). O-Xylene is included in the U.S. EPA’s Priority Pollutant List (Banaerjee et. al., 1997).

Some groundwater remediation strategies for treatment of organic contaminants include: chemical oxidation, coagulation, froth flotation and adsorption. Of these methods, adsorption appears to offer the best prospects for overall treatment (Singh et al., 1994). 
When choosing an adsorbent to remove organic compounds, cost effectiveness, availability and adsorptive properties are the main criteria (Virargharan, 1998). The use of Permeable Reactive Barriers (PRBs) is a proven remediation technique widely used for removal of metals and non-metals in aqueous solutions. For attenuation, barrier materials should provide retardation through: adsorption, precipitation, filtration, microbiodegradation, or any combination of these (Nhan et al., 1996). PRBs are inexpensive, low maintenance, in-situ, robust, passive remediation systems that are relatively easy to install. The PRB shape may be custom designed to provide maximum efficiency (Woodward, 2001). Adsorbents such as: activated carbon, polyurethane foam, olive shells, coconut shells, peanut hulls, montmorillonite, peat and red clay have proven effective, but are often costly. A widely available, low-cost adsorbent for organic chemicals would be high carbon coal fly ash.

High carbon coal fly ash meets all adsorbent and attenuation criteria especially when considering cost effectiveness compared to alternative sorbents. The relatively high loss on ignition content ( $\mathrm{LOI}=7.9 \%)$ of high carbon coal fly ash is indicative of its sorption affinity for low molecular weight, non-polar organic compounds in aqueous solution (Nahn et al., 1996). Fly ash has a significant capacity to absorb organic compounds in aqueous solution (Nelson and Guarino, 1969; Eye and Basu, 1970; Johnson et al., 1965; Deb et al., 1966; Grupta et al., 1988, 1990; Mott and Weber, 1992; Viraraghavan and Alfara, 1994). Fly ash is an active adsorbent, which adsorbs polycyclic aromatic hydrocarbons (Rothenberg, et al.). Fly ash has been demonstrated as capable of removing O-xylene from an aqueous solution (Banerjee et al, 1995). Coal Fly ash is a by-product material of modern coal fired power plants. It is collected via cyclonic and 
electrostatic precipitators, from flue gas, before entering the stacks. Collected fly ash is either disposed of in landfills or lagoons on site (Banerjee, 1995). Because coal fly ash is of organic origin, it naturally has high carbon content. The amount of carbon content with in coal fly ash is generally higher than most soils, but ranges depending upon the combustion facility. Carbon content is important because it is responsible for the organic sorption behavior. In the remediation industry, activated carbon is often used to adsorb aqueous and vapor phase organic contaminants. Coal fly ash is a potential substitute for activated carbon as a low-cost PRB sorbent medium. 


\section{Chapter 2: Literature Review}

At least 88 million tons of coal fly ash by-product materials are generated annually in the United States and 60 million tons annually in Europe (Querol et al., 1998). Over one billion tons of coal fly ash has been stockpiled in the United States. On average only about $25 \%$ of the coal fly ash is utilized (Nhan et al., 1996). Previous technologies involving the uses of fly ash have been as an ingredient in concrete and bricks, for the construction of roads, dams and bridges (Roy et al, 1981) (Figure1). Fly ash has been used extensively as an alkaline amendment to reduce acid mine drainage (Daniels et al, 1993; Skousen, 1998). Fly ash has also been used in the plastics industry as a low-cost, high performance substitute polymeric material filler (Quattroni, 1993). Coal fly ash is an effective chemical barrier for leachate of municipal solid waste landfills (Nhan et al., 1996).

Fly ash consists of an agglomeration of micro-spheres composed mostly of silica and aluminum, which are up to hundreds of micrometers in diameter. (Banerjee et al., 1995; Viraraghavan et al., 1998) (Figure2: Figure3). The dominant mineral compounds are amorphous silica and aluminum oxides (Tables 1: Table 2). Crystalline-like minerals include: quartz $\left(\mathrm{SiO}_{2}\right)$, hematite $\left(\mathrm{Fe}_{2} \mathrm{O}_{3}\right)$, magnetite $\left(\mathrm{Fe}_{3} \mathrm{O}_{4}\right)$, lime $(\mathrm{CaO})$, anhydrite $\left(\mathrm{CaSO}_{4}\right)$, mullite $\left(\mathrm{Al}_{6} \mathrm{Si}_{2} \mathrm{O}_{13}\right)$ and feldspars (Querol et al., 1998). The type of coal used and degree of combustion result in variable compositions of the above end members.

There are four main classes of coal combustion products (CCPs): 1) Class F, 2) Class C, 

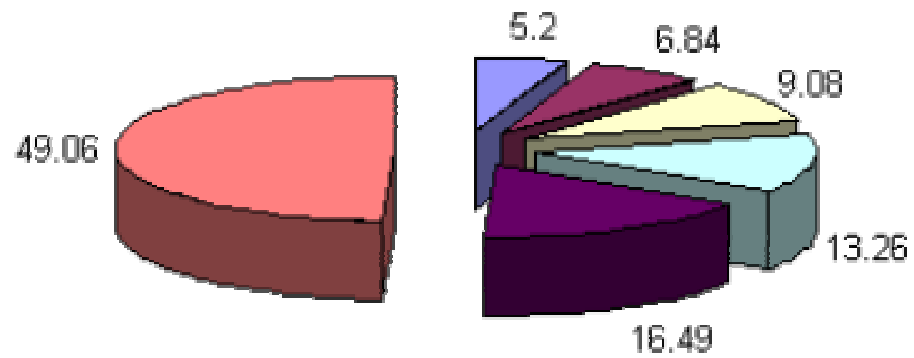

$\square$ Miscellaneous

$\square$ Road base-subbase

$\square$ Mining applications

$\square$ Structural Fill

- Waste Stabilization

$\square$ Concrete

Figure 1. Percentage of Leading Coal Fly Ash Uses, 1998 (Source: American Coal Ash Association; Taken From: Kalyoncu, 1998) 


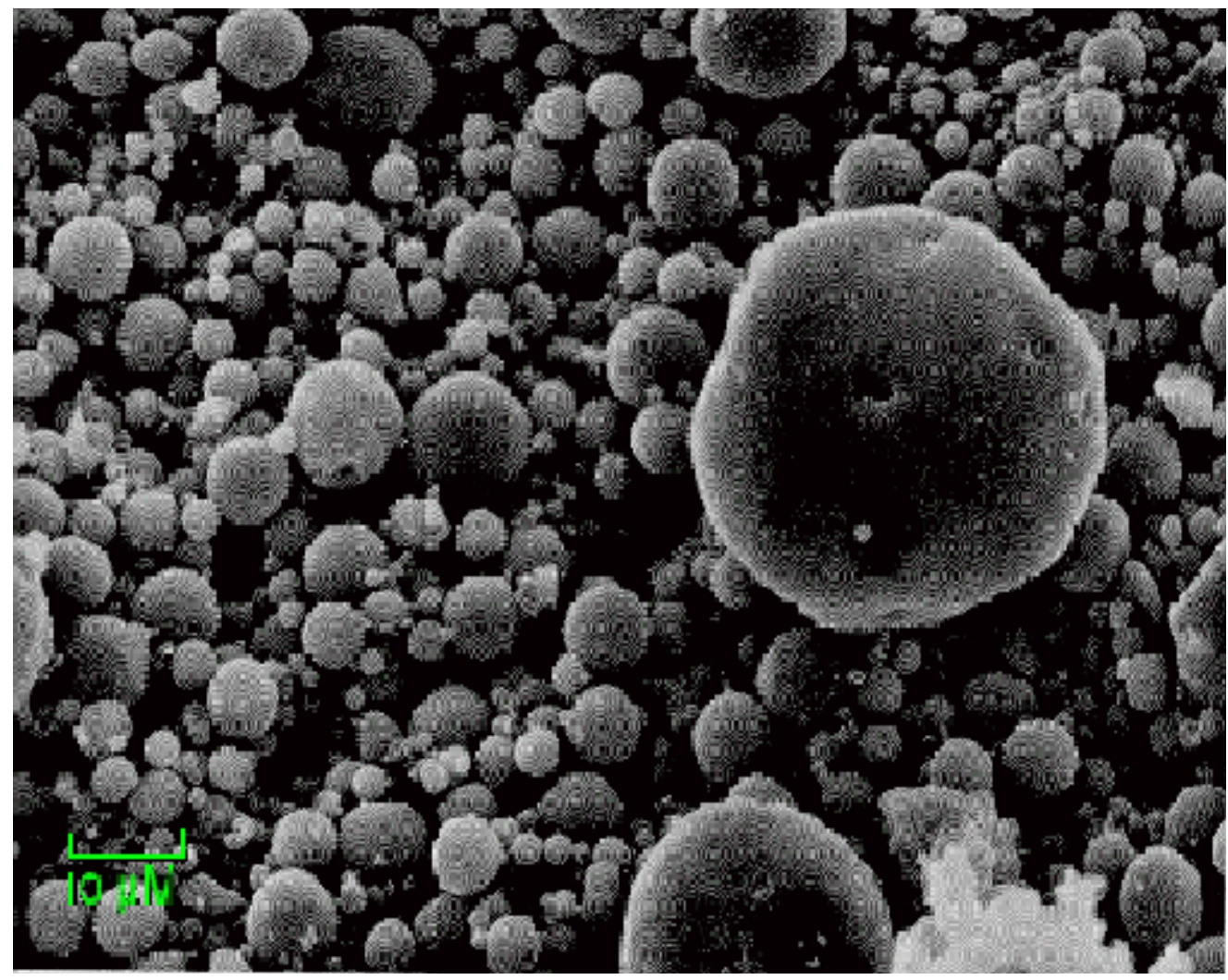

Figure 2. Microscopic Fly Ash Structure (From Western Fly Ash Company)

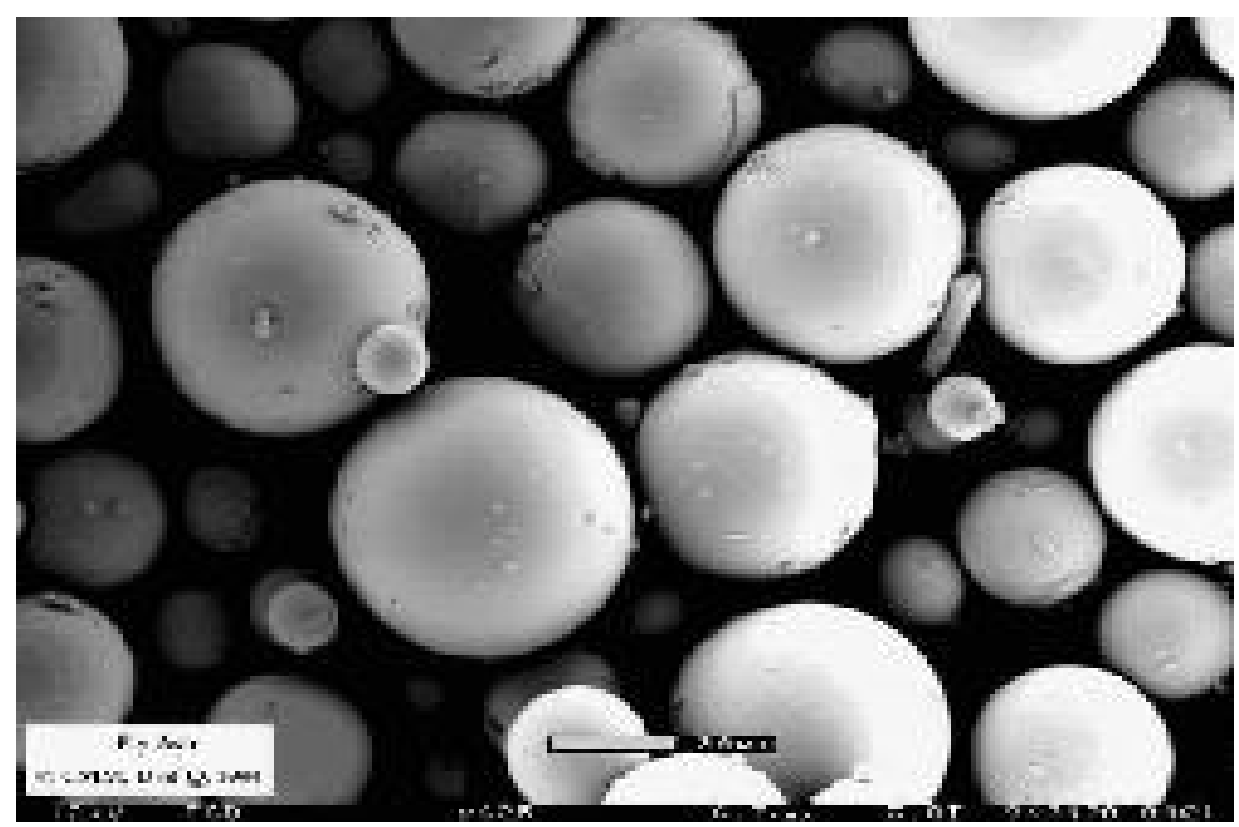

Figure 3. Microscopic Fly Ash (Courtesy of U. of Québec) 
Table 1. Chemical Composition (\% by weight) of ash from various coal power plants.

\begin{tabular}{|c|c|c|c|c|c|c|c|c|c|c|c|c|c|c|}
\hline \multirow[t]{2}{*}{ Coal Ash $^{1}$} & \multicolumn{14}{|c|}{ Constituent } \\
\hline & $\mathrm{MnO}$ & $\mathrm{K}_{2} \mathrm{O}$ & $\mathrm{SiO}_{2}$ & $\mathrm{Al}_{2} \mathrm{O}_{3}$ & $\mathrm{SO}_{3}$ & $\mathrm{Fe}_{2} \mathrm{O}_{3}$ & $\mathrm{Na}_{2} \mathrm{O}$ & $\mathrm{MgO}$ & $\mathrm{TiO}_{2}$ & $\mathrm{CaO}$ & $\mathrm{P}_{2} \mathrm{O}_{5}$ & $\mathrm{C}$ & $\mathrm{H}$ & $\mathrm{N}$ \\
\hline & & & & & & & $\%$ & & & & & & & \\
\hline SPC & . & & 50.7 & 21.8 & 0.53 & 4.5 & . & 4.3 & 0.8 & 11.5 & e & . & $\cdot$ & \\
\hline WV & . & 1.5 & 45.7 & 26 & 2.6 & 17.1 & 0.6 & 1.2 & 1.2 & 3.8 & 0.3 & . & . & . \\
\hline OHRD & . & & 42.3 & 23.2 & 0.9 & 14.7 & 0.7 & 1 & 1 & 2.8 & 0.5 & & & \\
\hline A-unknown & . & 2.3 & 62.5 & 24.6 & 0.4 & 1.2 & 0.2 & 0.3 & 0.6 & 0.3 & t & 9.2 & 0.2 & 0.3 \\
\hline A-Ulan & . & 0.6 & 58 & 27.2 & 0.1 & 2.7 & . & 0.1 & 1 & 0.2 & . & 3.5 & 0.1 & 0.2 \\
\hline A-Drayton I & . & & 50.5 & 26.3 & 0.5 & 8 & . & 0.3 & 1.7 & 2 & . & 4.6 & 0.1 & 0.2 \\
\hline A-Drayton II & . & . & 47.9 & 25.9 & 1 & 4.9 & . & 0.3 & 1.7 & 4.5 & . & 6.3 & 0.2 & 0.3 \\
\hline A-Grose Valley & . & 0.6 & 53.7 & 30.4 & 0.2 & 1.6 & . & 0.1 & 1.1 & 0.4 & . & 5 & 0.1 & 0.2 \\
\hline A-Hazelwood & . & 0.6 & 20.5 & 10.1 & 11.5 & 5.9 & 7 & 12 & 0.7 & 15.1 & . & 2.8 & 0.1 & 0.2 \\
\hline A-Yallourn & . & 0.2 & 3.7 & 1.4 & 14.5 & 26.2 & 5.3 & 20.1 & 0.1 & 8.7 & . & 7.5 & 0.2 & 0.2 \\
\hline A-Loy Yang 0130 & . & 0.3 & 16.3 & 20.4 & 12 & 6.9 & 6.5 & 13.3 & 0.6 & 4.1 & . & 5.4 & 0.2 & 0.3 \\
\hline A-Loy Yang 2100 & . & 0.9 & 51.4 & 18.3 & 3.5 & 7.4 & 3.5 & 5.5 & 1.3 & 1.9 & . & 2.4 & 0.1 & 0.2 \\
\hline S-Escatron & 0.02 & 0.6 & 19.6 & 5.1 & 23.2 & 2.7 & 0.5 & 0.7 & 0.2 & 44.5 & 0.08 & - & & \\
\hline S-Teruel & 0.04 & 1.6 & 47.2 & 25.6 & 0.6 & 16.6 & 0.2 & 1.2 & 0.8 & 5.6 & 0.2 & . & & \\
\hline S-Escucha & 0.03 & 2.3 & 49.5 & 26.7 & 0.4 & 14.3 & 0.3 & 1.1 & 1 & 2.3 & 0.3 & . & 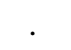 & . \\
\hline S-La Robla & 0.1 & 2.6 & 40.1 & 23.3 & 0.4 & 14.3 & 0.3 & 2 & 0.9 & 8.9 & 0.8 & . & 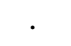 & \\
\hline S-Compos & 0.08 & 4.3 & 49.8 & 26.1 & 0.3 & 8.4 & 0.8 & 2.4 & 1 & 2.7 & 0.5 & . & 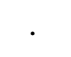 & \\
\hline S-Meirama & 0.05 & 0.8 & 51.9 & 26.4 & 0.2 & 4.8 & 0.4 & 2.3 & 1.5 & 7.5 & 0.4 & . & . & . \\
\hline S-Narcea & 0.09 & 3.9 & 54.3 & 23 & 0.1 & 7 & 0.8 & 2.7 & 1.1 & 4.2 & 0.2 & . & . & \\
\hline S-Pontes & 0.1 & 1.3 & 46.7 & 31 & 0.8 & 9.4 & 0.3 & 1.9 & 1.2 & 6.7 & 0.2 & . & . & \\
\hline S-Cercs & 0.05 & 0.9 & 27.8 & 13.7 & 3.3 & 4.3 & 0.6 & 0.8 & 0.5 & 42.6 & 0.4 & . & . & \\
\hline S-Dou He & 0 & 0.6 & 48.7 & 40.7 & 0.4 & 3.5 & 0.2 & 0.5 & 1.3 & 2.8 & 0.4 & . & . & \\
\hline S-Puerto & 0.1 & 2.4 & 58.4 & 29.3 & 0.2 & 7.5 & 0.4 & 1 & 0.7 & 0.9 & 0.1 & . & . & . \\
\hline S-Espiel & 0.1 & 4.1 & 52 & 34.2 & 0.1 & 6.1 & 0.6 & 1.6 & 0.9 & 2.1 & 0.4 & . & . & \\
\hline S-Barrios & 0.1 & 0.7 & 45.1 & 37.6 & 0.7 & 2.8 & 0.4 & 2.2 & 1.5 & 9 & 1.7 & . & . & \\
\hline S-Sribera & 0 & 4.2 & 49.6 & 32.3 & 0.4 & 7.7 & 0.7 & 1.7 & 0.9 & 3.2 & 0.1 & . & . & . \\
\hline Average & 0.1 & 1.7 & 44.0 & 24.3 & 3.0 & 8.1 & 1.4 & 3.1 & 1.0 & 7.6 & 0.4 & 5.2 & 0.1 & 0.2 \\
\hline Maximum & 0.1 & 4.3 & 62.5 & 40.7 & 23.2 & 26.2 & 7 & 20.1 & 1.7 & 44.5 & 0.5 & 9.2 & 0.2 & 0.3 \\
\hline Minimum & 0 & 0.2 & 3.7 & 1.4 & 0.1 & 1.2 & 0.2 & 0.1 & 0.1 & 0.2 & 0.3 & 2.4 & 0.1 & 0.2 \\
\hline
\end{tabular}


Table 2. Typical composition of Class F and C ashes as defined by ASTM (1997).

\begin{tabular}{ccc}
\hline Parameter & Class F & Class C \\
\hline $\mathrm{SiO} 2$ & 54.9 & 39.9 \\
$\mathrm{Al} 2 \mathrm{O} 3$ & 25.8 & 16.7 \\
$\mathrm{Fe} 2 \mathrm{O} 3$ & 6.9 & 5.8 \\
$\mathrm{CaO}$ & 8.7 & 24.3 \\
$\mathrm{SO} 3$ & 0.6 & 3.3 \\
Loss on Ignition (LOI)(@750C) & $2.8 \%$ & $0.5 \%$ \\
\hline (modified from Ziemkiewicz and Skousen, 2000)
\end{tabular}

Table 3. Comparative Surface Areas of Various Sorbents.

\begin{tabular}{lcl}
\hline Coal fly ash & Surface Area & Reference \\
\hline & $\mathrm{m}^{2} \mathrm{~g}^{-1}$ & \\
Karn & 1.14 & Mott and Webber, 1992 \\
Trenton & 2.65 & Mott and Webber, 1992 \\
Cobb & 3.52 & Mott and Webber, 1992 \\
SPC & $1.5-1.7$ & Viraraghavan and Alfaro, 1998 \\
Montana rosebud, FBC & 5.2 & Rothenberg, et. al., 1991 \\
Colorado, stoker fed & 37.2 & Rothenberg, et. al., 1991 \\
Western, pulverized & 5.2 & Rothenberg, et. al., 1991 \\
Typical Kaolinite clay & 12 & Fetter, 1993 \\
Activated Carbon & $1050-1250$ & CPL Carbon Link, 2000 \\
\hline
\end{tabular}


3) Fluidized Bed Combustion, and 4) Flue Gas Desulfurization. C- and F- classes comprise the bulk of CCPs. Fly ashes are characterized as C- or F- class based on the typical constituent chemical composition (Table 2). In addition C-class fly ash typically contains greater than $10 \%$ lime, whereas F-class contains less than $10 \%$ lime (Ziemkiewicz and Skousen,2000).

The percent weight loss on ignition (LOI) gives a crude measure of the organic content of the soil material or fly ash. As a result of organic content, high LOI coal fly ashes tend to be more favorable for sorption of organics chemicals compared to other coal fly ashes. High LOI coal fly ash exhibits many properties similar to that of activated carbon, which is commonly used in the environmental industry for vapor and liquid phase adsorption systems. Activated carbon is a generic term generally used to describe a variety of carbonaceous adsorbents with a highly crystalline form and extensively developed internal pore structure. The finer the particle size of activated carbon, the better the access to the surface area and the faster rate of adsorption kinetics (CPL Carbon Link Corporation, 2001). The sorption capacity is directly proportional to the total exposed surface (Banerjee et al., 1995). Similarly, fly ash is characterized by its fineness, spherical particles, large surface area and its wide particle size distribution (Banerjee et al., 1995). However, activated carbon surface areas tend to be much higher than that of coal fly ash (Table 3$)$.

The technique of steam activation, similar to coal combustion, is generally used for the activation of coal and coconut shell raw material. In the presence of steam, temperatures are raised to $800-1100^{\circ} \mathrm{C}$ to generate activated carbon. Coal combustion processes take 
place at higher temperatures of $1300-1700^{\circ} \mathrm{C}$ to generate steam to turn turbines. During steam activation, carbon monoxide and hydrogen gases are produced and further oxidized (burned). The resultant activated carbon exhibits a fine pore structure composed of micropores $(r<1 \mathrm{~nm})$, mesopores $(r=1-25 \mathrm{~nm})$ and macropores $(r>25 \mathrm{~nm})$, which are ideal for adsorption of both liquid and vapor phase (CPL Carbon Link Corporation, 2001).

Adsorption to the surface of the granular activated carbon (GAC) is usually considered negligible because the granular surface area is so small compared to that of the micropores and submicropores (Metcalf and Eddy, 1972). The macropores are used as the entrance to the activated carbon, mesopores for the transportation and micropores for adsorption (CPL Carbon Link Corporation, 2001). Similarly Banerjee et al. speculate two modes of diffusion may be responsible for the coal fly ash adsorption process. First, is the rapid external or surface diffusion of the sorbent on to the fly ash particles via molecular diffusion. Second, is the slower internal diffusion of solute among the pores and capillaries of the carbon content present with in the fly ash.

Sorption is the transformation processes by which soluble or vapor phase molecules (sorbate) transfer to the solid phase associated with the sorption medium (sorbent). Adsorption is a two-dimensional sorption surface process, whereas absorption refers to a three dimensional integrated sorption matrix process (Schwarzenbach et al, 1993) (Figure 4). The distinction between chemical and physical adsorption is difficult to differentiate, therefore the term sorption is referred to (Metcalf and Eddy, 1972). Sorption is important because it may directly be responsible for the fate and impact of chemicals in the environment (Schwarzenbach et al, 1993). Sorption is not always a single, simple 


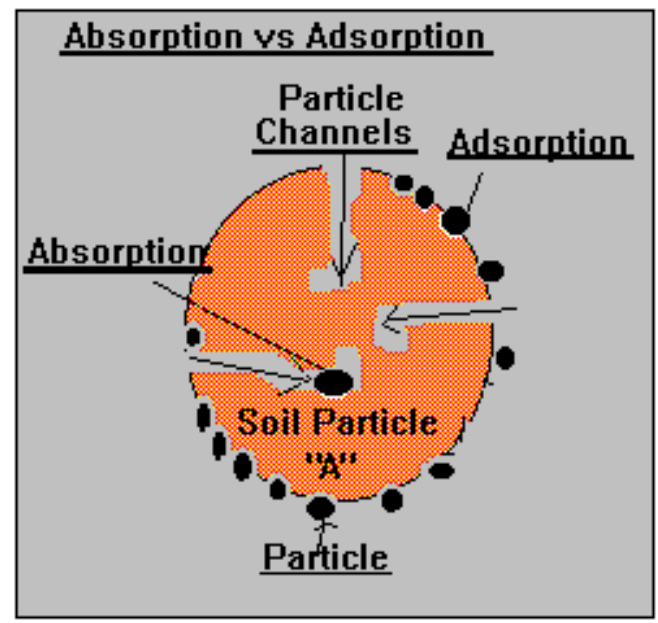

Figure 4. Schematic representation of sorption processes. (Dan Ferrante, 1996, Virginia Polytechnical Institute)

Table 4. Average carbon content and $K_{\mathrm{f}}$ values of threeMichigan fly ashes (modified from Mott and Webber, 1992).

\begin{tabular}{|c|c|c|c|c|}
\hline Ash Source ${ }^{1}$ & Carbon & $\mathrm{Kf}^{1}$ & $\mathrm{Kf}^{1}$ & $\mathrm{Kf}^{1}$ \\
\hline & $\%$ & CTET $^{2}$ & $\mathrm{TCE}^{3}$ & $\mathrm{TTCE}^{4}$ \\
\hline Karn & 4.69 & 0.348 & 0.658 & 1.37 \\
\hline Trenton & 6.14 & 0.387 & 0.920 & 2.39 \\
\hline Cobb & 6.52 & 1.53 & 1.71 & 4.88 \\
\hline
\end{tabular}


process. A combination of interactions between sorbent and sorbate are involved in the sorption process (Westall, 1987; Schwarzenbach et al, 1993).

Sorption of aromatic hydrocarbons has been shown to be proportional to residual carbon content of fly ash (Low and Bately, 1988; Mott and Webber, 1992). The capacity for adsorption increases with increasing carbon content of fly ash (Banerjee et al., 1995). Penetration of neutral organic chemicals into any solid phase, natural organic matter offers a relatively non-polar environment into which hydrophobic organic chemicals tend to be attracted with out competition from surrounding water molecules (Schwarzenbach, 1993; Fetter, 1993). Adsorption of PAH (polycyclic aromatic hydrocarbons) molecules was found to increase with increasing residual carbon content of the fly ash sorbent (Low and Batley, 1988). Mott and Weber, 1992, further demonstrate this aspect in Table 4. The Cobb fly ash, because of the larger percentage of carbon present and larger surface area (Table 3), had more sorption capacity compared to the Trenton and Karn fly ashes On average, carbon content in coal-burning fly ash is currently 6 percent (Hwang, et. al., 2002).

Ultimately, greater sorption by fly ash occurs with small particle size and higher temperatures (Singh et al., 1994). Kinetics studies by Banerjee et al., 1997 and Singh et al., 1994 of batch test sorption of O-xylene and phenol onto flyash demonstrate that adsorption rate increased with increasing temperature. Sorption by fly ash is an endothermic, kinetic process whereby the rate of removal or organics is proportional to temperature (Singh et al., 1994). Singh suggested that the number of active surface centers available for sorption have increased with temperature and that increasing the 
temperature may also enhance the rate of intraparticle diffusion. At high temperatures, the high negative values of molar free energy $(\Delta G)$ are indicative of high sorption (Singh et al., 1994).

Some problems with the use of a high carbon ash as a sorbent, are that some coal fly ashes have potential to leach metals and non-metals inherent to the ash origin. Studies of a fly ash landfill in southern Wisconsin have shown that ground water in contact with ash has been substantially modified primarily by sulfates, calcium and magnesium inherent to the ash. However, toxic metals with in the ash are generally quite immobile in the ground water (Cherkauer, 1981). Below are several leaching case studies of coal combustion products used for remediation purposes taken from Ziemkiewicz and Skousen (2000) presented in Table 5. Also listed below in Table 6 are Pennsylvania and West Virginia leachate compliance standards for CCPs.

The Chaplin Hill mine (Table 5) demonstrated substantial decreases in metals and sulfates concentrations. The Chaplin Hill case study has demonstrated that when the application of CCPs is considered for BTEX sorption, the overall remediation benefit may certainly outweigh the minimal, low concentration side effects associated with leaching. It is important to note that metals inherent to coal fly ash are more mobile in acidic soil and groundwater environments rather than more neutral $\mathrm{pH}$ environments. In addition, the metals inherent to fly ash are not free metals, but rather bound as post incinerated, metal oxides, which makes these metals less available for leaching. With regard to remediation, each application is site specific and there are advantages and disadvantages to each technique. 
Table 5. Summary of pre- and post-CCP application water quality at the Chaplin Hill Mine, Morgantown WV. (The data are for samples taken and analyzed by Anker Energy Corporation and reported to the state of West Virginia. All values in $\mathrm{mg} / \mathrm{L}$ ).

\begin{tabular}{|c|c|c|c|c|}
\hline $\begin{array}{l}\text { RCRA } \\
\text { Element }\end{array}$ & $\begin{array}{l}\text { TCLP } \\
\text { Limit }\end{array}$ & $\begin{array}{l}\text { EPA } \\
\text { Drinking } \\
\text { Water }\end{array}$ & Pre-CCB & Post-CCB \\
\hline $\mathrm{Sb}$ & 1 & 0.006 & 0.94 & 0.40 \\
\hline As & 5 & 0.05 & 1.28 & $<0.1$ \\
\hline $\mathrm{Ba}$ & 100 & 2 & $<0.1$ & $<0.1$ \\
\hline $\mathrm{Be}$ & 0.007 & 0.004 & 0.96 & $<0.1$ \\
\hline $\mathrm{Cd}$ & 1 & 0.005 & $<0.1$ & $<0.1$ \\
\hline $\mathrm{Cr}(6+)$ & 5 & 0.1 & 0.0001 & 0.0001 \\
\hline $\mathrm{Pb}$ & 5 & 0.015 & 0.72 & $<0.1$ \\
\hline $\mathrm{Hg}$ & 0.2 & 0.002 & $<0.0005$ & $<0.0005$ \\
\hline $\mathrm{Ni}$ & 70 & 0.01 & 1.16 & $<0.1$ \\
\hline $\mathrm{Se}$ & 1 & 0.05 & 1.29 & $<0.1$ \\
\hline $\mathrm{Ag}$ & 5 & & $<0.1$ & $<0.1$ \\
\hline $\mathrm{Tl}$ & 7 & 0.002 & 2.68 & 1.21 \\
\hline $\mathrm{Al}$ & & & 36 & $<0.1$ \\
\hline $\mathrm{Ca}$ & & & 450 & 750 \\
\hline $\mathrm{Fe}$ & & & 4 & $<0.1$ \\
\hline $\mathrm{Mg}$ & & & 296 & 450 \\
\hline $\mathrm{Mn}$ & & & 47 & 0.2 \\
\hline $\mathrm{SO} 4$ & & & 2022 & 1500 \\
\hline
\end{tabular}


Table 6. Comparison of West Virginia and Pennsylvania standards for CCP leachate concentrations (taken from Ziemkiewicz and Skousen, 2000).

\begin{tabular}{ccc}
\hline & Maximum Acceptable Leachate Concentrations $(\mathrm{mg} / \mathrm{L})$ \\
\hline State & $\begin{array}{c}\text { Pennsylvania } \\
\text { TCLP }\end{array}$ & $\begin{array}{c}\text { West Virginia } \\
\text { SPLP }\end{array}$ \\
\hline Test Method & & 5.0 \\
$\mathrm{Al}$ & 1 & 0.15 \\
$\mathrm{Sb}$ & 5 & 1.25 \\
$\mathrm{As}$ & 100 & 50 \\
$\mathrm{Ba}$ & 0.007 & \\
$\mathrm{Be}$ & & 31.50 \\
$\mathrm{~B}$ & 1 & 0.13 \\
$\mathrm{Cd}$ & 5 & 2.5 \\
$\mathrm{Cr}$ & & 32.5 \\
$\mathrm{Cu}$ & & 7.5 \\
$\mathrm{Fe}$ & 5 & 1.25 \\
$\mathrm{~Pb}$ & & 1.25 \\
$\mathrm{Mn}$ & 0.2 & 0.05 \\
$\mathrm{Hg}$ & & 4.38 \\
$\mathrm{Mo}$ & 70 & 2.5 \\
$\mathrm{Ni}$ & 1 & 1.00 \\
$\mathrm{Se}$ & 5 & \\
$\mathrm{Ag}$ & 7 & \\
$\mathrm{Tl}$ & & 125 \\
$\mathrm{Zn}$ & & 2500 \\
$\mathrm{SO} 4$ & & 2500 \\
$\mathrm{Cl}$ & &
\end{tabular}


Batch tests are the preferred method for studying most geochemical reactions associated with sorption and leaching (Zachara and Steile, Electrical Power Research Institute, 1991). Batch experiments are inexpensive and relatively easier to perform compared to other sorption/leaching experiments methods, such as column tests and can readily generate data for empirical applications. The batch reactor is the most direct way to obtain a distribution coefficient $\left(\mathrm{K}_{\mathrm{d}}\right)$ for saturated, porous media. Batch type sorption experiments are carried out by mixing aqueous phase organic chemicals at different concentrations and temperatures with coal fly ash (Singh et al., 1994). Samples are placed on a gyrating lateral shaker or end over end tumbler. Distilled, deionized water and coal fly ash are mixed with appropriate amounts of aqueous phase organic chemicals in $40 \mathrm{ml}$ amber vials with septum lined screw caps leaving no head space (Banerjee et. al., 1997). The aqueous phase organic chemicals are prepared form a stock solution based on the maximum solubility of the organic chemical at ambient temperature and are further diluted to achieve desired concentrations (Banerjee et. al., 1997). Walton et. al., 1992, carried out sorption experiments at five different concentrations for each individual organic chemical. To monitor vaporization losses and adsorption to glass, blank samples containing distilled, deionized water, added BTEX compounds and no ash are prepared with the same concentrations and in the same manner as those samples with ash (Jaynes and Vance, 1996; Viraraghavan, et. al. 1997). Banerjee used three vials for each adsorption data point. Two vials containing ash were used as reps. The vials with no ash were used as the control. Aliquots were centrifuged and analyzed spectrophotmetrically using a Spectronic 20 D spectrophotmeter at wavelengths that correspond to the maximum absorbances for the organic chemicals of interest (Viraraghavan, et. al. 1997, 
Singh et al., 1994).

Sorption may experimentally be quantified by the use of a mass balance equation (Schwarzenbach, 1993):

$$
\mathrm{Q}=\frac{\left(\mathrm{C}_{\mathrm{f}}-\mathrm{V}_{\mathrm{f}}\right)-\left(\mathrm{C}_{0}-\mathrm{V}_{0}\right)}{\mathrm{M}}
$$

where,

$$
\begin{aligned}
& \mathrm{Q}=\text { sorbed concentration }(\mathrm{mol} / \mathrm{kg}) \\
& \mathrm{C}_{\mathrm{f}}=\text { equilibrium concentration }(\mathrm{mol} / \mathrm{L}) \\
& \mathrm{C}_{\mathrm{o}}=\text { initial concentration }(\mathrm{mol} / \mathrm{L}) \\
& \mathrm{V}_{\mathrm{f}}=\text { final volume }(\mathrm{L}) \\
& \mathrm{V}_{\mathrm{o}}=\text { initial volume }(\mathrm{L}) \\
& \mathrm{M}=\text { mass of sorbent }(\mathrm{kg})
\end{aligned}
$$

Data are initially plotted as constant temperature isotherms with Adsorption (mol/Kg) vs. Equilibrium concentration (mol/L): y vs. $\mathrm{x}$ (adsorbed vs equilibrium y vs $\mathrm{x}$ ).

Equilibrium sorption data are often fit using either the Freundlich and Langmuir isotherms (Evangelou, 1998). The Langmuir approach suggests ion exchange mechanisms, which incorporate both organic and inorganic ion concentration charges, and total surface charge density (Schwarzenbach,1993). Through competitive ion interactions, a maximum capacity sorption plateau is achieved with the Langmuir isotherm. The Freundlich approach is most often used for nonlinear isotherms with no apparent sorption maximum ion capacity plateau. The Freundlich isotherm best describes 
the interactions between hydrophobic sorbate and hydrophobic sorbent with no apparent sorption maximum (Evangelou, 1998). The Freundlich adsorption isotherm is used to describe macroscopic data and no proof with regard to reaction mechanism should be inferred (Sparks, 1995). The use of an adsorption isotherm does not allow one to differentiate between adsorption and precipitation (Sparks, 1995). Sparks describes the Freundlich Equation as:

$$
\mathrm{Q}_{\mathrm{e}}=\mathrm{K}_{\mathrm{f}}\left(\mathrm{C}_{\mathrm{e}}\right)^{1 / \mathrm{n}}
$$

where,

$$
\begin{aligned}
& \mathrm{Q}_{\mathrm{e}}=\operatorname{amount} \text { of } \operatorname{adsorption}(\mathrm{mol} / \mathrm{kg}) \\
& \mathrm{C}_{\mathrm{e}}=\text { equilibrium concentration of the adsorptive }(\mathrm{mol} / \mathrm{L}) \\
& 1 / \mathrm{n}=\text { Freundlich fitting parameter } \\
& \mathrm{K}_{\mathrm{f}}=\text { Freundlich constant }(\mathrm{L} / \mathrm{kg})
\end{aligned}
$$

The linear form of the Freundlich adsorption isotherm is:

$$
\log \mathrm{Q}_{\mathrm{e}}=\log \mathrm{K}_{\mathrm{f}}+\frac{1}{\mathrm{n}} \log \mathrm{C}_{\mathrm{e}}
$$

If $1 / \mathrm{n}=1$, then $\mathrm{K}_{\mathrm{f}}=\mathrm{K}_{\mathrm{d}}$, the ratio of the substance's equilibrium concentration in the sorbed phase to that of the solution phase (Table 7):

$$
\mathrm{K}_{\mathrm{d}}=\frac{\mathrm{Q}_{\mathrm{e}}}{\mathrm{C}_{\mathrm{e}}}
$$


Table 7. BTEX Sorption Coefficients

\begin{tabular}{lccccc}
\hline & \multicolumn{5}{c}{ Sorbate } \\
\cline { 2 - 5 } Sorbent & Benzene & Toluene & Ethylbenzene & Total Xylenes & Total BTEX \\
\hline & 0.32 & & $\mathrm{~L} \mathrm{~kg}^{-1}$ & & \\
Soil $^{1}$ & 98.64 & 231.64 & 528.73 & 581.31 & 378.91 \\
Organo-clays $^{2}$ & & & & & \\
\hline
\end{tabular}

1. Schwarzenbach, 1993

2. Jaynes \& Vance, 1996

Table 8. Organic matter normalized sorption coefficients

\begin{tabular}{lccccc}
\hline \multirow{2}{*}{ Sorbent } & \multicolumn{5}{c}{ Sorbate } \\
\cline { 2 - 6 } & Benzene & Toluene & Ethylbenzene & Total Xylenes & Total BTEX \\
Soil $^{1}$ & 17 & & $\mathrm{~L} \mathrm{~kg}^{-1}$ & & \\
Organo-clays $^{2}$ & 2.5 & 2.83 & 3.18 & 3.22 & \\
\hline
\end{tabular}

${ }^{1 .}$ Schwarzenbach, 1993

2. Jaynes \& Vance, 1996

Table 9. Physical Characteristics of BTEX.

\begin{tabular}{|c|c|c|c|c|}
\hline & water solubility ${ }^{1}\left(25^{\circ} \mathrm{C}\right)$ & $\operatorname{density}^{1}\left(25 / 4^{\circ} \mathrm{C}\right)$ & $\log \mathrm{K}_{\mathrm{ow}}{ }^{\mathrm{I}}$ & formula weight $^{2}$ \\
\hline & $\mathrm{mg} / \mathrm{l}$ & $\mathrm{g} / \mathrm{cm}^{3}$ & & $\mathrm{~g} / \mathrm{mol}$ \\
\hline benzene & 1,780 & 0.874 & 2.13 & 78.11 \\
\hline toluene & 535 & 0.862 & 2.16 & 92.14 \\
\hline ethyl benzene & 152 & 0.867 & 3.13 & 106.17 \\
\hline o-xylene & 175 & 0.88 & 3.13 & 106.17 \\
\hline m-xylene & 130 & 0.868 & 3.13 & 106.17 \\
\hline p-xylene & 196 & & & \\
\hline total xylenes & 167 & 0.857 & 3.18 & 106.17 \\
\hline
\end{tabular}


Partitioning of a solute onto a mineral or organic content of the soil is almost exclusively a function of the organic carbon fraction of the soil $\left(f_{\text {om }}\right)$ if it constitutes at least $1 \%$ (Fetter, 1993). As a result, a partition coefficient $\left(\mathrm{K}_{\mathrm{om}}\right.$; Table 8$)$ with respect to carbon fraction of soil matter is expressed as:

$$
\mathrm{K}_{\mathrm{OM}}=\frac{\mathrm{K}_{\mathrm{d}}}{\mathrm{f}_{\mathrm{Om}}}
$$

The octanol/water partition coefficient $\left(\mathrm{K}_{\mathrm{ow}}\right.$; Table 9$)$ is used by researchers to simulate hydrophobic sorption by soil organic matter. It is a measure of hydrophobicity. The $\mathrm{K}_{\mathrm{ow}}$ represents the ratio of organic contaminant in octanol $\left(C_{0}\right)$ to that of water $\left(C_{w}\right)$ (Evangelou, 1998).

$$
\mathrm{K}_{\mathrm{ow}}=\frac{\mathrm{C}_{\mathrm{o}}}{\mathrm{C}_{\mathrm{w}}}
$$

The BTEX class of aromatic, petroleum, hydrocarbon chemicals consist of: benzene, toluene, ethylbenzene and 3 xylene isomers (Figure 5: Table 9). Benzene, the simplest aromatic hydrocarbon, is a carcinogen, highly toxic and flammable. It is colorless to light yellow, mobile, non-polar liquid (Sax and Lewis, 1987). Benzene has a water solubility of 1,780mg/L at 25 degrees C (USEPA, 2001), density of 0.87378 at 25/4 degrees C (Kirchnerova and Cave, 1976), and an octanol/water partition coefficient, log $\mathrm{K}_{\mathrm{ow}}$, of 2.13 (DeKock and Lord, 1987; Hansch and Fujita, 1964),

Toluene is a colorless liquid with a benzene-like odor, flammable and toxic(Sax and Lewis, 1987). Toluene has a water solubility of $535 \mathrm{mg} / \mathrm{L}$ at 25 degrees $\mathrm{C}$ (Benerjee et al., 1984) density of 0.86233 at 25/4 degrees C (Huntress and Mulliken, 1941) and an -20 - 

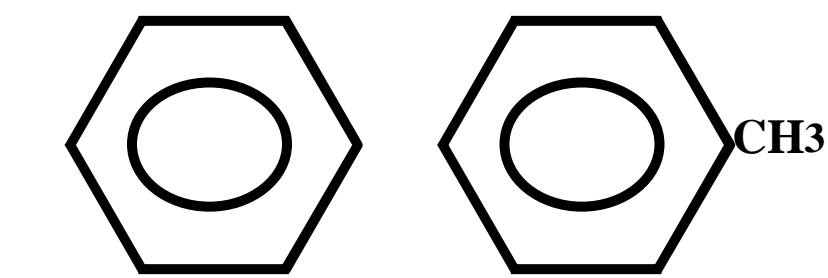

Toluene

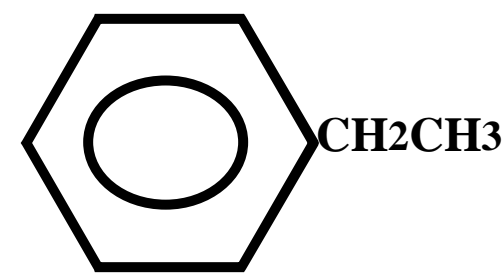

Ethyl Benzene

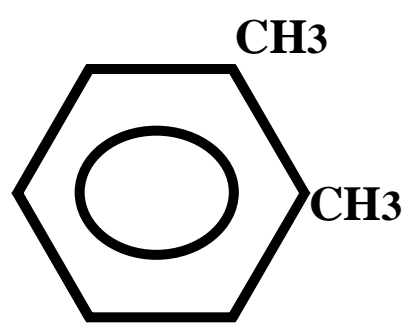

O-Xylene

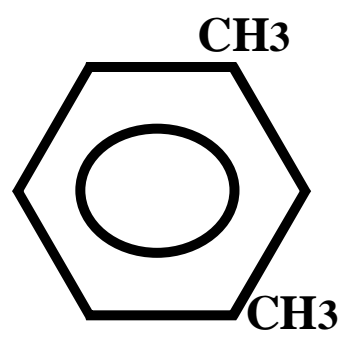

M-Xylene

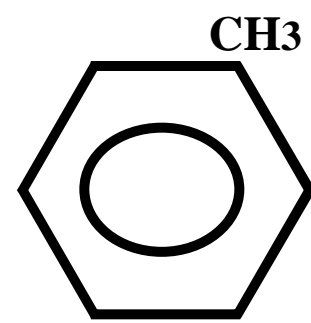

CH3

P-Xylene

Figure 5. BTEX Molecular Organic Structures (taken from Sax and

Lewis, Hawley's Condensed Chemical Dictionary. $11^{\text {th }}$ ed., 1987). 
octanol/water coefficient, $\mathrm{K}_{\mathrm{ow}}$, of 2.61 (Sangster, 1989).

Ethylbenzene is a flammable, colorless, toxic liquid with an aromatic odor (Sax and Lewis, 1987). Methylbenzene has a water solubility of $152 \mathrm{mg} / \mathrm{L}$ at 25 degrees C (Miller et al., 1985), a density of 0.867 at 25 degrees C (Hunterss and Mulliken, 1941), and an octanol/water coefficient, $\log \mathrm{K}_{\mathrm{ow}}$, of 3.13 (Wasik et al., 1981, 1983; Yalkowsky et al., 1983).

O-Xylene (1,2 dimethylbenzene) is also a clear, colorless liquid with an aromatic odor that is moderately flammable (Sax and Lewis, 1987). O-Xylene has a water solubility of 175mg/L at 25 degrees C(Andrews and Keefer, 1949), density of 0.8802 at 20 degrees C (Weast, 1986), octanol/water partition coefficient, $\log \mathrm{K}_{\mathrm{ow}}$, of 3.13(Tewari et al., 1982, Wasik et al., 1981, 1983).

M-Xylene (1,3-dimethylbenzene) is a clear, colorless watery liquid with a sweet aromatic odor that is moderately flammable (Sax and Lewis, 1987). M-Xylene has a water solubility of 130mg/L at 25 degrees C (Andrews and Keefer, 1949), density of 0.8684 at 25 degrees $\mathrm{C}$ (Hawley, 1981) and octanol/water partition coefficient, $\log \mathrm{K}_{\mathrm{ow}}$, of 3.13 (Wasik et al., 1981, 1983).

P-Xylene (1,4-dimethylbenzene) is also a colorless, watery liquid, with a sweet aromatic odor that is highly flammable (Sax and Lewis, 1987). P-Xylene has a water solubility of 196mg/L at 25 degrees C (Andrews and Keefer, 1949), density of 0.85665 at 25 degrees C (Kirchnerova and Cave, 1976) and octanol/water partition coefficient of 3.18 (Tewari et al., 1982; Wasik et al., 1981, 1983). 


\section{Chapter 3: Materials and Methods}

\subsection{Chemical Composition:}

The constituent XRF chemical composition was determined through a Phillips 1480 XRF Wavelength Spectrometer courtesy of Dr. John Renton and Harry(Duke)Brown in the West Virginia University Department of Geology and Geography.

\subsection{Classification:}

Coal fly ash samples were analyzed in terms of chemical composition using XRF analysis and further classified as C or F class using the ASTM classification for coal fly ash.

\subsection{Percent Carbon:}

The percent carbon was determined with a LECO CNS-2000 courtesy of Dr. John Sencindiver and Brian Cooley from the College of Agriculture and Forestry and Consumer Sciences, division of Plant and Soil Sciences.

\subsection{Batch Test:}

After the method of Banerjee et al. (1995) and Mott et al. (1992), the fly ashes were mixed with Benzene, Toluene, Ethyl benzene, and Xylene samples separately at varying temperatures and concentrations of BTEX. 


\subsection{Sample Preparation:}

Day 1: A total of $15,40 \mathrm{ml}$ amber glass vials with Teflon-lined screw caps were used for each batch test experiment. Experimentally, 3, 4 and 5 gram masses of ash were taken, placed in 10 out of 15 of the amber vials. The vials with out flyash were used as a control. Two sets vials with fly ash yielded replicates. Subsequently all amber vials were filled with distilled, deionized water to the appropriate volume via pipet and $10 \mathrm{ml}$ volumetric cylinder. All pipets and volumetric cylinders were calibrated daily to deliver distilled deionized water.

All 15 vials were then vortexed and placed at the corresponding isotherm temperature for a period of $12 \mathrm{hrs}$.

The BTEX stock solution was prepared by adding distilled, deionized water and individual BTEX organic chemicals into a seperatory funnel, shaken vigorously and let stand overnite. Aqueous phase BTEX stock solutions were based on the maximum solubities of each individual species (Table 9).

Day 2: The aqueous phase organic stock solution was withdrawn from the bottom of the seperatory funnel into a tallform beaker covered with a watch glass. Aqueous phase BTEX solute stock solutions were immediately pipetted into the corresponding amber vials to appropriate diluted concentrations, sealed immediately, leaving no head space. Benzene and Toluene concentrations ranged from 400mg/L to 0mg/l. Ethyl Benzene and Xylenes concentrations ranged from $100 \mathrm{mg} / \mathrm{L}$ to $0 \mathrm{mg} / \mathrm{L}$. Amber vial sample lids were further sealed with paraffin wrap to maintain seal and prevent breakage. All pipets were 
calibrated daily to deliver appropriate amounts of BTEX solution.

All samples were further vortex and subsequently placed on either an end over end tumbler or a lateral shaker, and allowed to equilibrate at constant temperature for a period of $12 \mathrm{hrs}$.

Day 3: All samples were centrifuged for $1 / 2$ hour at 2500 rpm. Solid coal fly ash settled to the bottom of the $40 \mathrm{ml}$ amber vials and aloquits of aqueous phase BTEX were extracted from the top of each vial. Subsequently, all samples were analyzed via UV spectroscopy at corresponding wavelength values of maximum absorbance for each BTEX sample (Table 10)

\subsection{UV Analytical Procedure:}

The Spectronic 20®, Genesys 5, single wavelength Spectrophotmeter (UV Spec 20), courtesy of Dr. Sven Verlinden in the WVU college of Agriculture, Forestry and Consumer Science, Division of Plant and Soil Science, was turned on at least $1 / 2 \mathrm{hr}$. before any samples were run to allow the machine to warm up. Viraraghavan et. al. 1998 and Singh and Rawat, 1994 also analyzed fly ash sorption of organic chemicals using UV Spec 20.

Quartz cuvettes were initially rinsed with ethanol followed by distilled, deionized water. A new, dedicated, disposable pipette tip was used each time to withdraw aliquots from the amber sample vials into the quartz cuvette. The cuvette was then rinsed once with sample. Then the cuvette was refilled with sample aliquot, wiped clean outside with a disposable Kimwipe ${ }^{\circledR}$ and placed in the UV spectrophotometer chamber where 
Table 10. Max UV Absorbance Peaks for BTEX

$\begin{array}{llc}\text { Substance } & \text { Formula } & \text { Max UV Absorbance Peaks } \\ \text { Benzene } & \mathrm{C}_{6} \mathrm{H}_{6} & 254 *_{+} \\ \text {Toluene } & \mathrm{C}_{7} \mathrm{H}_{8} & 261 *_{+} \\ \text {EthylBenzene } & \mathrm{C}_{8} \mathrm{H}_{10} & 270 \\ \text { Xylenes } & \mathrm{C}_{8} \mathrm{H}_{10} & 264 *_{+} \\ & \\ & \\ & \text {*Source:Colby College Dept.of Chemistry } \\ & \text { www.colby.edu/chemistry/cmp/mole.cgi } \\ & \text { +Source:Applied Analytics, Inc. } \\ & \text { www.a-a-inc.com/BTX?BTX1.htm } \\ & \text { Sadtler UV Indexes (1960,1961,1963,1966) }\end{array}$


maximum absorbance was recorded. First, a zero value absorbance baseline was established with sample containing only distilled, deionized water. The UV analytical device was then calibrated from strongest concentration to weakest concentration with the 5 control samples which had no ash added.

The 10 samples (2 reps) which had ash added were analyzed via UV spectrophotometry ranging from strongest concentration to weakest concentration. Between trials, all cuvettes were rinsed and prepared in the same manner as the zero absorbance value.

Lastly, the UV Spec 20 analytical device was recalibrated with blank sample from weakest concentration to strongest concentration. The average of initial and final absorbance values of blank samples were used as calibration standard curves for each batch test experiment.

Appendix II contains UV calibration curves for analytical work performed for this thesis.

\subsection{Glassware cleaning and Preparation:}

All glassware used during the batch test experiments were rinsed with distilled, deionized water, followed by ethanol. All glassware were then soaked overnite with Liquinox soap, rinsed with tap water, followed by distilled, deionized water and set inverted to dry on drying racks.

\subsection{Particle Size Distribution:}

The particle size analysis was determined using the most widely accepted pipet extraction method (Indorante et. al., 1990). 
Masses of 10 grams of ash were placed in a tared 500ml Fleaker. One Fleaker contained no ash and was used as a blank control. Organic matter in the samples was digested with $30 \%$ hydrogen peroxide and heated on a hotplate to approximately $60^{\circ} \mathrm{C}$ prior to the particle size analysis.

A volume of $10 \mathrm{ml}$ of $10 \% \mathrm{Na}-\mathrm{Hexametaphosphate} \mathrm{dispersion} \mathrm{solution} \mathrm{was} \mathrm{then} \mathrm{added} \mathrm{to}$ each Fleaker and the volume was brought to $150 \mathrm{ml}$ with distilled, deionized water. The blank control was used as the correction factor for Na-hexametaphosphate. All Fleakers were stoppered and shaken overnite at a minimum of 120 oscillations per minute.

Stoppers were next removed and fleakers were brought to an exact volume of $400 \mathrm{ml}$ with distilled deionized water at room temperature. Then, samples were shaken vigorously to ensure no particle adherence to the bottom of the Fleaker. Fleaker stoppers were left ajar and arranged for pipetting based on Stokes Law for corresponding temperatures for pipeting of fractions $<2$ micrometers at $5 \mathrm{~cm}$ depth. Aliquots were withdrawn and dispensed into a tared beaker, oven dried, cooled in a desicator and masses taken. Mass of Na-hexametaphosphate was subtracted and percent clay size particles determined. Soils remaining in the Fleaker were wet sieved through a tared, 270 mesh size sieve. Sand fractions remaining were oven dried prior to mass taken as determined by the Soil Survey Staff (1984).

$$
\begin{aligned}
& \% \text { sand }=100 \times(\text { total sand weight } / \text { total soil weight }) \\
& \% \text { clay }=(\text { clay weight }) \times(400 / \text { pipet volume })(100 / \text { total soil weight }) \\
& \% \text { silt }=100-(\% \text { sand }+\% \text { clay })
\end{aligned}
$$




\subsection{Surface Area:}

The surface areas of the three fly ash samples were determined by Multipoint BET Quantachrome ${ }^{\circledR}$ Autosorb gas sorption system analysis courtesy of Bob Romanofski and Don Floyd, DOE, National Energy Technology Laboratories (NETL), Morgantown, WV.

\subsection{Experimental Focus:}

The focus of these batch test experiments was to test a broad range of BTEX sorption with respect to coal fly ash. An assumption was made that if sorption occurred at higher concentrations, then it would certainly be reliable at more dilute concentrations of BTEX. When chemicals are released into the environment, the actual solubilities are far lower than the published solubilities. This is because most chemicals, like petroleum hydrocarbon fuel exist as a mixture and their concentrations depend on the abundance of the individual chemical in the mixture, otherwise know as the effective solubility. Benzene has a published solubility in water of $1780 \mathrm{mg} / \mathrm{L}$. Typical fuel mixture concentrations of Benzene at equilibrium in the aqueous phase are 20-40mg/L (U.S.EPA, 2001). The sorption isotherm line is inclusive of low concentrations when it is traced to zero $\mathrm{X}$ and $\mathrm{Y}$ axis values of the sorption isotherms. In addition, the single wavelength UV Spec 20 analytical device used in these experiments was more reliable for organic chemicals at higher concentrations resulting in a stronger peak.

\subsection{Freundlich Model Rationale:}

The Freundlich model approach was used to fit isotherms where it applies. The Freundlich isotherm best describes the interactions between hydrophobic sorbate and 
hydrophobic sorbent (Evangelou, 1998). The most significant sorption attributes of these batch test experiments were assumed to be the interactions of hydrophobic properties associated with the BTEXs and the high carbon content nature of coal fly ash. The Langmuir approach was abandoned because organic and inorganic ion concentration charges and total surface charge density were not assumed significant interactions with respect to coal fly ash sorption of BTEX. The Freundlich equilibrium sorption model was possible to fit in some cases where Log [Eqm] v. Log [Ads] fit a straight line with at least three valid data points. The Freundlich sorption isotherm model is acquired by empirically fitting experimental data. The Freundlich isotherm is fit by taking the Log of the $\mathrm{X}$ and $\mathrm{Y}$ axis of the sorption isotherm. The purpose of fitting a Freundlich isotherm is to linearize sorption isotherms so that the $\mathrm{K}_{\mathrm{f}}$ and $1 / \mathrm{n}$ terms may be extracted over a significant range. The distribution coefficient, $\mathrm{K}_{\mathrm{f}}$ value, is the $\mathrm{y}$-intercept of the linearized $\log ($ Eqm) v. Log (Ads) plot of the empirical sorption data. $1 / \mathrm{n}$ is the empirical linearization constant obtained from the slope of the Freundlich plot (Evangelou, 1998). In some cases, whereby $1 / n=1$, the linear isotherm is a special case and the $\mathrm{K}_{\mathrm{f}}$ is equal to the slope of the line. A disadvantage of the Freundlich isotherm is that it cannot predict an adsorption maximum (Sparks, 1995). The linear isotherm equation should not be extrapolated beyond the limits of the experimental data (Fetter,1999). Statistical analysis presented in Table 13 and Table 14 were performed using the GLM Procedure, with all factors as class variables and Mean Separations using Duncan's Multiple Range Test. (SAS Inst., Cary, NC; version 8.01). Full model analyses were performed with all possible interactions. Non- Significant parameters were removed based on Type III Sum of Squares. The best model was chosen based on 
minimizing Mean Square Error.

\subsection{Statistical Analysis}

Statistical analysis presented in Table 13 and Table 14 were performed using the GLM Procedure, with all factors as class variables and Mean Separations using Duncan's Multiple Range Test. (SAS Inst., Cary, NC; version 8.01). Full model analyses were performed with all possible interactions. Non- Significant parameters were removed based on Type III Sum of Squares. The best model was chosen based on minimizing Mean Square Error. 


\section{Chapter 4: Results}

\subsection{Ash Characterization}

As discussed in Chapter 2, the dominant matrix components of coal fly ash are amorphous micro-spheres predominantly composed of silica and aluminum oxides. The average of 26 coal fly ashes sampled from three continents (Table 1) contained over 60\% silica and aluminum oxides. In this study, XRF analysis from Table 11 demonstrates that both the Alb-D and Alb-L contained more than the average of the 26 samples, with over $80 \% \mathrm{w} / \mathrm{w}$ silica and aluminum oxides. The MEA-L ash contained over $50 \% \mathrm{w} / \mathrm{w}$ silica and aluminum oxides, which was more similar to the average of the 26 fly ashes sampled. According to the XRF analysis, Table 11, the MEA-L ash had greater than $10 \% \mathrm{CaO}$, while the Alb-D and Alb-L coal fly ashes contained less that $10 \% \mathrm{CaO}$. On average, the 26 fly ash samples from Table 1, contained less than $10 \% \mathrm{CaO}$. The differences in $\mathrm{CaO}$ composition among the ashes are the result of combustion type influences. The MEA power plant is a modern Fluidized Bed Combustion (FBC) facility, which requires the addition of lime $(\mathrm{CaO})$ to aid in the reduction of sulfur emissions, by precipitating sulfur as gypsum (CaSO4) (Ziemkiewicz and Skousen, 2000). The Albright Power Station is a pulverized coal combustion facility. As a result, Alb-D and Alb-L ashes would be considered Class F, while the MEA-L ash would be considered Class C or FBC type ash, based on the XRF analysis and in accordance with the typical composition of Class F and C ashes defined by ASTM (1997; Table 11).

From Table 12, it can be determined that the Alb-D had $26.94 \%$ carbon, which is $86.34 \%$ 
Table 11. XRF Chemical Composition \% by weight

\begin{tabular}{|c|c|c|c|c|c|c|c|c|c|c|c|c|}
\hline \multirow[b]{2}{*}{ Coal Ash } & \multicolumn{12}{|c|}{ Constituent } \\
\hline & $\mathrm{MnO}$ & $\mathrm{K}_{2} \mathrm{O}$ & $\mathrm{SiO}_{2}$ & $\mathrm{Al}_{2} \mathrm{O}_{3}$ & $\mathrm{SO}_{2}$ & $\mathrm{SO}_{3}$ & $\mathrm{Fe}_{2} \mathrm{O}_{3}$ & $\mathrm{Na}_{2} \mathrm{O}$ & $\mathrm{MgO}$ & $\mathrm{TiO}_{2}$ & $\mathrm{CaO}$ & $\mathrm{P}_{2} \mathrm{O}_{5}$ \\
\hline & & & & & & & $\%(\mathrm{w} / \mathrm{w}$ & & & & & -- \\
\hline Alb-D ${ }^{1}$ & 0.04 & 1.6 & 56.14 & 31.87 & 0.76 & - & 2.61 & 0.18 & 0.65 & 2.74 & 3 & 0.41 \\
\hline Alb- $\mathrm{L}^{2}$ & 0.02 & 2.35 & 54.52 & 30.22 & 0.08 & - & 7.55 & 0.47 & 0.83 & 1.69 & 1.97 & 0.3 \\
\hline MEA-L ${ }^{3}$ & 0.04 & 1.62 & 37.19 & 16.11 & 7.08 & - & 6.1 & 0.68 & 1.59 & 1.1 & 28.27 & 0.24 \\
\hline Average & 0.033 & 1.86 & 49.28 & 26.07 & 2.64 & - & 5.42 & 0.44 & 1.02 & 1.84 & 11.08 & 0.32 \\
\hline Maximum & 0.04 & 2.35 & 56.14 & 31.87 & 7.08 & 0 & 7.55 & 0.68 & 1.59 & 2.74 & 28.27 & 0.41 \\
\hline Minimum & 0.02 & 1.6 & 37.19 & 16.11 & 0.08 & 0 & 2.61 & 0.18 & 0.65 & 1.1 & 1.97 & 0.24 \\
\hline
\end{tabular}

${ }^{1 .}$ Albright Dark fly ash, Albright Power Station, Albright, WV

2. Albright Light fly ash, Albright Power Station, Albright, WV

${ }^{3 .}$ Morgantown Energy Assoc. Light fly ash, Morgantown Energy Assoc. Power Station, Morgantown, WV

\section{Table 12. Coal Flyash Physical Characteristics}

\begin{tabular}{|c|c|c|c|c|c|}
\hline Coal Ash & Surface Area & Sand & Silt & Clay & Carbon \\
\hline & $\mathrm{m}^{2} \mathrm{~g}^{-1}$ & & 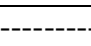 & $\%$ & -------- \\
\hline Alb-D ${ }^{1}$ & 27.09 & 67.77 & 27.66 & 6.58 & 26.94 \\
\hline Alb- $\mathrm{L}^{2}$ & 3.42 & 83.70 & 13.91 & 2.39 & 3.68 \\
\hline MEA-L ${ }^{3}$ & 13.53 & 46.77 & 52.80 & 0.43 & 2.36 \\
\hline
\end{tabular}

1. Albright Dark fly ash, Albright Power Station, Albright, WV

2. Albright Light fly ash, Albright Power Station, Albright, WV

${ }^{3 .}$ Morgantown Energy Associates Light fly ash, Morgantown Energy Associates Power Station, Morgantown, WV 
more carbon content than the Alb-L and 91.24\% more carbon content than the MEA-L. The carbon content of the Alb-D was well above the 2002 average of $6 \%$ carbon for coalburning fly ash (Hwang, et. al., 2002). While the carbon content of the Alb-L and MEAL coal fly ashes fell below average at $3.68 \%$ and $2.36 \%$ respectively.

Other important sorption attributes are surface area and particle size distribution. As discussed in Chapter 2, the coal fly ashes with greater percentage of clay size particles and larger surface areas have potential to sorb more BTEX. Table 12 list surface area measurements on the three coal fly ashes in this study, which were 3.42, 13.53 and 27.09 $\mathrm{m}^{2} / \mathrm{g}$ for Alb-L, MEA-L and Alb-D respectively and the results of particle size analysis performed in the soils testing laboratory at the WVU college of Agriculture and Forestry and Consumer Sciences, Soil Science Division. From Table 12, the percent clay size particles are 0.43, 2.39 and 6.58 for MEA-L, Alb-L and Alb-D respectively. Table 13 demonstrates that on average the Alb-D ash had a greater percentage of benzene sorption than either the Alb-L or MEA-L ashes. However, the differences between percent benzene sorption of Alb-L and Alb-D were not as great as one would expect with respect to variability in surface area and particle size between the two ashes. As discussed in Chapter 2, surface areas for activated carbon, on the order of 1,050 to $1,250 \mathrm{~m}^{2} / \mathrm{g}$, are substantially higher than that of coal fly ash as a result of greater surface areas found in the micropores of the activated carbon particles. Surface areas for seven coal fly ashes in Table 3, ranged from 1.14 to $37.5 \mathrm{~m}^{2} / \mathrm{g}$. Both coal fly ash and activated carbon sorption rely on high surface areas for greater access for adsorption. 
Table 13. Effects of temperature and ash source on average (standard deviation) percent benzene sorption.

\begin{tabular}{ccccc}
\hline Temperature & Alb-Dark & Alb-Light & MEA & avg \\
\hline & --1.9 & 45.3 & 6.1 & $31.1^{\mathrm{a}}$ \\
$25^{\circ} \mathrm{C}$ & $(0.31)$ & $(1.73)$ & $(0.17)$ & \\
$45^{\circ} \mathrm{C}$ & 67.2 & 46.7 & -14.0 & $33.8^{\mathrm{a}}$ \\
& $(0.01)$ & $(2.18)$ & & \\
avg. & $54.6^{\mathrm{a}}$ & $46.8^{\mathrm{b}}$ & $-3.9^{\mathrm{c}}$ & 32.5 \\
\hline
\end{tabular}




\subsection{Effect of Carbon on Benzene Sorption}

The overall model for the effect of ash type and temperature on percent benzene sorption was significant $\left(\operatorname{Pr}>\mathrm{F}<0.0001 ; \mathrm{R}^{2}=0.99\right)$ with significant effects due to ash type $(\operatorname{Pr}>\mathrm{F}$ $<0.001)$ and ash type $*$ temperature interaction $(\mathrm{Pr}>\mathrm{F}=0.0002)$. The temperature effect was not significant $(\mathrm{Pr}>\mathrm{F}=0.1807)$. The Albright-Dark ash had the highest average percent sorption and the MEA ash had the lowest (Table 13). There was no significant effect of temperature on percent benzene sorption to the Albright-Light ash. Increasing temperature increased percent sorption to the Albright-Dark ash, but decreased percent sorption to the MEA ash (Table 13). The relationship between percent sorption and percent carbon was not linear, which suggests there may be differences in the quality of the carbon on each ash and/or differences in mineral matrix, which may influence analyte sorption.

The best fit isotherms among two trials for benzene sorption to three different coal ashes is demonstrated in Figure 6. The Alb-D- $45^{\circ} \mathrm{C}, \mathrm{Alb}-\mathrm{L}-5^{\circ} \mathrm{C}$ and Alb-L-45 ${ }^{\circ} \mathrm{C}$ are Case I isotherms whereby at higher and higher concentrations it becomes more difficult to sorb additional molecules (Schwarzenbach, 1993). Alb-D-25 ${ }^{\circ} \mathrm{C}$ and Alb-L-25 ${ }^{\circ} \mathrm{C}$ are Case II isotherms whereby the attractiveness of the solid for the sorbate remains constant for all levels of the sorbed state (Schwarzenbach, 1993). MEA-L- $5^{\circ} \mathrm{C}, \mathrm{MEA}-\mathrm{L}-25^{\circ} \mathrm{C}$ and MEA- 


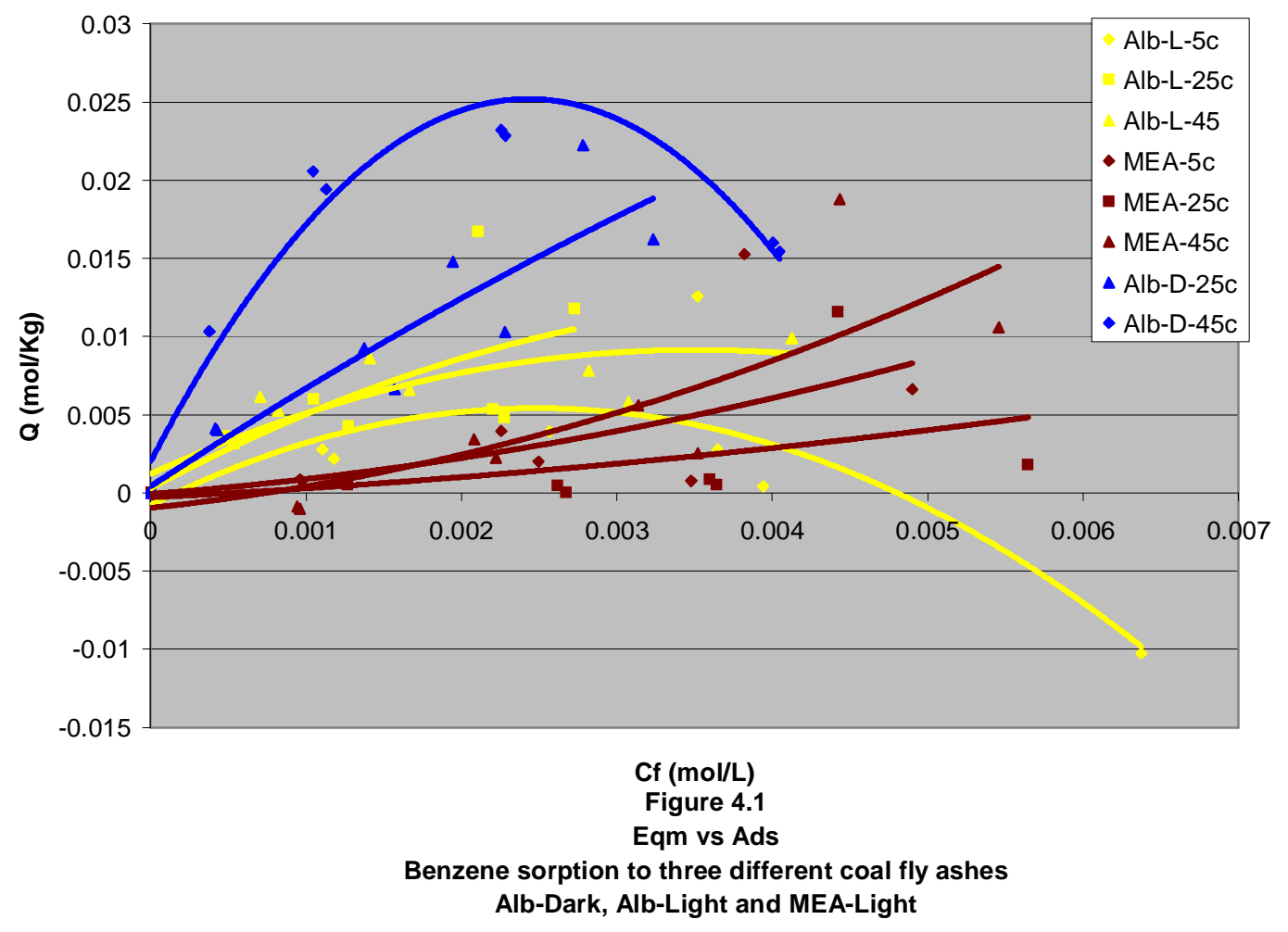

Figure 6. Benzene sorption onto three different coal fly ashes: Alb-dark, Ald-light, and MEA-light 
$\mathrm{L}-45^{\circ} \mathrm{C}$ are Class III isotherms in which previously sorbed molecules modify the surface which favors further sorption (Schwarzenbach, 1993).

In general, at higher concentrations of benzene, analytes tend to reach a sorption peak and begin to desorb except in the Case III isotherms typical of the MEA-L ash. This desorption effect may be attributed to overloading of sorbate at higher concentrations, which results in the analyte acting as a solvent for other UV-active components of the ash.

For benzene sorption to coal fly ashes (Figure 6), the Albright dark ash at $25^{\circ} \mathrm{C}$ is the only ash for which the Freundlich model reasonably fits with an $\mathrm{R}^{2}$ value of 0.8421 . The calculated Freundlich parameters are $K_{f}=0.8943$ and $1 / n=0.7295$. The $R^{2}$ values for the Alb-L and MEA-L ash sorption of benzene are less than 0.5 at $25^{\circ} \mathrm{C}$.

\subsection{Effects of analyte and temperature on two low carbon ashes}

The analyte*temperature and analyte*ash interactions are the main effects which influence BTEX sorption, and are compared below in Table 14. From Table 14, the overall model is significant $\left(\operatorname{Pr}>\mathrm{F}<0.0001 ; \mathrm{R}^{2}=0.99\right)$

\subsubsection{Temperature effects}

For the analyte*temperature interaction, there is a general trend of increase in sorption with increase in temperature. Maximum percent sorption occurred at $25^{\circ} \mathrm{C}$ for benzene and toluene, and $45^{\circ} \mathrm{C}$ for xylenes and ethyl benzene (Table 14). 


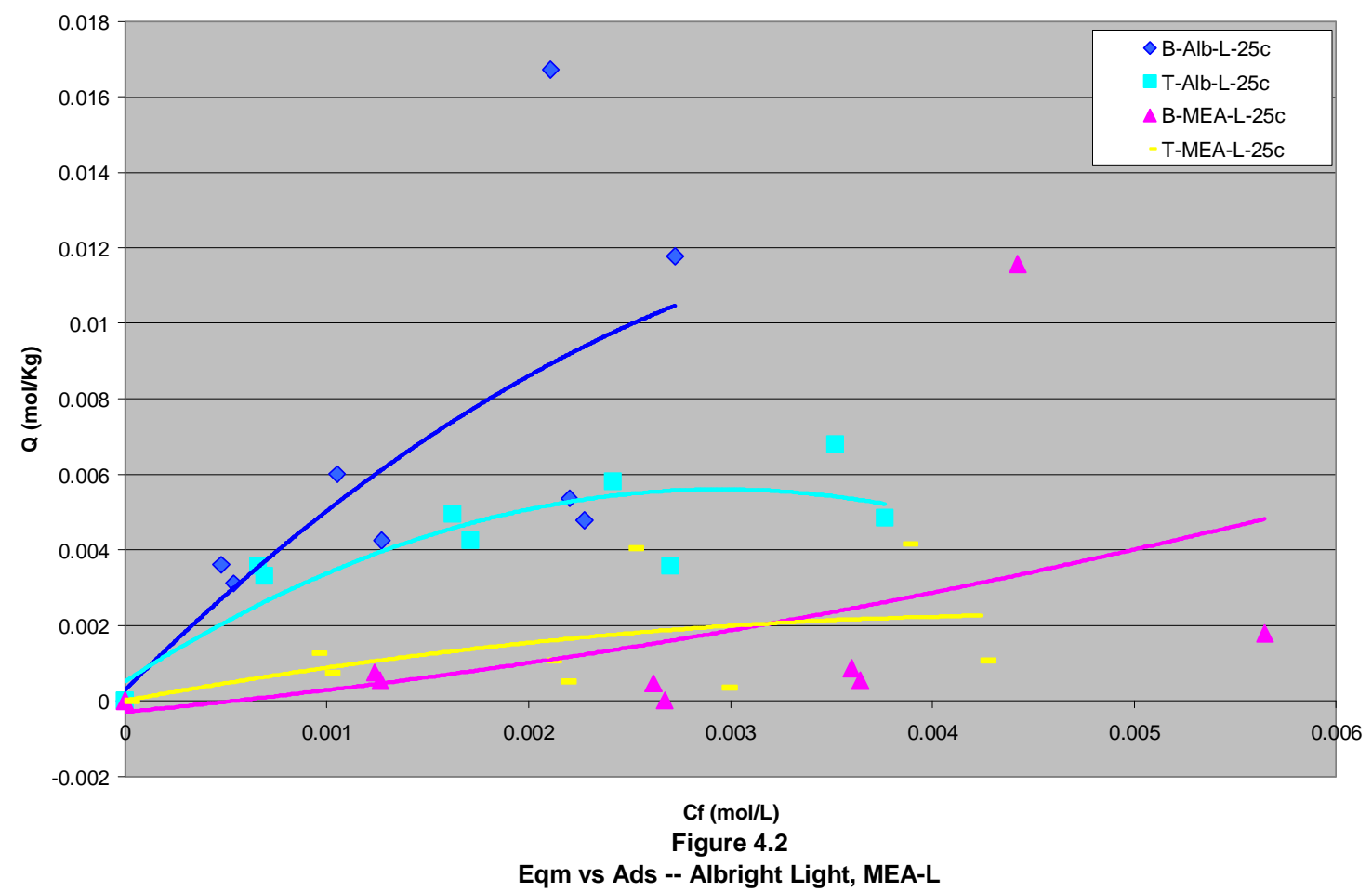

Benzene \& Toluene at 25C

Figure 7. Equilibrium concentration vs adsorbed concentration of benzene and toluene on ashes Alb-L and MEA-L at $25^{\circ} \mathrm{C}$. 


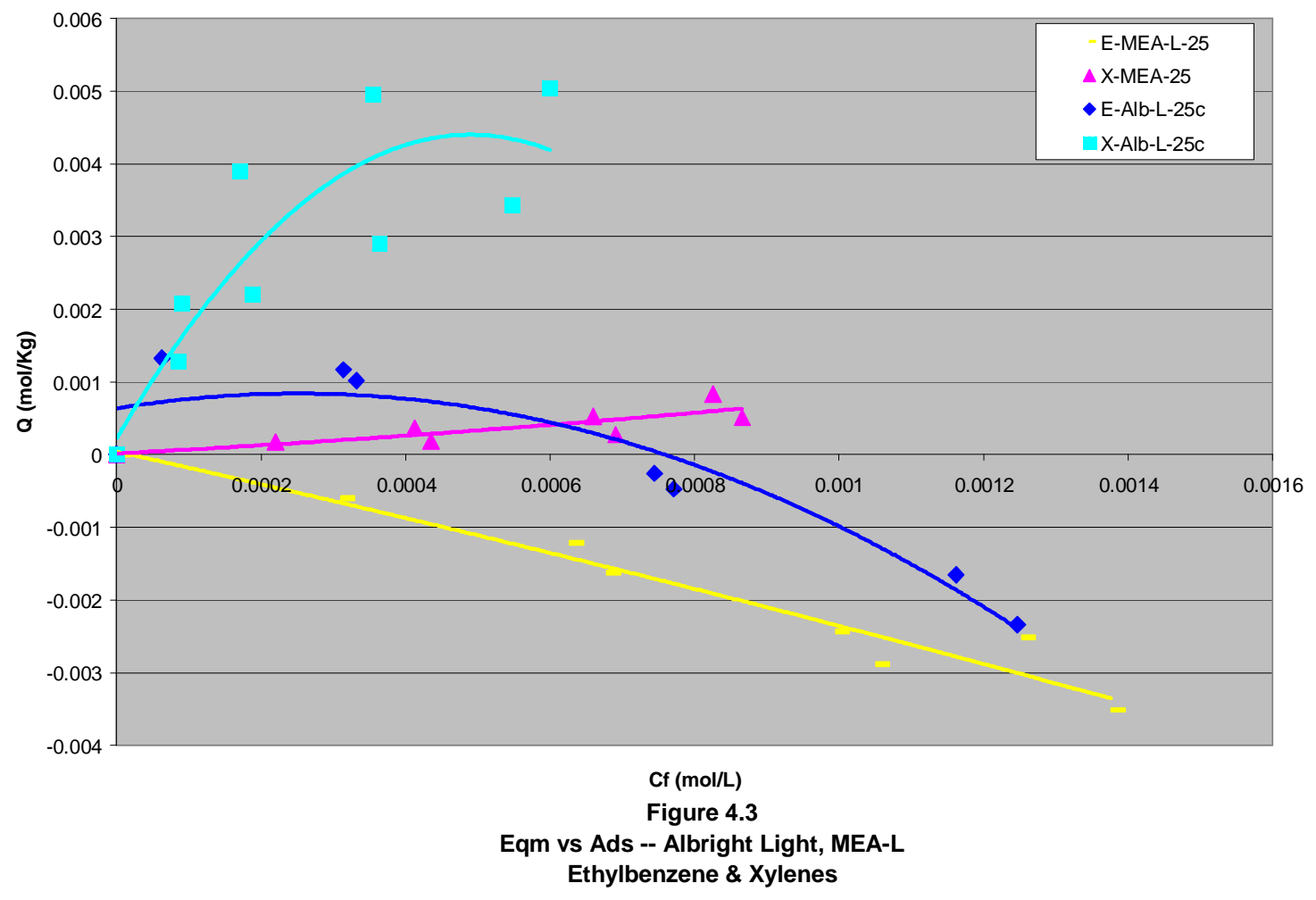

Figure 8. Equilibrium concentration vs adsorbed concentration of ethylbenzene and xylene on ashes Alb-L and MEA-L at $25^{\circ} \mathrm{C}$. 
Table 14.The SAS System, GLM Procedure: Duncan's Multiple Range Test for Percent Sorption

\begin{tabular}{|c|c|c|c|}
\hline Ash & Analyte & Temperature $^{\circ} \mathrm{C}$ & Mean \\
\hline Albright Light & & & $51.6^{\mathrm{a}}$ \\
\hline \multirow{8}{*}{ MEA } & & & $-3.8^{b}$ \\
\hline & Xylenes & & $41.6^{\mathrm{a}}$ \\
\hline & Ethylbenzene & & $16.7^{\mathrm{b}}$ \\
\hline & Benzene & & $19.4^{\mathrm{b}}$ \\
\hline & Toluene & & $18.0^{\mathrm{b}}$ \\
\hline & & 5 & $20.0^{\mathrm{b}}$ \\
\hline & & 25 & $26.3^{\mathrm{a}}$ \\
\hline & & 45 & $25.5^{\mathrm{a}}$ \\
\hline Albright Light & Xylene & & 73.6 \\
\hline Albright Light & Ethylbenzene & & 66.2 \\
\hline Albright Light & Benzene & & 38.3 \\
\hline Albright Light & Toluene & & 28.4 \\
\hline MEA & Xylene & & 9.5 \\
\hline MEA & Ethylbenzene & & -32.7 \\
\hline MEA & Benzene & & 0.56 \\
\hline \multirow[t]{13}{*}{ MEA } & Toluene & & 7.6 \\
\hline & Xylenes & 5 & 41.0 \\
\hline & Xylenes & 25 & 36.5 \\
\hline & Xylenes & 45 & 47.1 \\
\hline & Ethylbenzene & 5 & 8.7 \\
\hline & Ethylbenzene & 25 & 20.2 \\
\hline & Ethylbenzene & 45 & 21.3 \\
\hline & Benzene & 5 & 15.4 \\
\hline & Benzene & 25 & 25.7 \\
\hline & Benzene & 45 & 17.1 \\
\hline & Toluene & 5 & 14.9 \\
\hline & Toluene & 25 & 22.8 \\
\hline & Toluene & 45 & 16.4 \\
\hline
\end{tabular}




\subsubsection{Analyte effects}

For the analyte*ash interaction, the percent sorption onto the MEA-L ash is low for all analytes as demonstrated in Table 14, Figure 7 and Figure 8. The Albright light ash demonstrates much greater percent sorption compared to MEA-L in a preferred order (Xylenes >Ethylbenzene>Benzene >Toluene). Ethylbenzene is $66.2 \%$ sorbed to Alb-L and desorbed by $-32.7 \%$ from MEA-L In the case of ethylbenzene sorption to MEA-L, more sorbate was found at the end of the batch test experiment than at the beginning. The increase in ethylbenzene at the end of the experiment may be attributed to an analyte solvent leaching effect of ethylbenzene inherent to the MEA-L ash or other chemical species inherent to the MEA-L ash which have broad overlap interferences of the same UV analytical absorbance wavelength peak.

The individual BTEX sorbate chemical species also proved to have a significant effect on the sorption process. Benzene is favorable to sorption compared to toluene, and xylenes are favorable to sorption compared to ethylbenzene. Therefore, the effect of sorption may be related to the solubility of the chemical species. Benzene $(1780 \mathrm{mg} / \mathrm{L})$ is more soluble than toluene $(535 \mathrm{mg} / \mathrm{L})$, and total xylenes $(167 \mathrm{mg} / \mathrm{L})$ are more soluble that ethylbenzene (152 mg/L). The low sorption effect of xylenes may be attributed to differences in solubility and interferences of the xylene isomers. Therefore, it would be recommended that individual xylene isomers be tested separately in future experiments.

The Albright light ash sorption of toluene at $45^{\circ} \mathrm{C}$ and sorption of xylenes at $5^{\circ} \mathrm{C}, 25^{\circ} \mathrm{C}$ and $45^{\circ} \mathrm{C}$ are isotherms which significantly fit the Freundlich model by taking the log of equilibrium (Cf) versus the $\log$ of sorption $(\mathrm{Q})$ with $\mathrm{R}^{2}$ values close to one. The 
calculated Freundlich parameters for the Albright light ash sorption of toluene at $45^{\circ} \mathrm{C}$ are $K_{\mathrm{f}}=0.1095$ and $1 / \mathrm{n}=1.1645$, with an $\mathrm{R}^{2}$ value of 0.8541 . The calculated Freundlich parameters for Albright light ash sorption of xylenes are: $K_{\mathrm{f}}=5.0119$ and $1 / \mathrm{n}=0.4449$ with an $\mathrm{R}^{2}$ value of 0.9697 at $5^{\circ} \mathrm{C}, \mathrm{K}_{\mathrm{f}}=4.3102$ and $1 / \mathrm{n}=0.4929$ with an $\mathrm{R}^{2}$ value of .9085 at $25^{\circ} \mathrm{C}$ and $\mathrm{K}_{\mathrm{f}}=3.8851$ and $1 / \mathrm{n}=0.4640$ with an $\mathrm{R}^{2}$ value of 0.9692 at $45^{\circ} \mathrm{C}$.

When a sorption isotherm is not straight or cannot be fit to the Freundlich isotherm model it does not mean that sorption did not occur. In fact in almost all cases, except batch tests with ethylbenzene, there was a reduction in benzene, toluene and xylenes attributed to percent sorption as demonstrated in Table 14. 


\section{Chapter 5: Conclusion and Discussion}

The temperatures at with the batch tests took place were varied to compare results for optimum sorption. The statistical analysis presented in Table 13 and Table 14 demonstrate a significant difference between benzene and toluene, and between ethylbenzene and xylenes with respect to mean percent sorption for the effect of temperature. In general when considering sorption potential and temperature, it is true that sorption increased with increasing temperature. However, in some cases, such as ethyl benzene sorption onto MEA-L ash, the effect was opposite (Figure 8). In fact, there was a gain in the maximum UV analytical absorbance wavelength peak for average ethylbenzene sorbance to the MEA-L ash as temperature increased from $5^{\circ} \mathrm{C}$ to $45^{\circ} \mathrm{C}$. The MEA-L ash is non-ideal for ethylbenzene sorption and poor for toluene and xylenes sorption. There are no significant sorption increases of BTEX by the MEA-L ash when considering temperature.

The types of ash used in these batch test experiments prove to have significant effects with respect to mean percent sorption (Figures 7: Figure 8: Tables 13: Table14). The sorption effect has been attributed to the greater percentage of carbon content inherent to the ash (Low and Bately, 1988; Mott and Webber, 1992; Banerjee et al., 1995). As discussed in Chapter 2, sorption capacity increases with increasing carbon content of the coal fly ash (Banerjee et al., 1995). However, during these experiments the relationship between percent carbon and percent sorption was not linear. The non-linear effect may be attributed to variation in carbon quality as a raw coal product combined with variable 
combustion procedures. Also, the complex mineral properties of coal, demonstrated in the XRF analysis in Table 11, may interfere with or modify the sorptive properties of carbon content of the coal fly ash product. Additional work, perhaps with a scanning electron microscope, would be necessary to evaluate the carbon quality in relation to its structure in the context of soption potential.

Both coal fly ash and activated carbon offer a relatively non-polar, natural, solid, organic substrate for the adherence and penetration of neutral, hydrophobic, organic chemicals. However, coal fly ash offers less of this non-polar, natural, solid organic substrate because it inherently contains less carbon, less surface area of carbon material and mineral components inherent to coal as compared to activated carbon. Freundlich models do not fit well to the MEA-L batch test trials with BTEX. Therefore, the MEA-L ash is non-ideal for sorption of BTEX, but because of the higher ratio of calcium oxide compared to other ashes observed in this study, it may be more suitable for remedial applications which require the addition of lime.

The Alb-D and Alb-L ashes tend to show more sorption potential for BTEX versus the MEA-L ash. Greater sorption is mostly attributed to the higher percent carbon content, higher temperatures and larger percentage of clay size particles and surface area. These observations are consistent with Sign's 1994 study. Based on previous studies by Banerjee, Schwarzenbach, Low and Bately and Mott and Webber, discussed in Chapter 2, one would expect the Alb-D ash to have a greater percent sorption of BTEX versus the Alb-L ash because it contains $86.34 \%$ more carbon content, a greater percentage of clay size particles and larger surface area compared to the Alb-L ash as presented in Table 12. 
Instead the results of the batch test experiments in this study indicate that the percent sorption of benzene between the two ashes is not much different as presented in Table 13. Future experiments would be recommended at lower BTEX concentrations more typical of fuel mixture concentrations found in groundwater which may be less likely to desorb and with an analytical device that is more discrete to detect BTEX analytes with out interference or overlap of absorbance peaks.

In conclusion, coal fly ash is not only a waste byproduct of the coal combustion process, but is a highly available, low maintenance and more cost effective for consideration of sorption in the aqueous setting even though it sorbs less BTEX as compare to activated carbon. 


\section{Literature Cited}

Anzzolin, A. and Siedlecki, M.T., The value of ground water monitoring. Ground Water Monitoring and Remediation. 21(2001)36-40.

Applied Analytics, Inc., 1995, Publication \#P952510. www.a-a-inc.com/BTX?BTX1.htm

Banerjee, K. et al., Adsorption kinetics of o-xylene by flyash. Water Research. 31(1997)249-61.

Banerjee, K. 1984, taken from Montgomery, J.H. Groundwater Chemicals Desk Reference. $2^{\text {nd }}$ ed., 1996, CRC Press Inc., Boca Raton, FL.

Daniels, W.L. et al., Utilization of flyash to prevent acid mine drainage from coal refuse. In Proc. $10^{\text {th }}$ Int. Ash Use Symposium (1993)22.1-22.13.

Deb, P.K. et al., Removal of COD from wastewater by flyash. In Proc. $21^{\text {st }}$ Ind. Waste Conference(1966)848-860. Purdue University, W. Lafayette, Indiana.

DeKock and Lord, 1987; Hansch and Fujita. 1964. taken from Montgomery, J.H., Groundwater Chemicals Desk Reference. $2^{\text {nd }}$ ed., 1996, CRC Press Inc., Boca Raton, FL.

Environmental Protection Agency, U.S., Modeling Subsurface Transport of Petroleum Hydrocarbons: Effective Solubility Calculation (2001). An online training course of EPA region 9 and ERD, Athens, GA.

Evangelou, V.P. 1998. Environmental Soil and Water Chemistry, $1^{\text {st }}$ ed., John Wiley 
and Sons Inc. New York, New York.

Ferrante, Dan. 1996. Sorption Processes, Groundwater Pollution Primer, CE 4594: Soil and Groundwater Pollution, Civil Engineering Dept., Virginia Tech.

Fetter, C.W. 1999. Contaminant Hydrogeology, $2^{\text {nd }}$ ed., Prentice-Hall, Upper Saddle River, NJ.

Gangoli, N. et al., Removal of heavy metal ions from aqueous solutions with flyash. Water, Air, and Soil Pollution. 37(1975)13-24.

Grupta, G.S. et al., Removal of color from wastewater by sorption for water reuse. $J$. Environ. Sci. Health. A23(3)(1988)205-217.

Grupta, G.S. et al., Removal of chrome dye from aqueous solutions by mixed adsorbent: flyash and coal. Water Research, 24(1)(1990)45-50.

Montgomery, J.H., Groundwater Chemicals Desk Reference. $2^{\text {nd }}$ ed., 1996, CRC Press, Boca Raton, FL.

Montgomery, J.H., Groundwater Chemicals Desk Reference. $2^{\text {nd }}$ ed., 1996, CRC Press, Boca Raton, FL.

Hwang J.Y., et. al. 2000. Control of Mercury Emissions from Coal Fired Power Plants Using Fly-Ash-Derived Carbon. EPA Grant Number: R825370C028. Michigan Technological University. Institute of Materials Processing (IMP). Houghton, MI.

Indorante, S.J., et al., Particle-Size Analysis By A Modified Pipette Procedure. Soil Sci. 
Soc. Am. J., Vol. 54, March-April 1990.

Jaynes, W.F. and Vance, G.F. 1996. BTEX Sorption by Organo-Clays: Cosorption Enhancement and Equivalence of Interlayer Complexes. Soil Sci. Soc. Am. J., Vol. 60:1742-1749.

Johnson, G.E. et al., Use of coal and flyash as adsorbents for removing organic contaminants from secondary municipal effluents. IandEC Process Design Develop. 4(1965)323-327.

Low, G.K.-C. et al., Comparative studies of Adsorption of polycyclic aromatic hydrocarbons by fly ashes from the combustion of some Australian coals. Environ. Sci. Technol. 22(1988)322-27.

Metcalf and Eddy, 1972. Wastewater Engineering, $3^{\text {rd }}$ ed., McGraw-Hill, New York, NY.

Mott, H. and Weber, W. J., Sorption of low molecular weight organic contaminants: considerations for the enhancement of cutoff barrier performance. Environ. Sci. Technol. 26(1992) 1234-1242.

Nelson, M. and Guarino, C.F., The use of flyash in municipal waste treatment. J. Water Pollut. Control Fed. 41(1969)1905-1911.

Nhan, C.T. et al., Utilizing coal fly ash as a landfill barrier material. Waste Management. 16(1996)587-95.

Panday, K.K. at al., Copper II removal from aqueous solutions by flyash. Wat. Res. 19(1985)869-73. 
Parsa, J. et al., Stabilization/solidification of Hazardous wastes using fly ash. $J$. Environmental Engineering. 122(1996)935-40.

Prabhu, P.V.S.S., et al. Adsorption of zinc by aqueous solution by flyash. IAWPC. Tech. Annual. 8(1981)46-52.

Querol, X. et al., Physiochemical characteristics of Spanish fly ashes. Energy Sources. 21(1999)883-898.

Rothenberg, S.J. et al., Adsorption kinetics of vapor-phase m-xylene on coal fly ash. Environ. Sci. Technol. 25(1991)930-935.

Roy, W.R. et al., Coal flyash: a review of the literature and proposed classification system with emphasis on environmental impact. Environ. Geol. Notes. 16(1981)143.

Sadtler, Samuel P. and Sons, Inc. Sadtler Analytical Ultraviolet Spectrometry Indexes, 1960, 1961, 1963, 1966, Philadelphia, PA

Sax, I.N. and Lewis, R.J., Hawley's Condensed Chemical Dictionary. $11^{\text {th }}$ ed., 1987, Van Norstrand Reinhold Co., New York, NY.

Schwarzenbach, R. P. et al., 1993. Environmental Organic Chemistry. John Wiley and Sons, Inc., New York, NY.

Sen, A.K. and De, A.K., Adsorption of mercury(II) by coal flyash. Wat. Res. 21(1987)885888. 
Singh, B.K. and Rawat, Narendra S., Comparative sorption equilibrium studies of toxic phenols on flyash and impregnated flyash. J. Chem. Tech. Biotechnol. 61(1994)307-317.

Singh, B.K. and Rawat, Narendra S., Comparative Sorption Studies of phenolic compounds on fly ash and impregnated fly ash. J. Chem. Tech. Biotechnol. 61(1994)57-65.

Skousen, J. Reclamation of Disturbed Soils. 1998. Agron. 255 vol 1, Teacher's Press, Morgantown, WV.

Soil Survey Staff. 1984. Procedures for collecting soil samples and methods of analysis for soil survey. USDA Soil Surv. Investig. Rep. No. 1. U.S. Gov. Print Office, Washington, D.C.

Sparks, D. L. Environmental Soil Chemistry. 1995. Academic Press, San Diego, CA

Verschueren, K. Handbook of Environmental Data on Organic Chemicals. 1977. Van Nostrand Reinhold Company, New York, NY.

Viraraghavan, T. and Dronamraju, M.M., Utilization of coal ash in water pollution control. J. Environ. Studies. 40(1992)79-85.

Viraraghavan, T. and Alfaro, F., Adsorption of phenol from wastewater by peat, flyash and bentonite. Journal. of Hazardous Materials, 57(1988)59-70.

Viraraghavan, T. and Alfaro, F., Removal of phenol from wastewater by adsorption on peat, flyash and bentonite. In Proc. $26^{\text {th }}$ Mid Atlantic Ind. Waste Conf. (1994)311- 
317. Newark, Delaware. Technomic Publishing Co., Lancaster, PA.

Weng, C.H. and Huang, C.P., Removal of trace heavy metals by adsorption onto flyash. In Proc. 1990 Speciality Conf. (1990)923-24. C.R. O'Melia, ed. ASCE, NY, NY.

Weng, C.H. and Huang, C.P., Treatment of metal industrial wastewater by flyash and cement fixation. J. Environ. Eng., 120(1994)1470-1487.

Westall, J.C., Adsorption mechanisms in aquatic surface chemistry. Aquatic Surface Chemistry, W. Stumm, Ed., Wiley-Interscience, New York, pp. 3-32, 1987.

Woodward, R.E., Permeable reactive barriers and reactive zones for remediation of MTBE and TBA. June, 2001 NGWA Focus Conference, MTBE in Ground Water: Assessment, Remediation Technologies and Public Policy.. Marriot Inner Harbor, Baltimore, Maryland.

Yadava, K.P. et al., Flyash for the treatment of water enriched in lead(II). J. Envir. Sci. Health. Part A, 24(1989)783-808.

Zachara, J.M. and Striele, G.P. 1991. Use of Batch and Column Methodologies to Asses Utility Waste Leaching and Subsurface Chemical Attenuation, Research Project 2485-8. Electrical Power Research Institute.

Ziemkiewicz, P.F. and Skousen, J. 2000. Use of Coal Combustion Products for Reclamation. Green Lands. 
Appendix I. Batch Test Experimental Data 


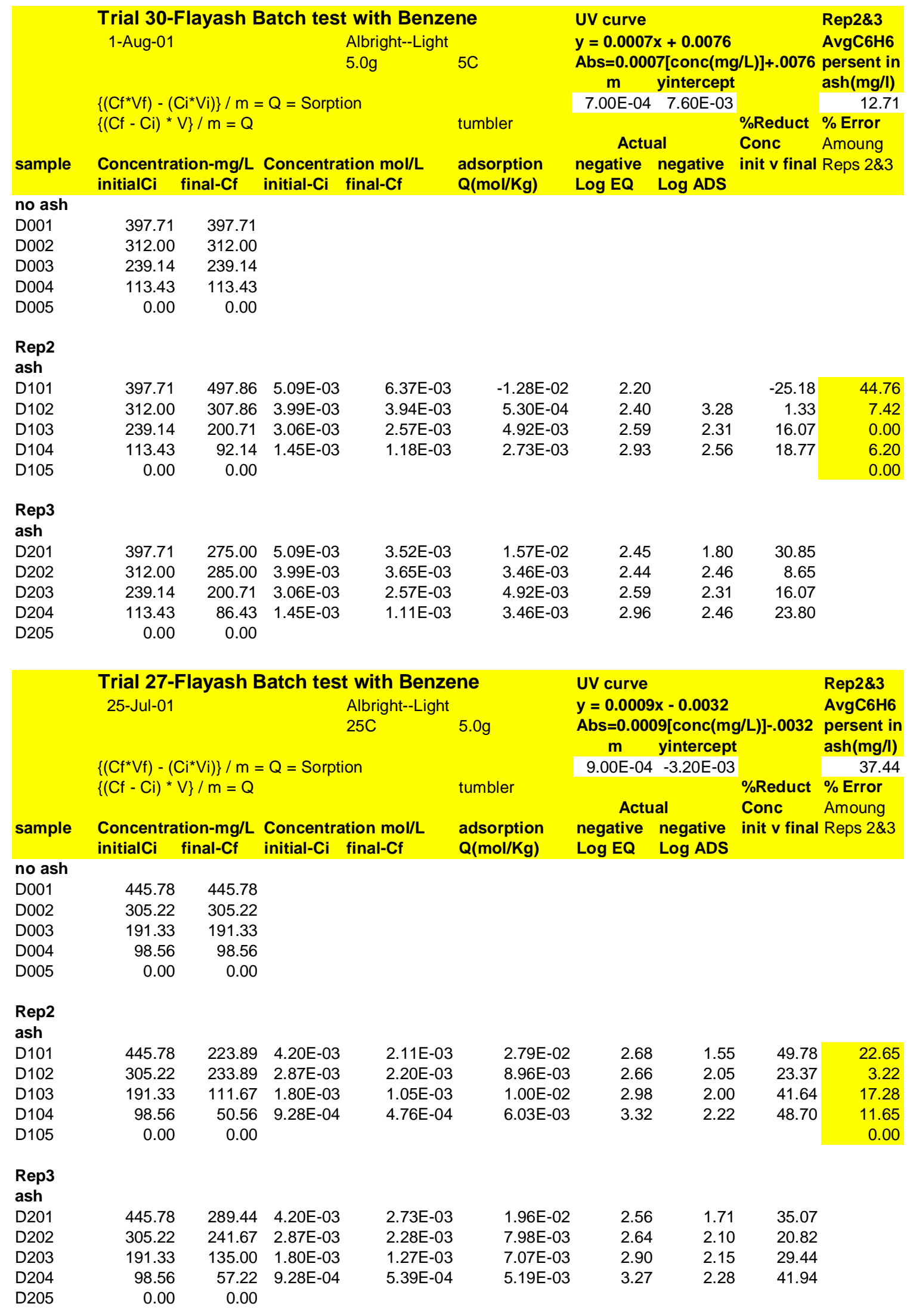




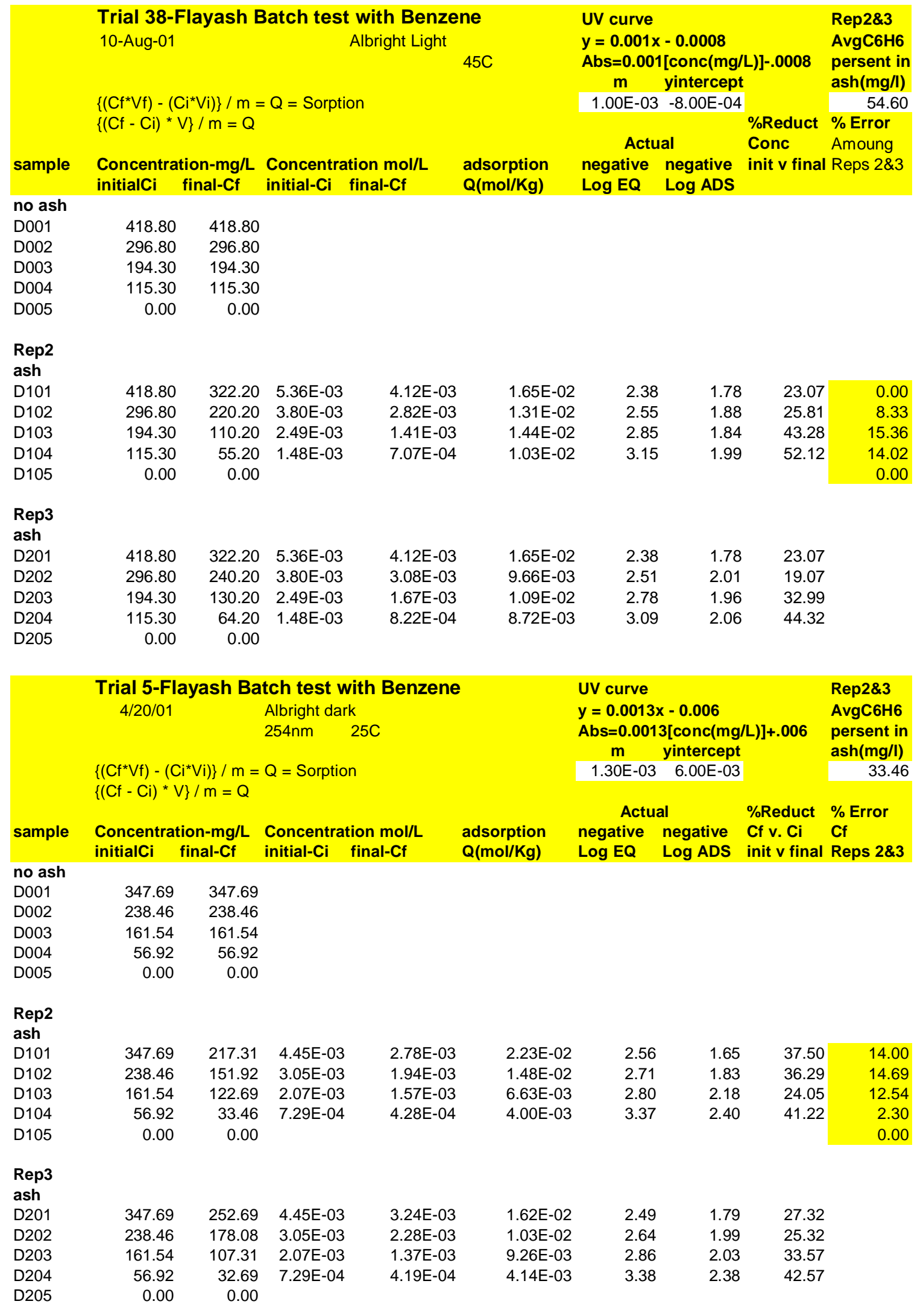




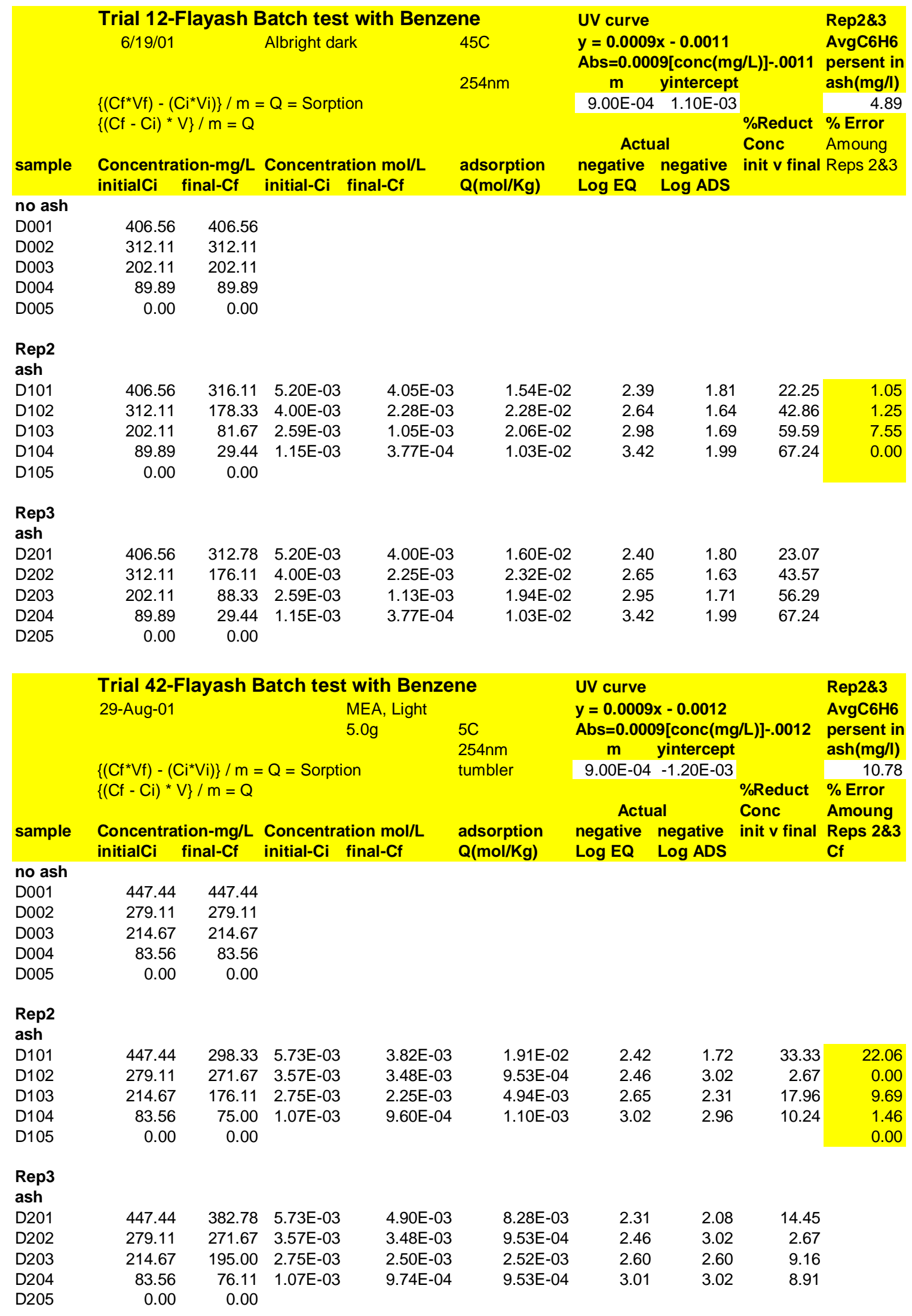




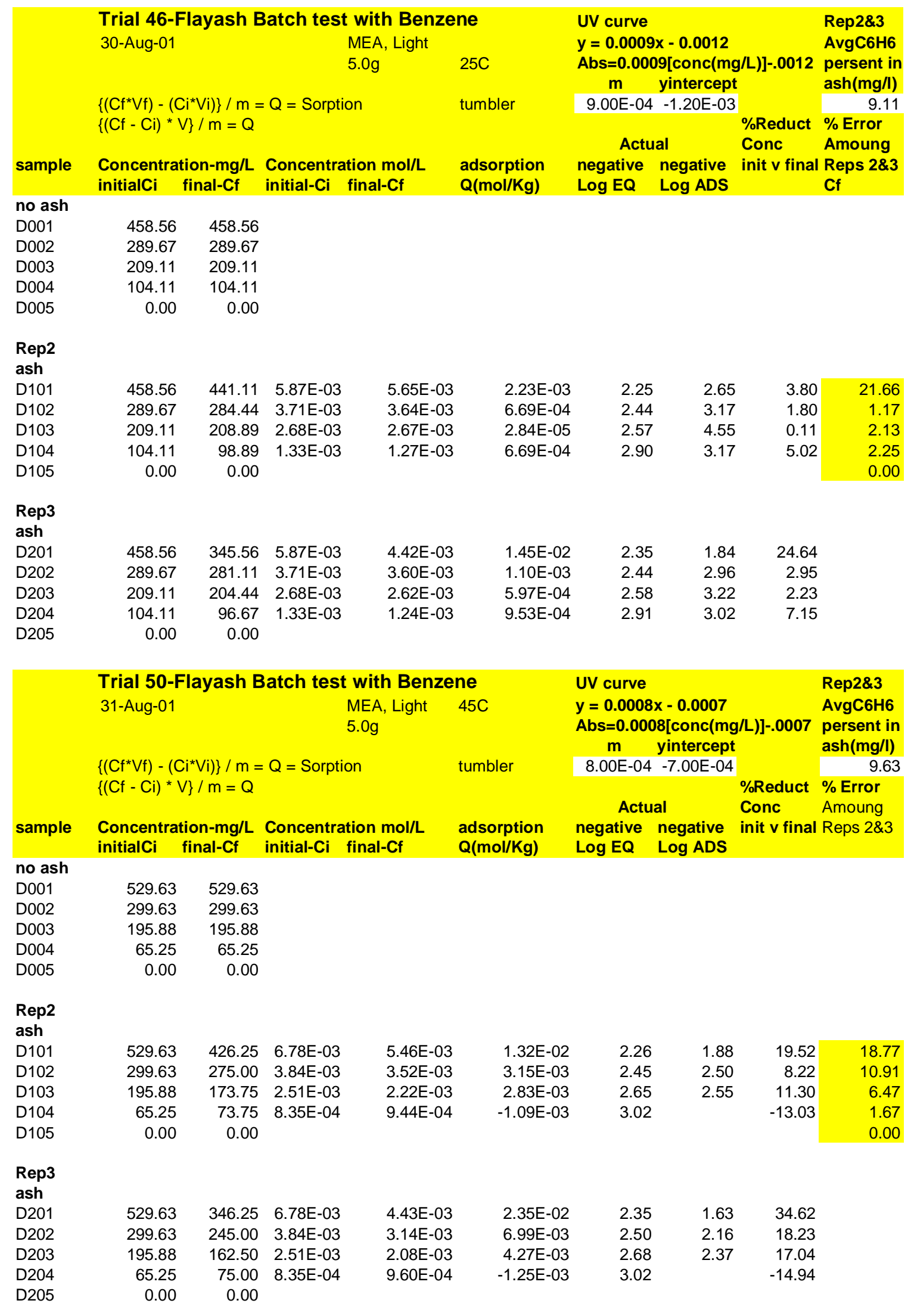




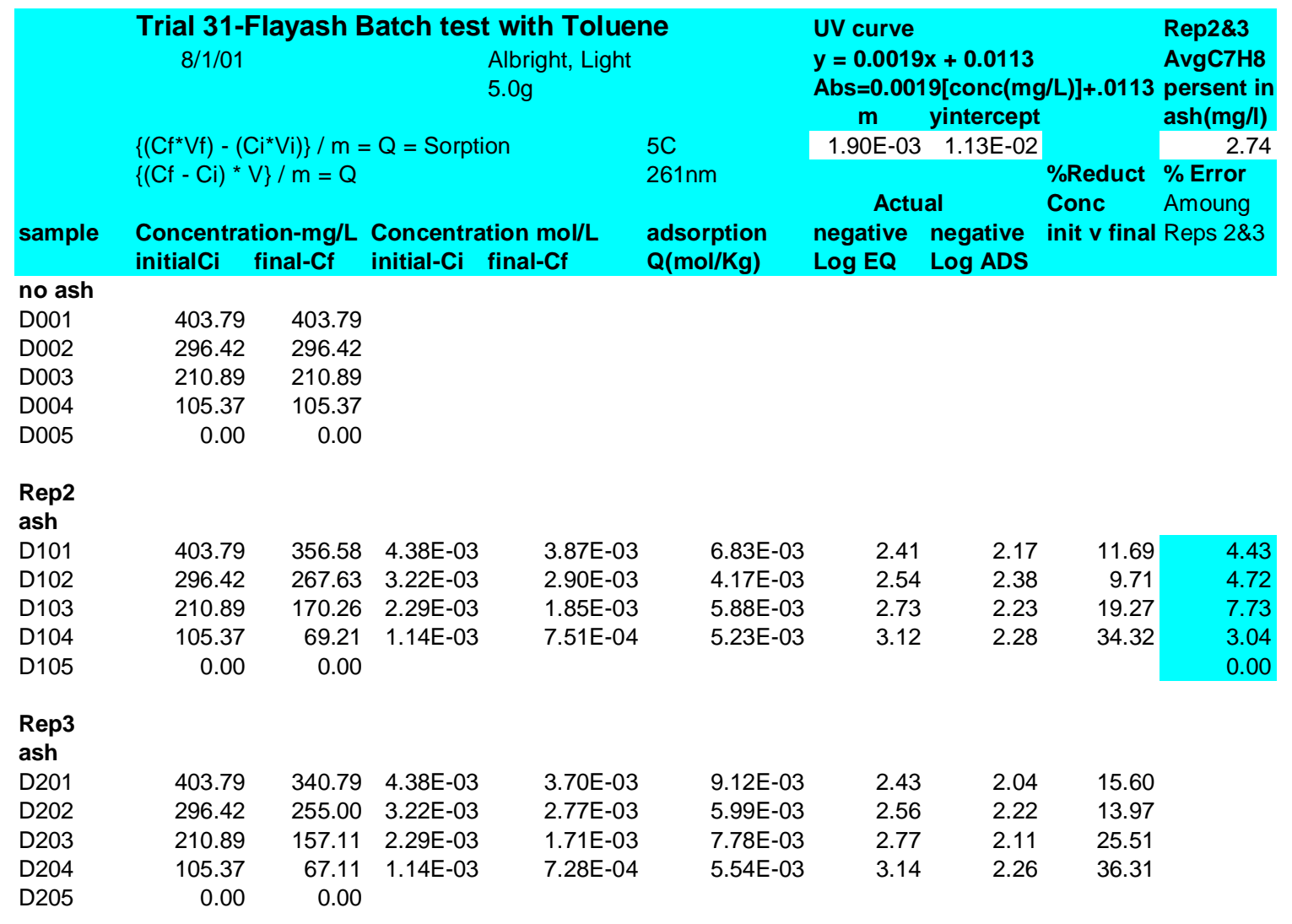

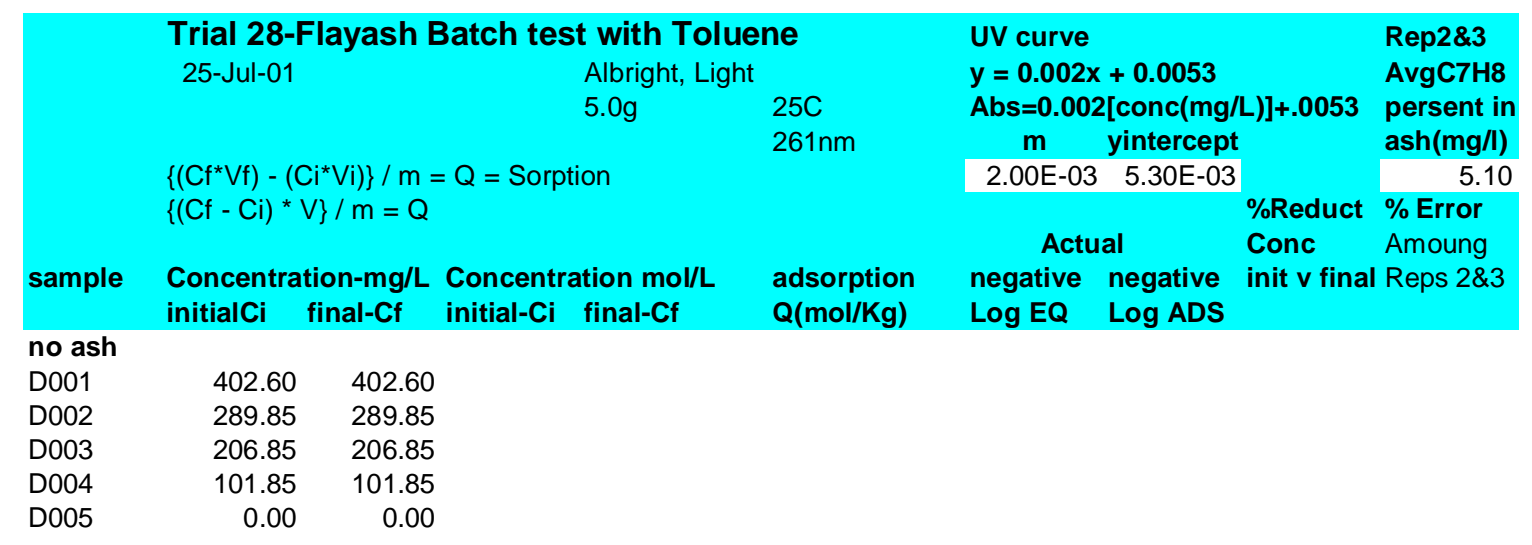

Rep2

ash

D101

D102

D103

D104

D105

$\begin{array}{rrr}402.60 & 324.25 & 4.37 \mathrm{E}-03 \\ 289.85 & 248.75 & 3.15 \mathrm{E}-03 \\ 206.85 & 157.75 & 2.24 \mathrm{E}-03 \\ 101.85 & 60.75 & 1.11 \mathrm{E}-03 \\ 0.00 & 0.00 & \end{array}$

$3.52 \mathrm{E}-03$
$2.70 \mathrm{E}-03$
$1.71 \mathrm{E}-03$
$6.59 \mathrm{E}-04$

1.13E-02

2.45

\begin{tabular}{l|l|l|}
1.95 & 19.461 & 6.488825 \\
\hline
\end{tabular}

5.95E-03 2.57

7.11E-03 2.77

$\begin{array}{llll}2.23 & 14.17975 & 10.45226\end{array}$

$\begin{array}{llll}2.15 & 23.73701 & 5.071315\end{array}$

5.95E-03

3.18

$2.23 \quad 40.35346 \quad 4.705882$

Rep3

ash

D201

D202

D203

D204

D205

$\begin{array}{rrr}402.60 & 346.75 & 4.37 \mathrm{E}-03 \\ 289.85 & 222.75 & 3.15 \mathrm{E}-03 \\ 206.85 & 149.75 & 2.24 \mathrm{E}-03 \\ 101.85 & 63.75 & 1.11 \mathrm{E}-03 \\ 0.00 & 0.00 & \end{array}$

3.76E-03

2.42E-03

$1.63 \mathrm{E}-03$

6.92E-04
8.08E-03
$9.71 \mathrm{E}-03$
$8.26 \mathrm{E}-03$
$5.51 \mathrm{E}-03$

2.42

2.62

2.79

3.16

2.0913 .87233

$2.01 \quad 23.14991$

$2.08 \quad 27.60454$

$2.26 \quad 37.40795$ 


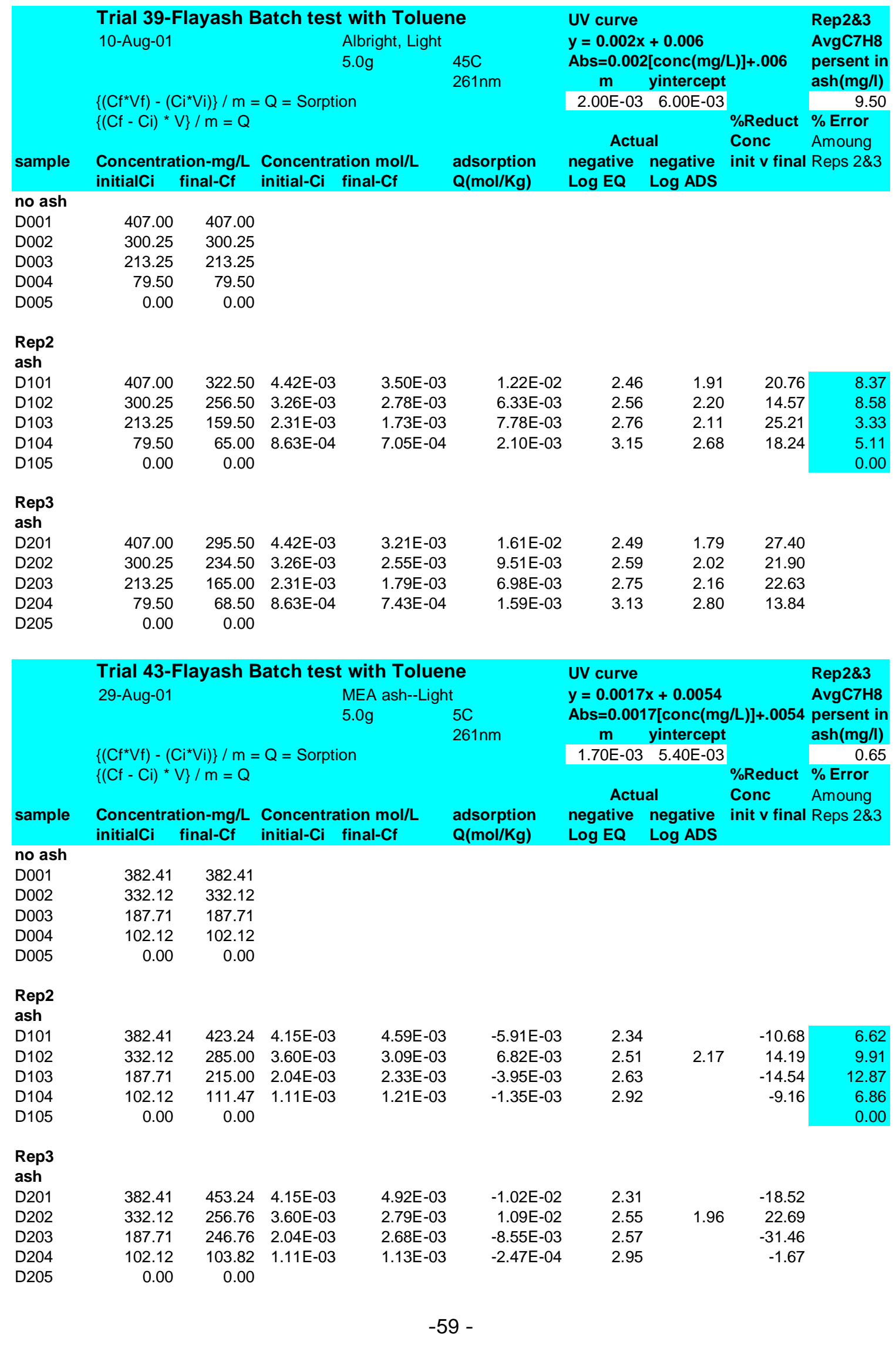




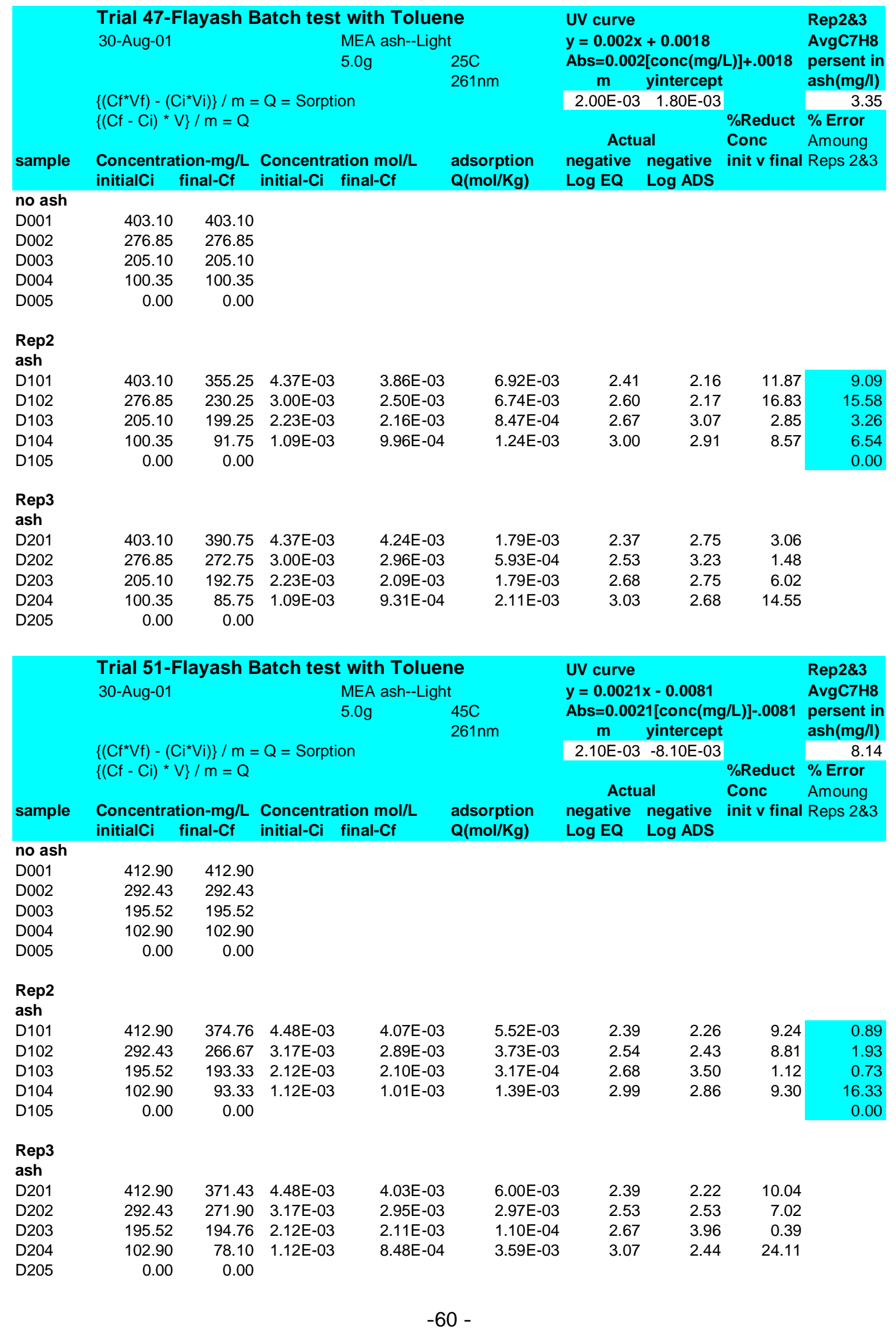




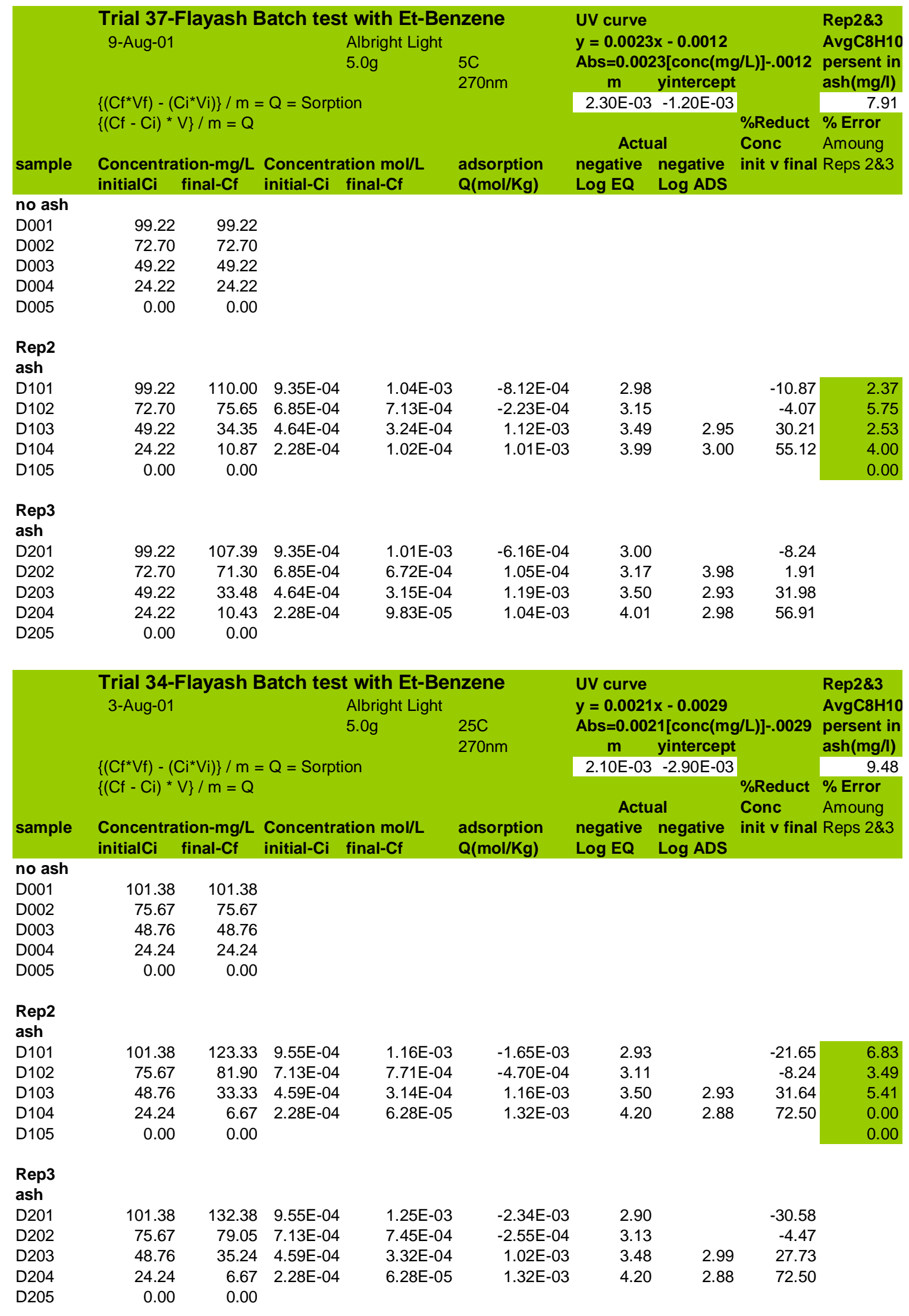




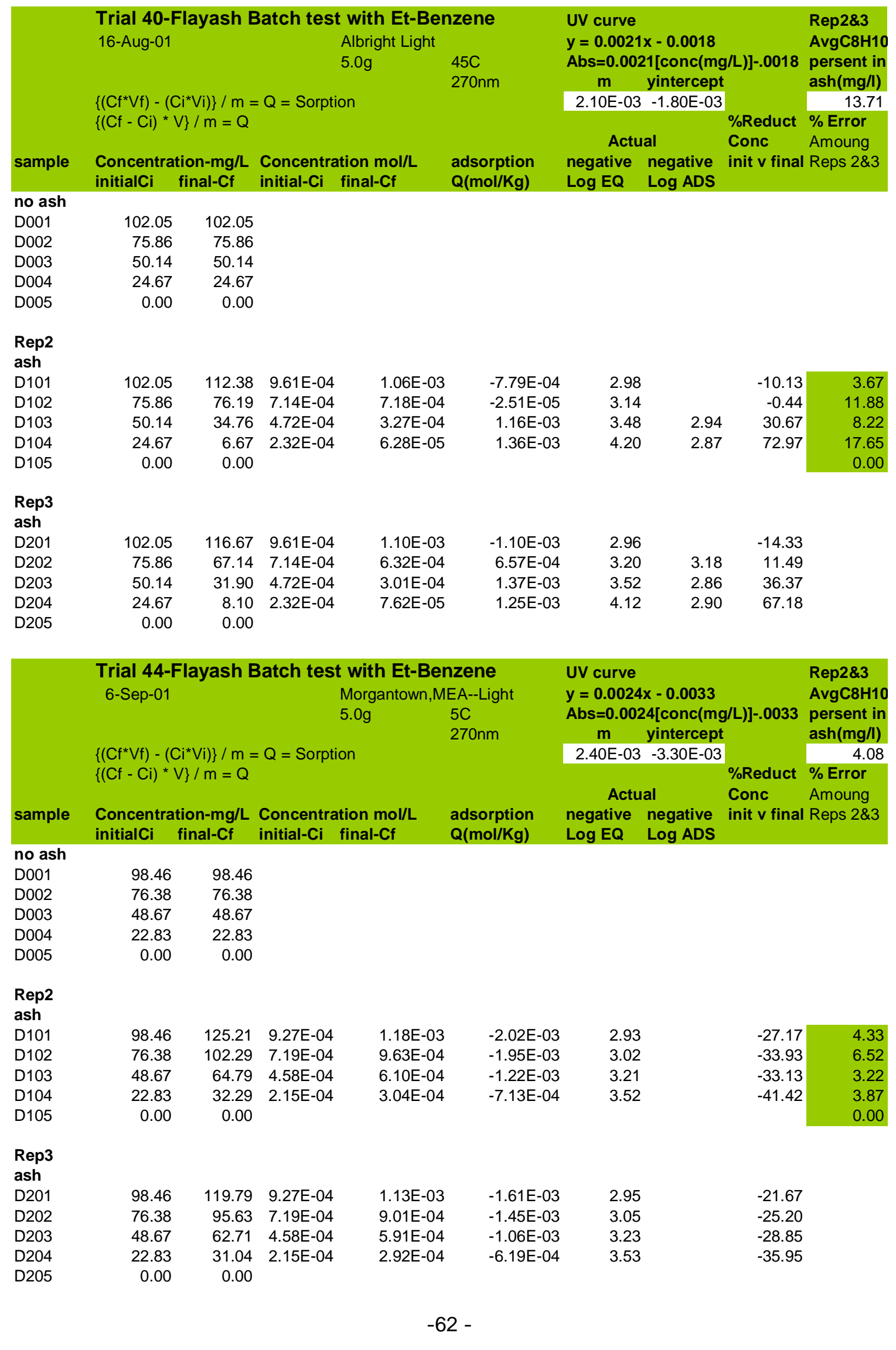




\begin{tabular}{|c|c|c|c|c|c|c|c|c|}
\hline & Trial 48-FI & ayash B & 3atch test & t with Et-Ber & nzene & UV curve & & Rep2\&3 \\
\hline & 7-Sep-01 & & & Morgantown,M & AEA--Light & $y=0.0022 x+0.0006$ & & Avg 8 H10 \\
\hline & & & & $5.0 \mathrm{~g}$ & $25 \mathrm{C}$ & Abs $=0.0022[\operatorname{conc}(\mathrm{mg} /$ & $g / L)]+.0006$ & persent in \\
\hline & & & & & & m yintercept & & $\operatorname{ash}(\mathrm{mg} / \mathrm{l})$ \\
\hline & $\left\{\left(C f^{*} V f\right)-\left(C^{\prime}\right.\right.$ & $\mathrm{Vi})\} / \mathrm{m}=$ & $=Q=$ Sorptic & & & $2.20 \mathrm{E}-03 \quad 6.00 \mathrm{E}-04$ & & 3.14 \\
\hline & $\left\{(\mathrm{Cf}-\mathrm{Ci})^{*} \mathrm{~V}\right\}$ & $/ \mathrm{m}=\mathrm{Q}$ & & & & & \%Reduct & $\%$ Error \\
\hline & & & & & & Actual & Conc & Amoung \\
\hline sample & $\begin{array}{l}\text { Concentratic } \\
\text { initial } \mathrm{Ci} \quad \mathrm{fi}\end{array}$ & $\begin{array}{l}\text { on-mg/L } \\
\text { nal-Cf i }\end{array}$ & $\begin{array}{l}\text { Concentrat } \\
\text { initial-Ci }\end{array}$ & $\begin{array}{l}\text { tion } \mathrm{mol} / \mathrm{L} \\
\text { final-Cf }\end{array}$ & $\begin{array}{l}\text { adsorption } \\
Q(\mathrm{~mol} / \mathrm{Kg})\end{array}$ & $\begin{array}{ll}\text { negative } & \text { negative } \\
\text { Log } E Q & \text { Log ADS }\end{array}$ & & \\
\hline no ash & & & & & & & & \\
\hline D001 & 99.50 & 99.50 & & & & & & \\
\hline D002 & 73.36 & 73.36 & & & & & & \\
\hline D003 & 50.41 & 50.41 & & & & & & \\
\hline D004 & 24.95 & 24.95 & & & & & & \\
\hline D005 & 0.00 & 0.00 & & & & & & \\
\hline $\begin{array}{l}\text { Rep2 } \\
\text { ash }\end{array}$ & & & & & & & & \\
\hline D101 & 99.50 & 146.14 & 9.37E-04 & $1.38 \mathrm{E}-03$ & $-3.51 E-03$ & 2.86 & -46.87 & 9.02 \\
\hline D102 & 73.36 & 105.68 & 6.91E-04 & $9.95 \mathrm{E}-04$ & $-2.44 \mathrm{E}-03$ & 3.00 & -44.05 & 5.30 \\
\hline D103 & 50.41 & 72.05 & $4.75 \mathrm{E}-04$ & $6.79 \mathrm{E}-04$ & $-1.63 E-03$ & 3.17 & -42.92 & 7.57 \\
\hline D104 & 24.95 & 32.95 & $2.35 \mathrm{E}-04$ & 3.10E-04 & $-6.03 E-04$ & 3.51 & -32.06 & 0.00 \\
\hline D105 & 0.00 & 0.00 & & & & & & 0.00 \\
\hline $\begin{array}{l}\text { Rep3 } \\
\text { ash }\end{array}$ & & & & & & & & \\
\hline D201 & 99.50 & 132.95 & 9.37E-04 & $1.25 \mathrm{E}-03$ & $-2.52 E-03$ & 2.90 & -33.62 & \\
\hline D202 & 73.36 & 111.59 & $6.91 \mathrm{E}-04$ & $1.05 \mathrm{E}-03$ & $-2.88 E-03$ & 2.98 & -52.11 & \\
\hline D203 & 50.41 & 66.59 & 4.75E-04 & $6.27 \mathrm{E}-04$ & $-1.22 \mathrm{E}-03$ & 3.20 & -32.10 & \\
\hline D204 & 24.95 & 32.95 & 2.35E-04 & $3.10 \mathrm{E}-04$ & $-6.03 E-04$ & 3.51 & -32.06 & \\
\hline D205 & 0.00 & 0.00 & & & & & & \\
\hline & Trial 52-FI & ayash B & 3atch test & t with Et-Ber & nzene & UV curve & & Rep2\&3 \\
\hline & 12-Sep-01 & & & Morgantown,M & IEA--Light & $y=0.0024 x-0.0028$ & & Avg 8 H10 \\
\hline & & & & $5.0 \mathrm{~g}$ & $\begin{array}{l}45 \mathrm{C} \\
270 \mathrm{~nm}\end{array}$ & $\begin{array}{c}\text { Abs }=0.0024[\operatorname{conc}(\mathrm{mg} / \\
\mathrm{m} \text { yintercept }\end{array}$ & /L)]-.0028 & $\begin{array}{l}\text { persent in } \\
\text { ash(mg/l) }\end{array}$ \\
\hline & $\left\{\left(C f^{*} V f\right)-\left(C^{\prime}\right.\right.$ & Vi) $\} / m=$ & $=Q=$ Sorptic & & & $2.40 \mathrm{E}-03-2.80 \mathrm{E}-03$ & & 4.08 \\
\hline & $\{(\mathrm{Cf}-\mathrm{Ci}) * \mathrm{~V}\}$ & $/ \mathrm{m}=\mathrm{Q}$ & & & & & \%Reduct & $\%$ Error \\
\hline & & & & & & Actual & Conc & Amoung \\
\hline sample & $\begin{array}{l}\text { Concentrati } \\
\text { initialCi fi }\end{array}$ & nal-Cf i & $\begin{array}{l}\text { Concentrat } \\
\text { initial-Ci }\end{array}$ & $\begin{array}{l}\text { ation } \mathrm{mol} / \mathrm{L} \\
\text { final-Cf }\end{array}$ & $\begin{array}{l}\text { adsorption } \\
Q(\mathrm{~mol} / \mathrm{Kg})\end{array}$ & $\begin{array}{ll}\text { negative } & \text { negative } \\
\text { Log EQ } & \text { Log ADS }\end{array}$ & init $v$ final & Reps 2\&3 \\
\hline no ash & & & & & & & & \\
\hline D001 & 99.29 & 99.29 & & & & & & \\
\hline D002 & 77.42 & 77.42 & & & & & & \\
\hline D003 & 43.46 & 43.46 & & & & & & \\
\hline D004 & 26.17 & 26.17 & & & & & & \\
\hline D005 & 0.00 & 0.00 & & & & & & \\
\hline $\begin{array}{l}\text { Rep2 } \\
\text { ash }\end{array}$ & & & & & & & & \\
\hline D101 & 99.29 & 156.25 & $9.35 \mathrm{E}-04$ & 1.47E-03 & $-4.29 E-03$ & 2.83 & -57.36 & 11.73 \\
\hline D102 & 77.42 & 111.25 & 7.29E-04 & $1.05 E-03$ & $-2.55 E-03$ & 2.98 & -43.70 & 3.96 \\
\hline D103 & 43.46 & 72.08 & 4.09E-04 & 6.79E-04 & $-2.16 \mathrm{E}-03$ & 3.17 & -65.87 & 0.00 \\
\hline D104 & 26.17 & 34.17 & 2.46E-04 & $3.22 E-04$ & $-6.03 E-04$ & 3.49 & -30.57 & 4.88 \\
\hline D105 & 0.00 & 0.00 & & & & & & 0.00 \\
\hline $\begin{array}{l}\text { Rep3 } \\
\text { ash }\end{array}$ & & & & & & & & \\
\hline D201 & 99.29 & 137.92 & $9.35 E-04$ & $1.30 \mathrm{E}-03$ & $-2.91 E-03$ & 2.89 & -38.90 & \\
\hline D202 & 77.42 & 115.83 & 7.29E-04 & $1.09 \mathrm{E}-03$ & $-2.89 \mathrm{E}-03$ & 2.96 & -49.62 & \\
\hline D203 & 43.46 & 72.08 & 4.09E-04 & $6.79 E-04$ & $-2.16 E-03$ & 3.17 & -65.87 & \\
\hline D204 & 26.17 & 32.50 & 2.46E-04 & 3.06E-04 & $-4.77 \mathrm{E}-04$ & 3.51 & -24.20 & \\
\hline D205 & 0.00 & 0.00 & & & & & & \\
\hline
\end{tabular}




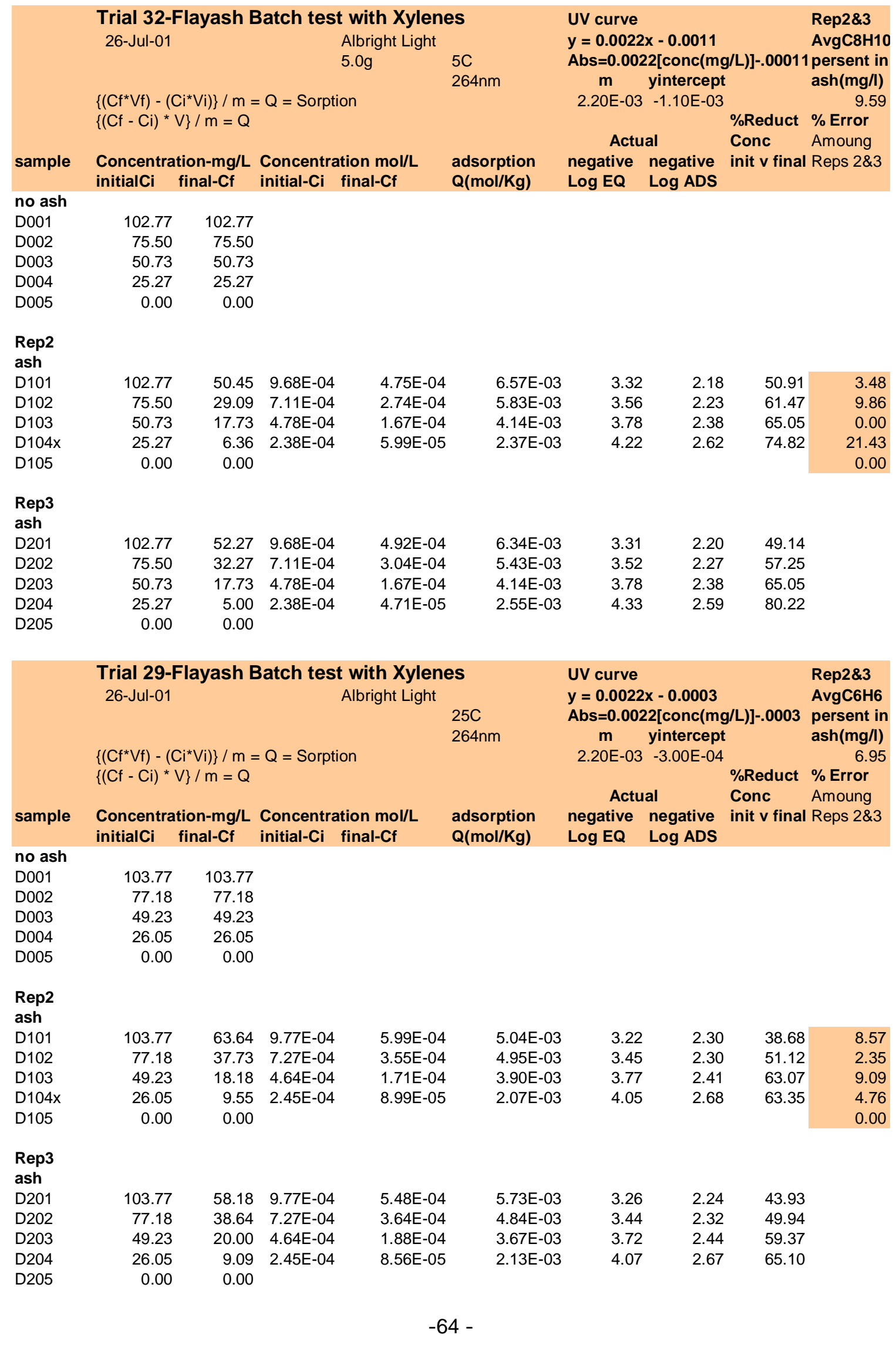




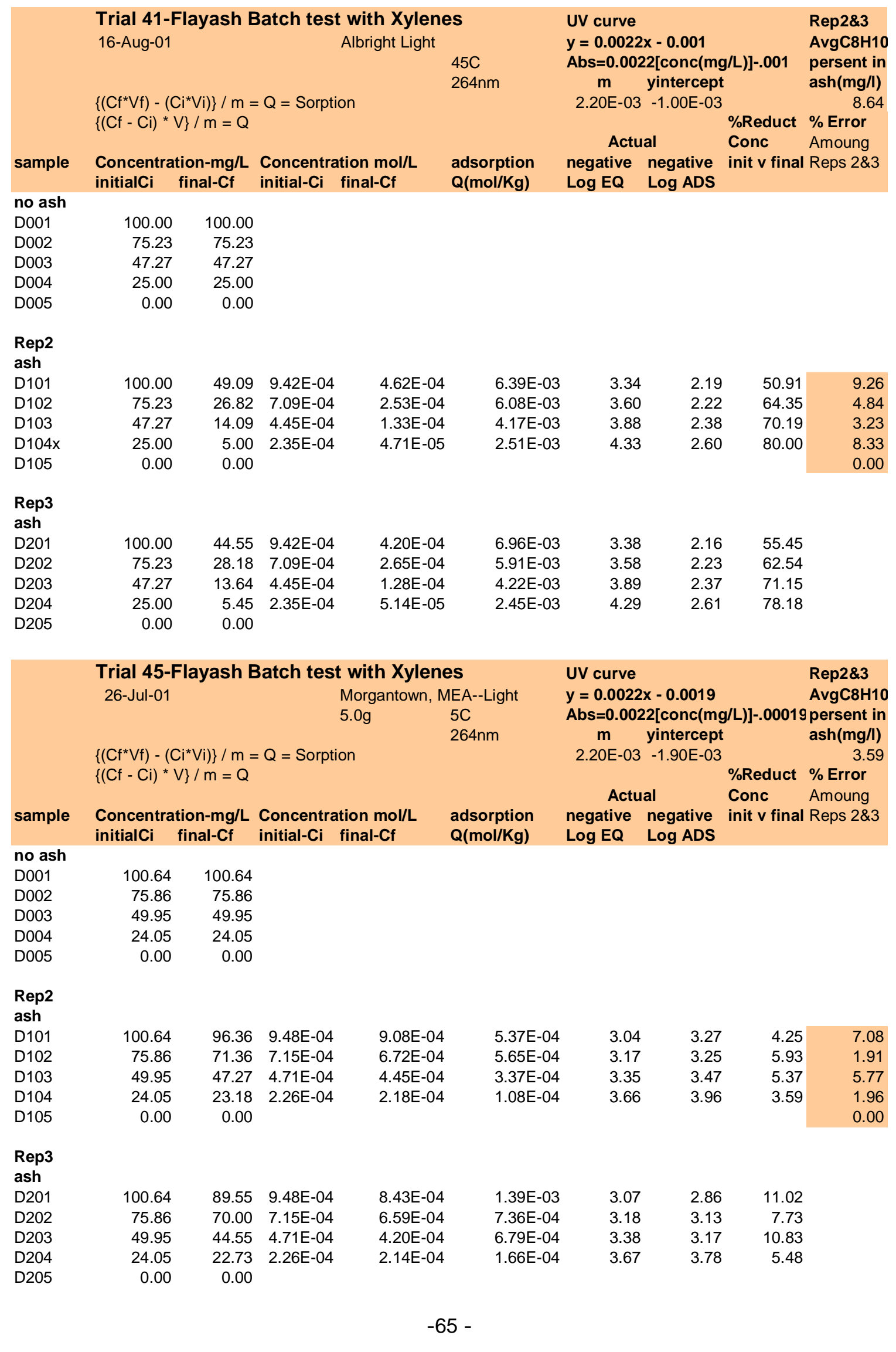




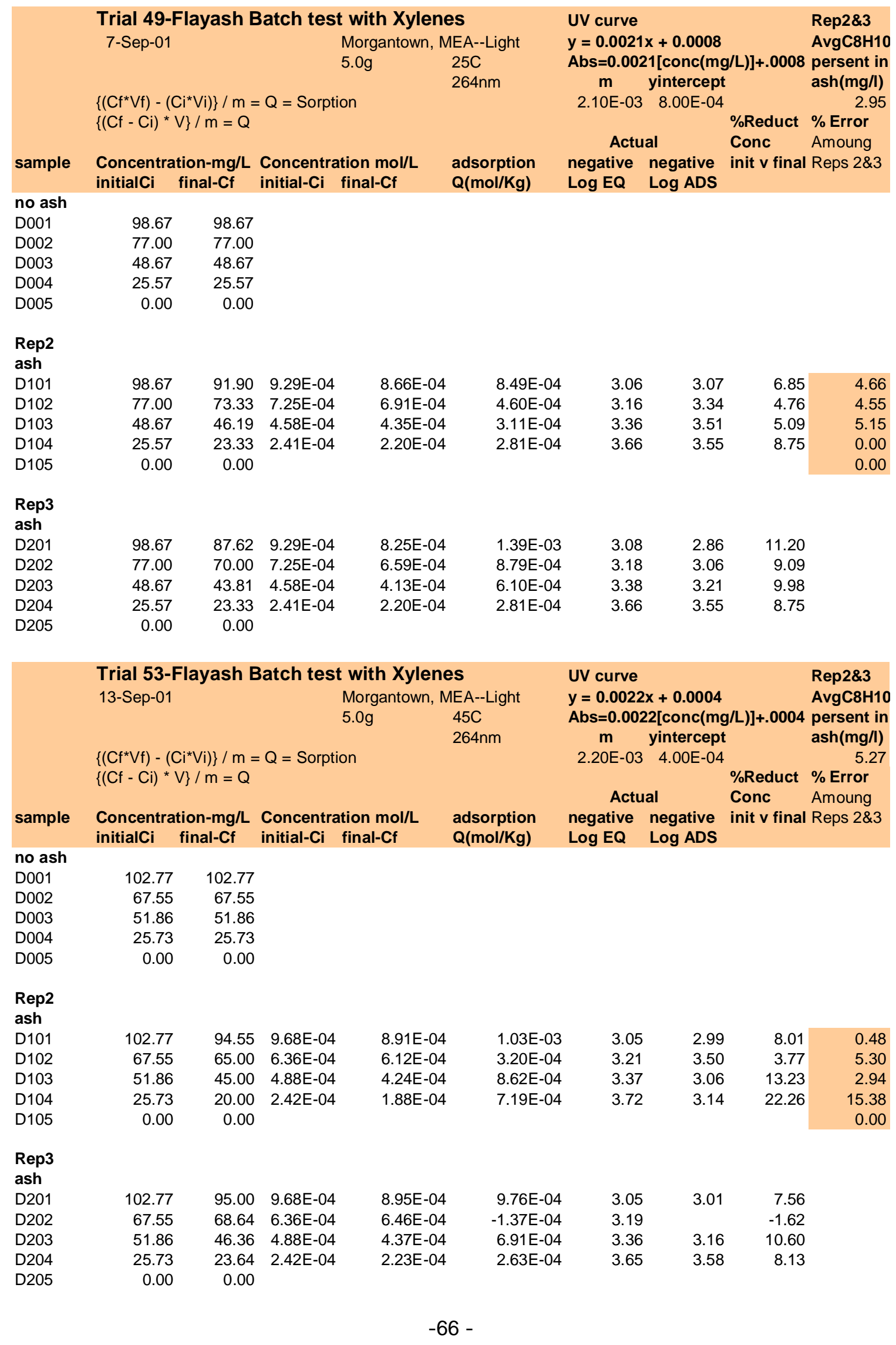




\section{Appendix II. UV Analytical Curves}




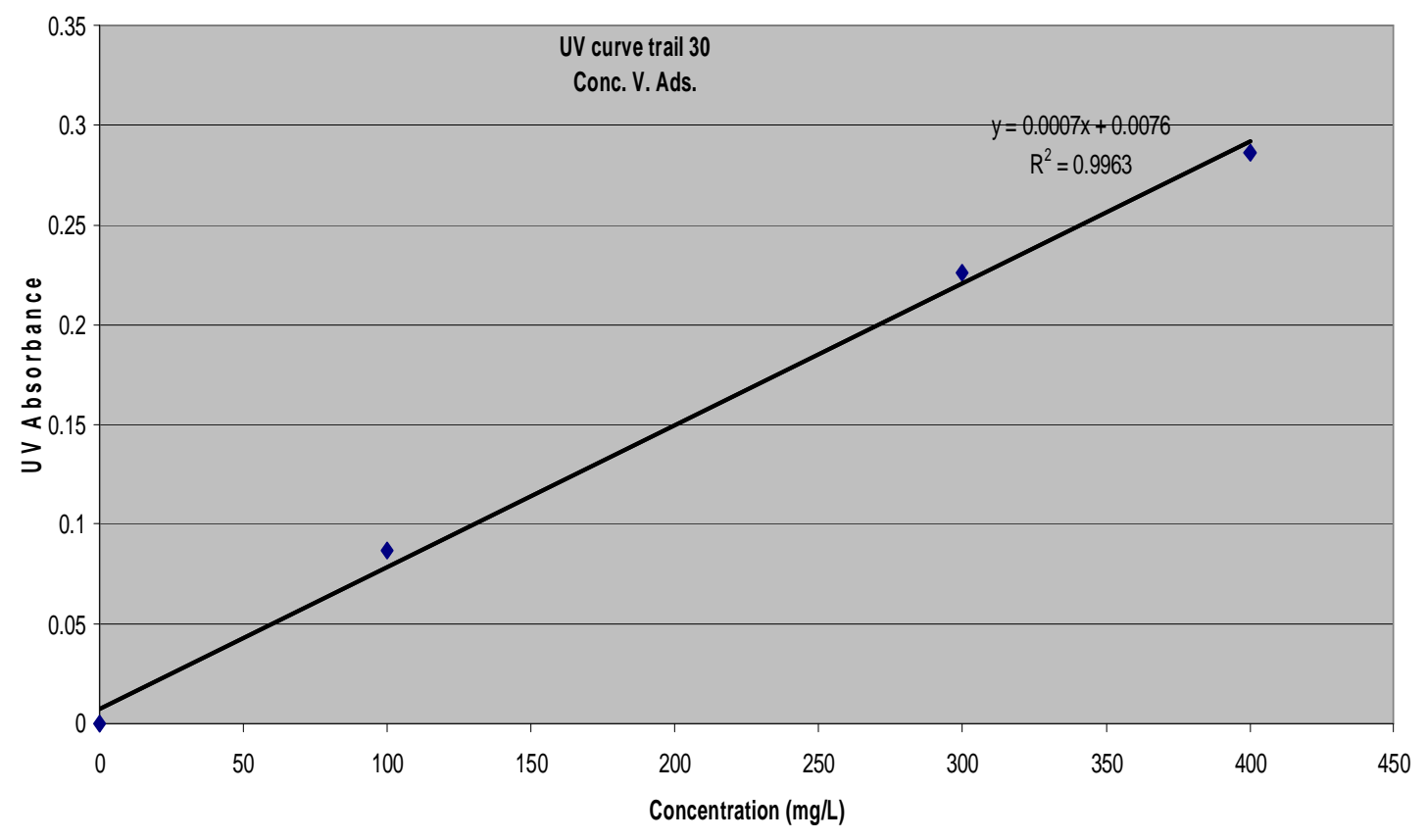

UV Qnve Tria 30 Wevelength=254m

Canc Abs Mexebsabance

ppm

$400 \quad 0.286$

$300 \quad 0.260$

$100 \quad 0.087$

$0 \quad 0$ 


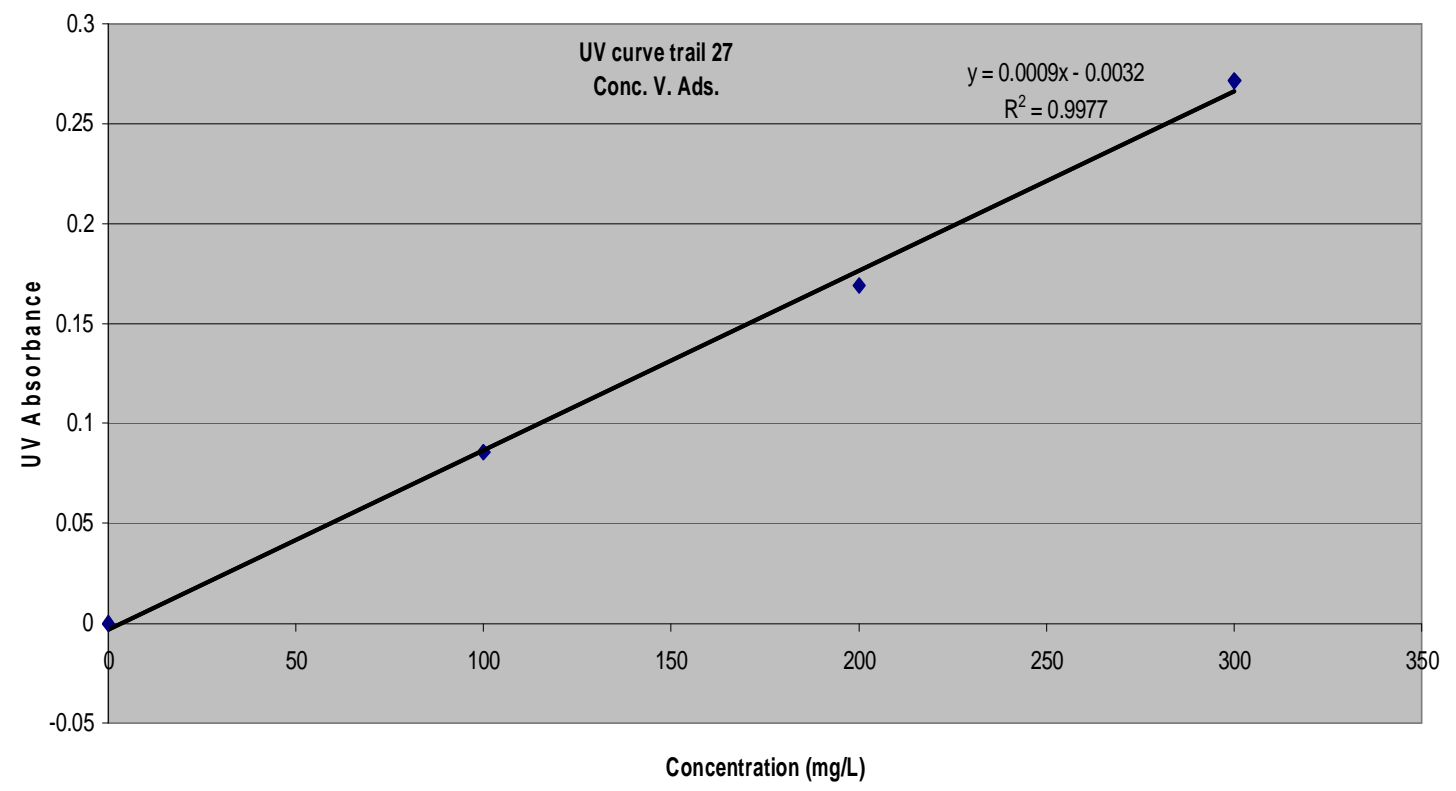

UV Curve Trial 27 Wavelength=254nm

Conc. Abs. Max absorbance

ppm

$\begin{array}{rr}300 & 0.2715 \\ 200 & 0.169 \\ 100 & 0.0855 \\ 0 & 0\end{array}$




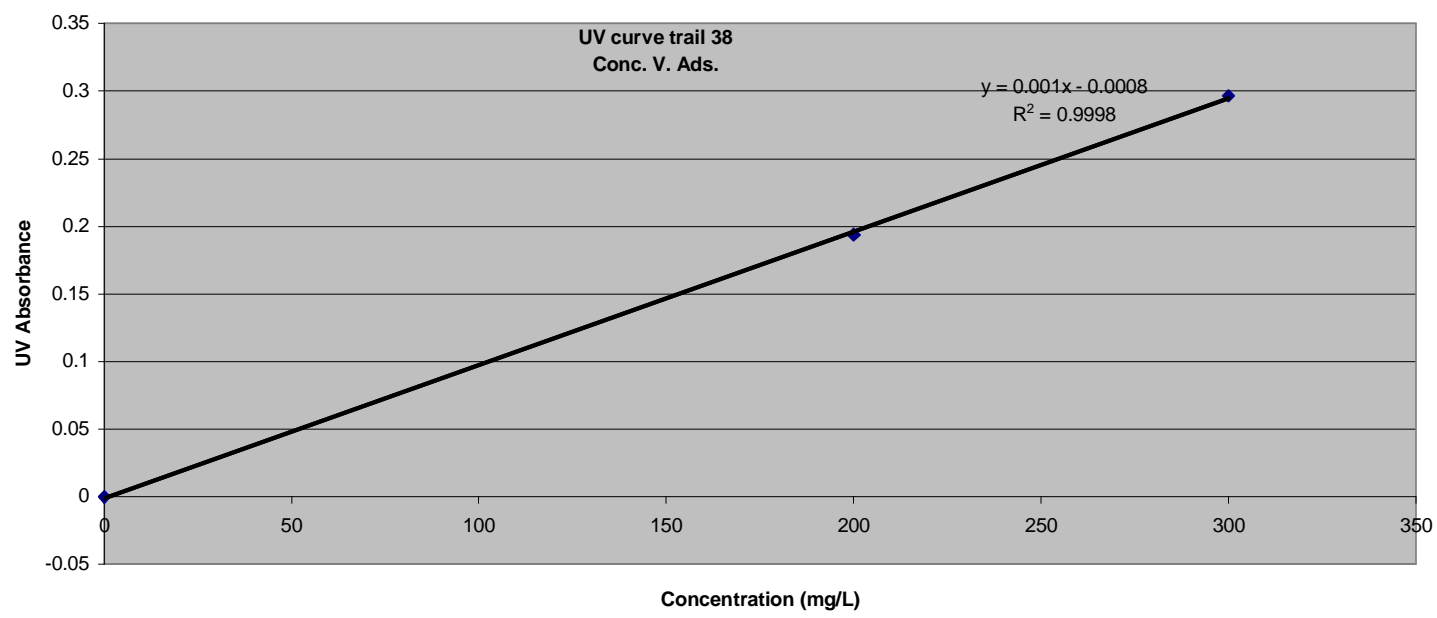

UV Curve Trial 38 Wavelength $=254 \mathrm{~nm}$

Conc. Abs. Max absorbance

ppm

$300 \quad 0.296$

$200 \quad 0.1935$

$0 \quad 0$ 


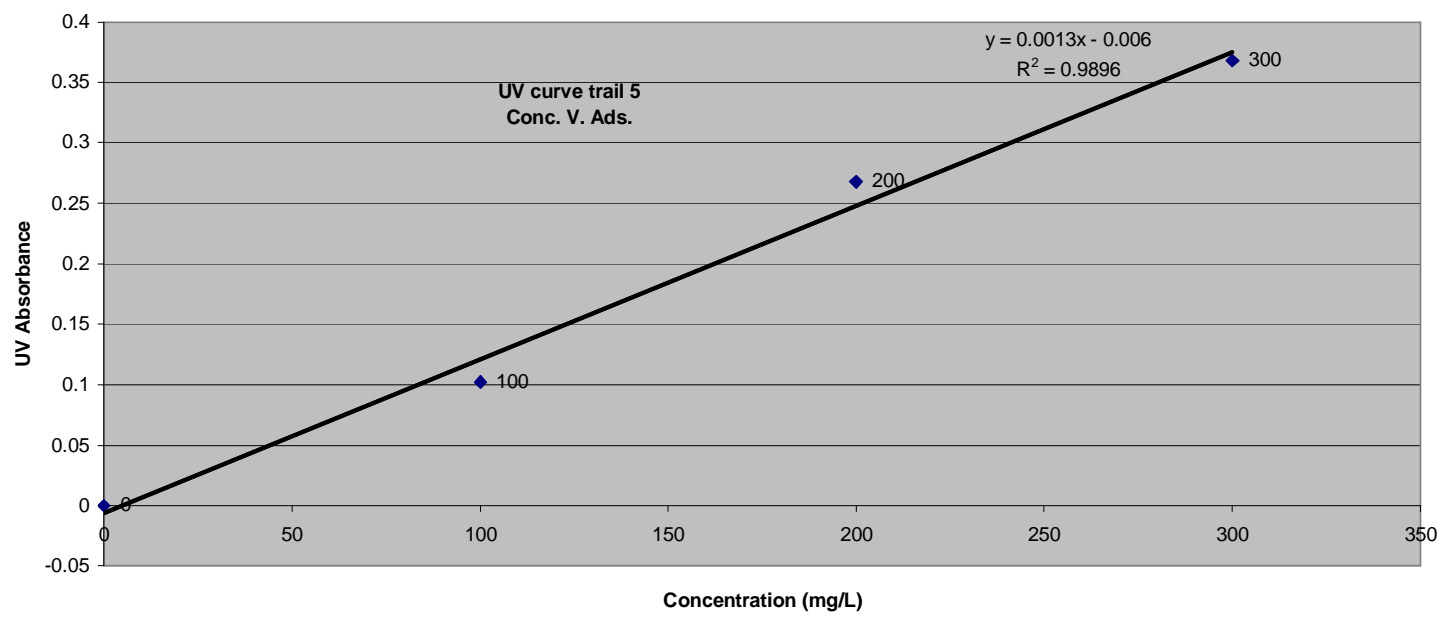

UV Curve Trial 5 Wavelength $=254 \mathrm{~nm}$

Conc. Abs. Max absorbance

ppm

$300 \quad 0.368$

$200 \quad 0.268$

$100 \quad 0.102$

$0 \quad 0$ 


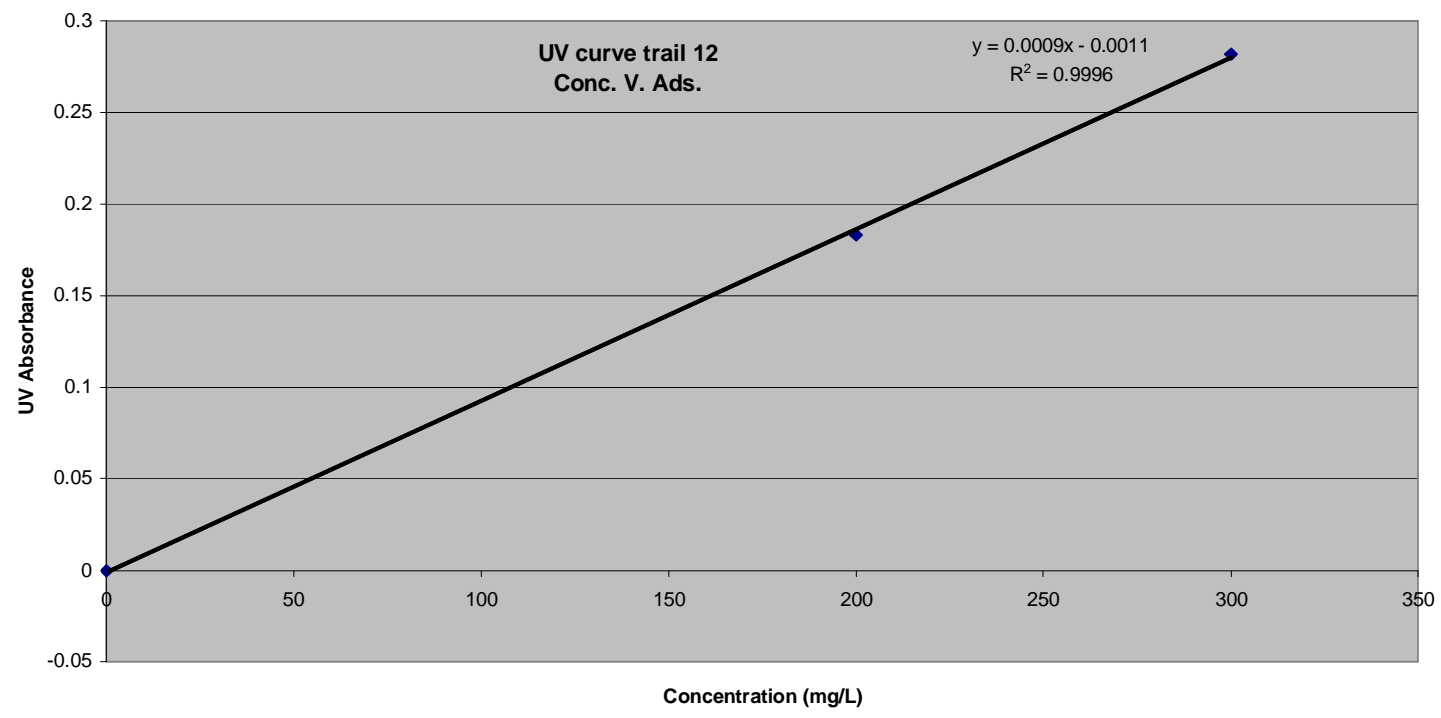

UV Curve Trial 12 Wavelength $=254 \mathrm{~nm}$

Conc. Abs. Max absorbance

ppm

$\begin{array}{rr}300 & 0.282 \\ 200 & 0.183 \\ & 0.082 \\ 0 & 0\end{array}$




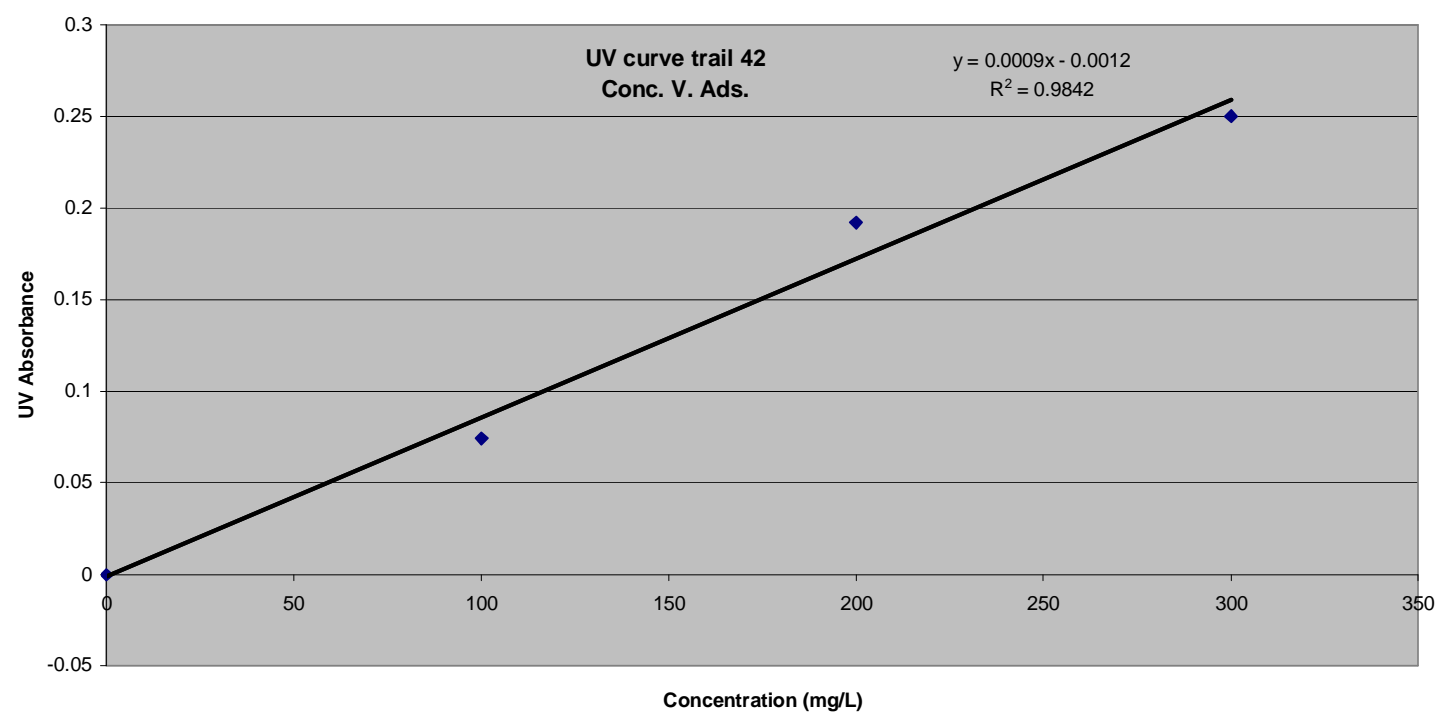

UV Curve Trial 42 Wavelength $=254 \mathrm{~nm}$

Conc. Abs. Max absorbance

ppm

$\begin{array}{rr}300 & 0.25 \\ 200 & 0.192 \\ 100 & 0.074 \\ 0 & 0\end{array}$




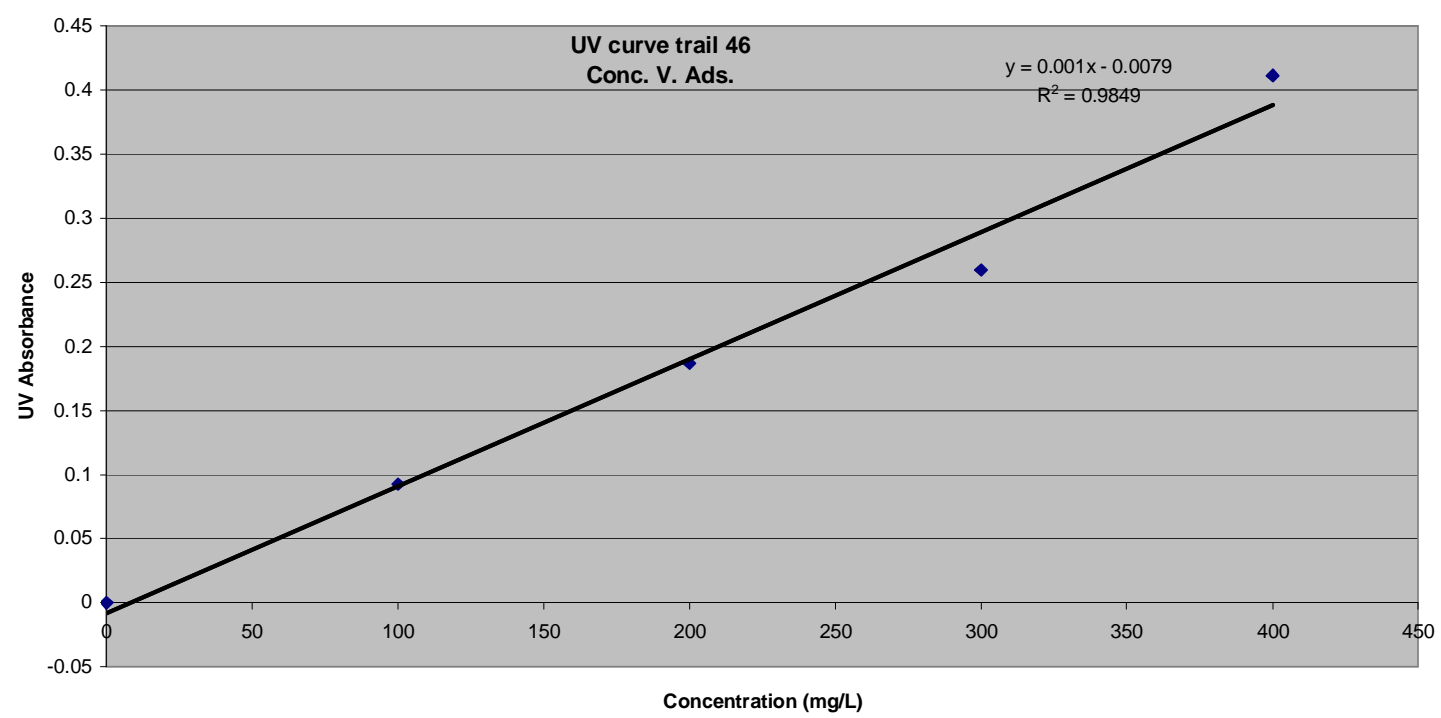

UV Curve Trial 46 Wavelength $=254 \mathrm{~nm}$

Conc. Abs. Max absorbance

ppm

$400 \quad 0.4115$

$300 \quad 0.2595$

$200 \quad 0.187$

$100 \quad 0.0925$

$0 \quad 0$ 


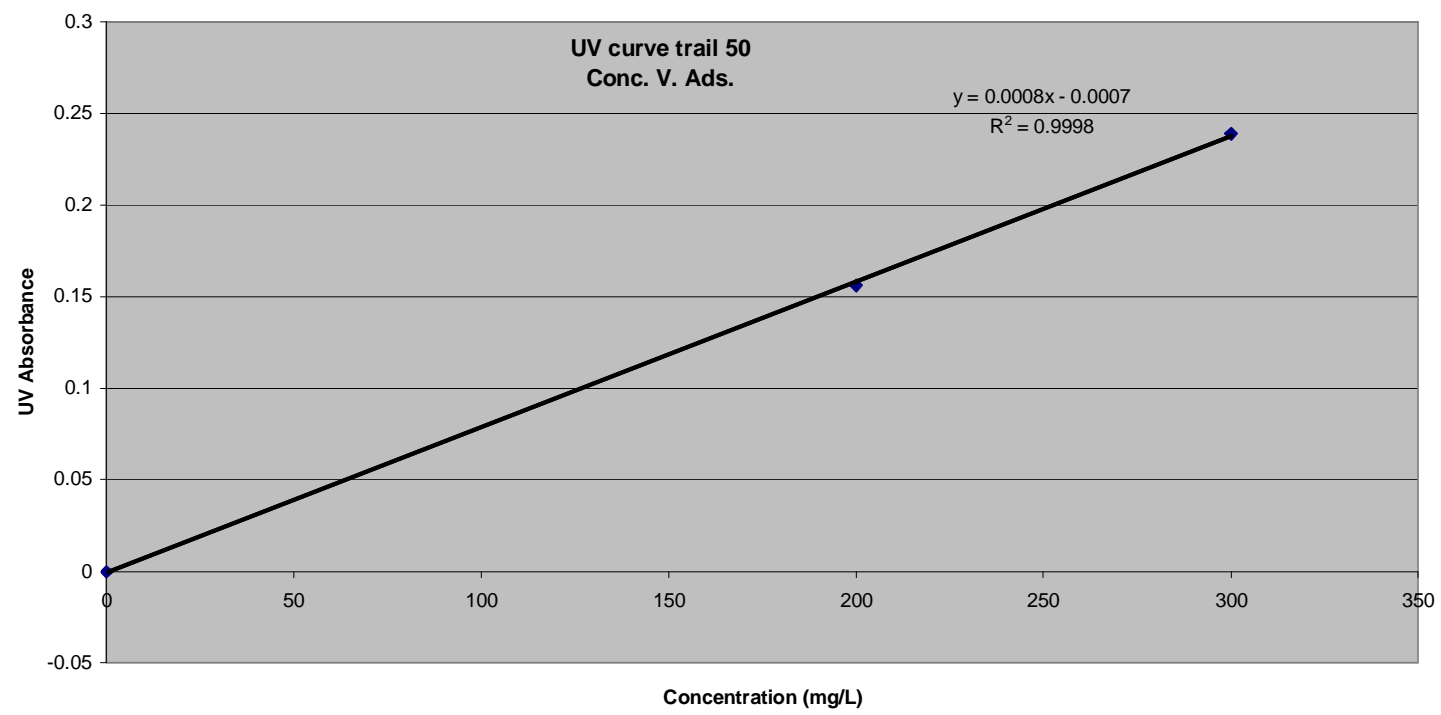

UV Curve Trial 50 Wavelength $=254 \mathrm{~nm}$

Conc. Abs. Max absorbance

ppm

$300 \quad 0.239$

$200 \quad 0.156$

$0 \quad 0$ 


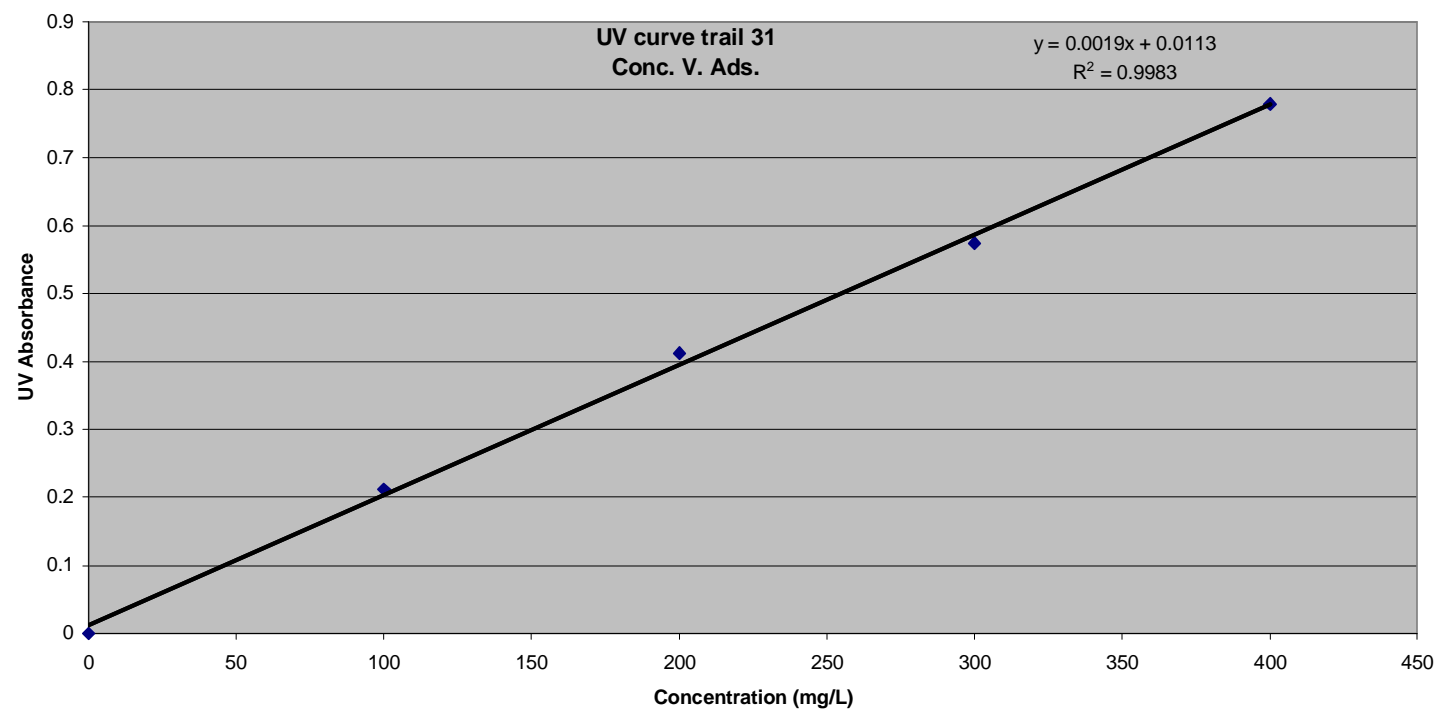

UV Curve Trial 31 Wavelength $=261 \mathrm{~nm}$

Conc. Abs. Max absorbance

ppm

$400 \quad 0.7785$

$300 \quad 0.5745$

$200 \quad 0.412$

$100 \quad 0.2115$

$0 \quad 0$ 


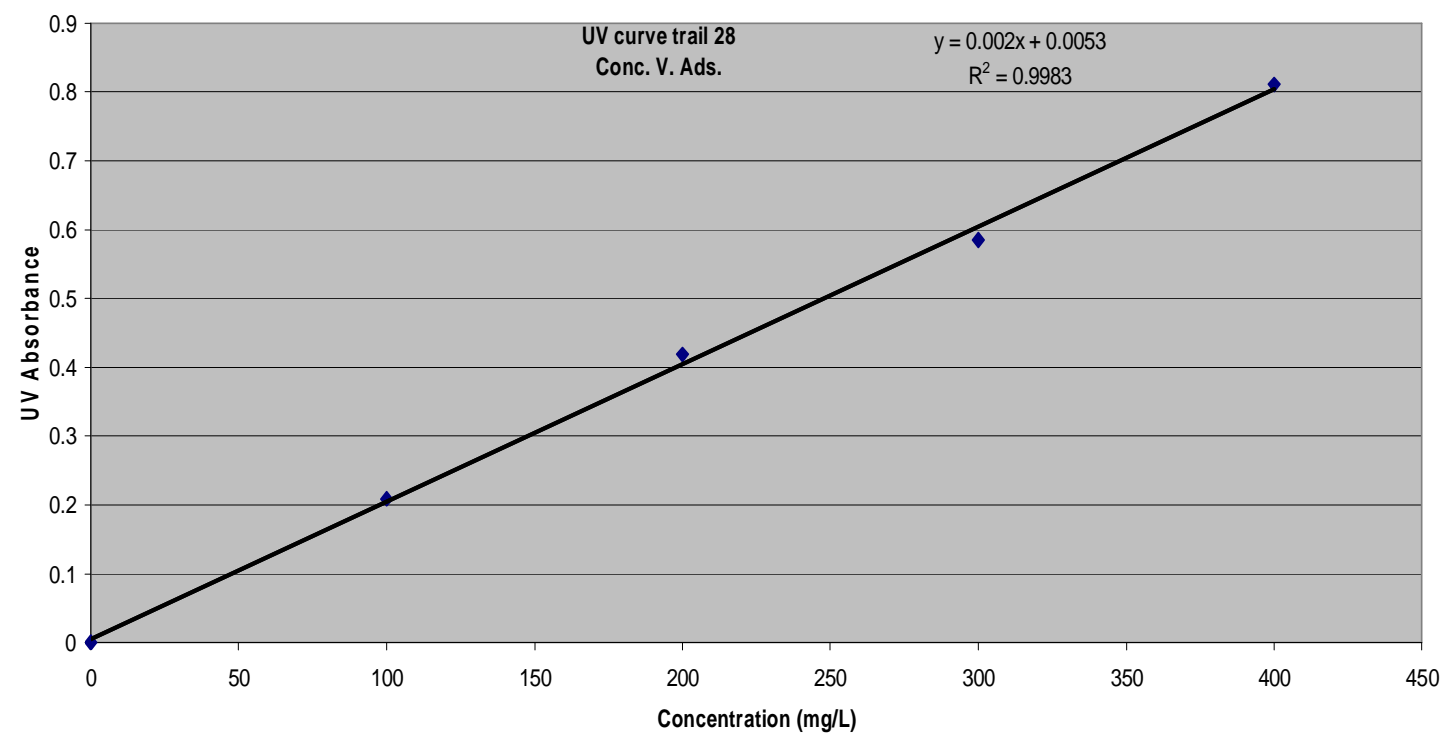

UV Curve Trial 28 Wavelength $=261 \mathrm{~nm}$

Conc. Abs. Max absorbance

ppm

$400 \quad 0.8105$

$300 \quad 0.585$

$200 \quad 0.419$

$100 \quad 0.209$

$0 \quad 0$ 


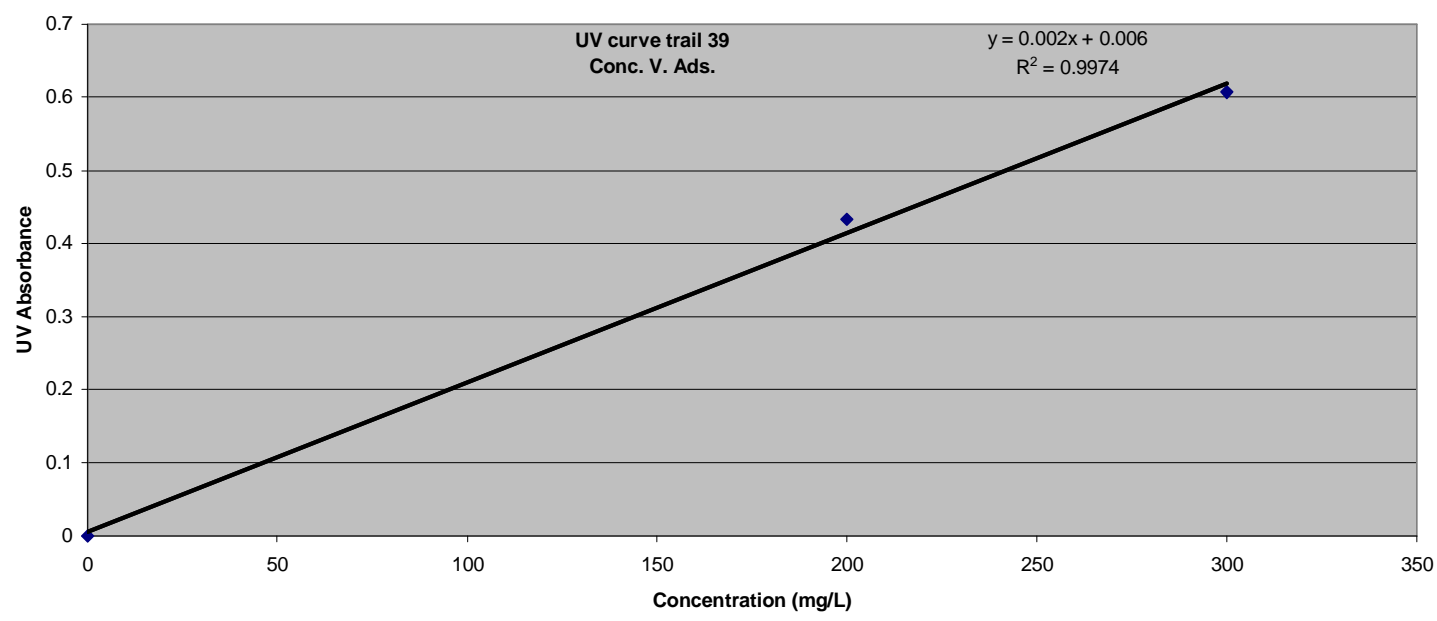

UV Curve Trial 39 Wavelength $=261 \mathrm{~nm}$

Conc. Abs. Max absorbance

ppm

$300 \quad 0.6065$

$200 \quad 0.4325$

$0 \quad 0$ 


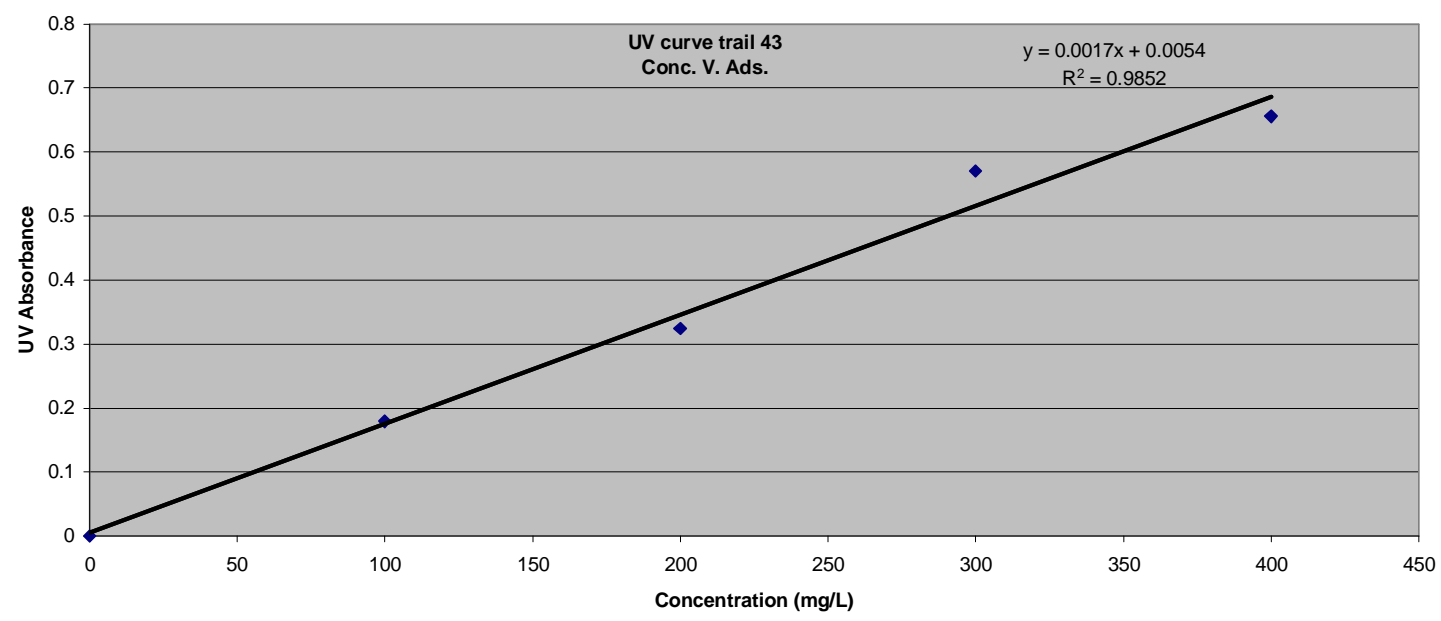

$\begin{array}{lll}\text { UV Curve } & \text { Trial } 43 & \text { Wavelength }=261 \mathrm{~nm} \\ \text { Conc. } & \text { Abs. } & \text { Max absorbance }\end{array}$

$\begin{array}{rr}\text { ppm } & \\ 400 & 0.6555 \\ 300 & 0.57 \\ 200 & 0.3245 \\ 100 & 0.179 \\ 0 & 0\end{array}$




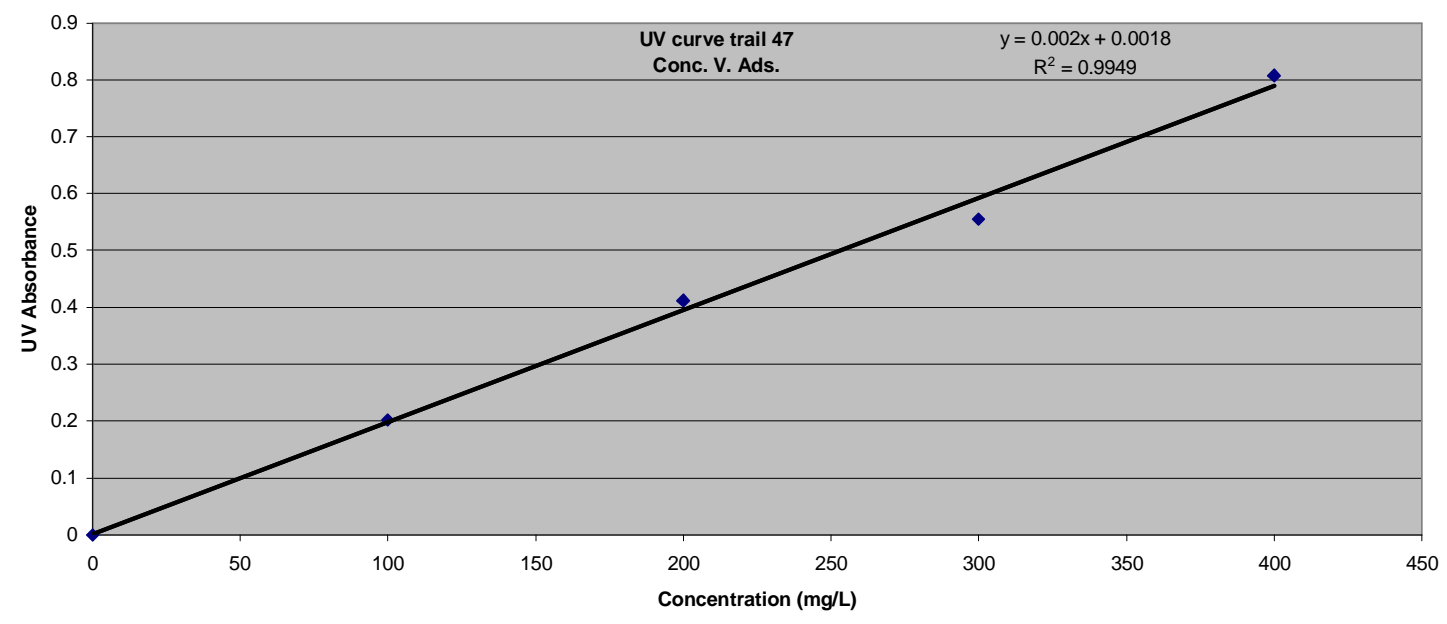

$\begin{array}{lll}\text { UV Curve } & \text { Trial } 47 & \text { Wavelength=261nm } \\ \text { Conc. } & \text { Abs. } & \text { Max absorbance }\end{array}$

$\begin{array}{rr}\text { ppm } & \\ 400 & 0.808 \\ 300 & 0.5555 \\ 200 & 0.412 \\ 100 & 0.2025 \\ 0 & 0\end{array}$




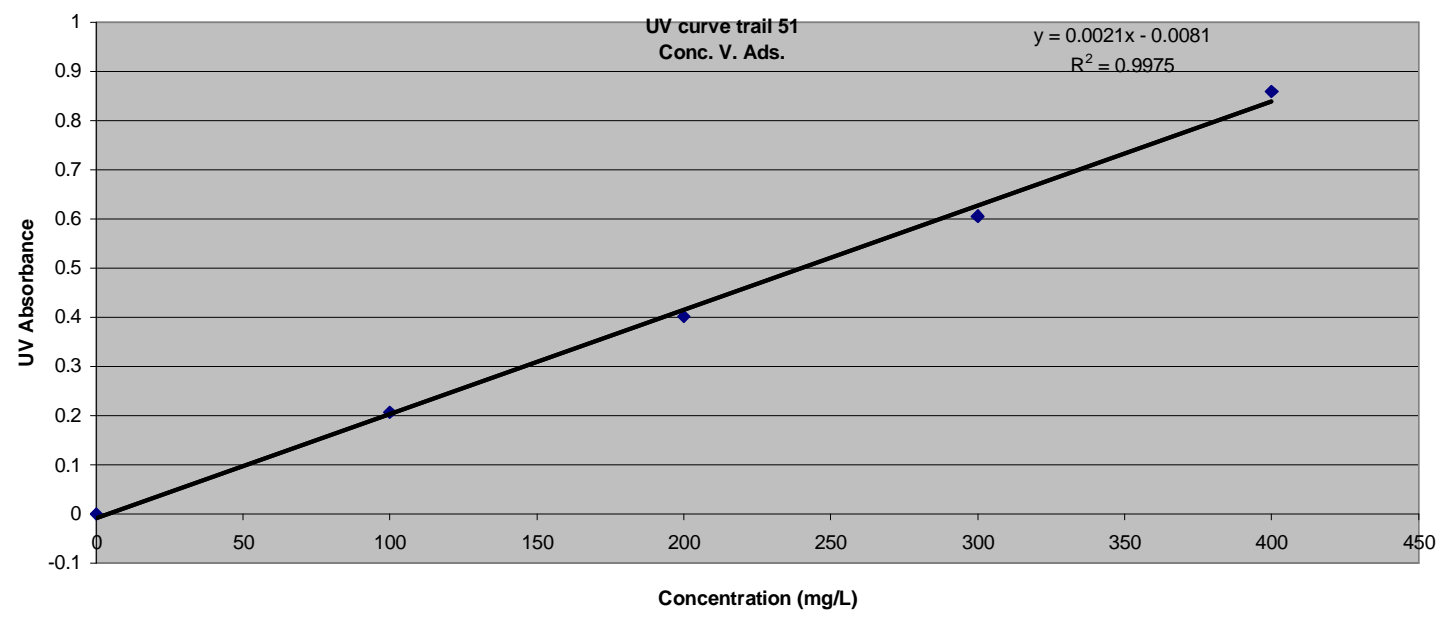

$\begin{array}{lll}\text { UV Curve } & \text { Trial } 51 & \text { Wavelength=261nm } \\ \text { Conc } & \text { Abs. } & \text { Max absorbance }\end{array}$

$\begin{array}{rr}\text { ppm } & \\ 400 & 0.859 \\ 300 & 0.606 \\ 200 & 0.4025 \\ 100 & 0.208 \\ 0 & 0\end{array}$




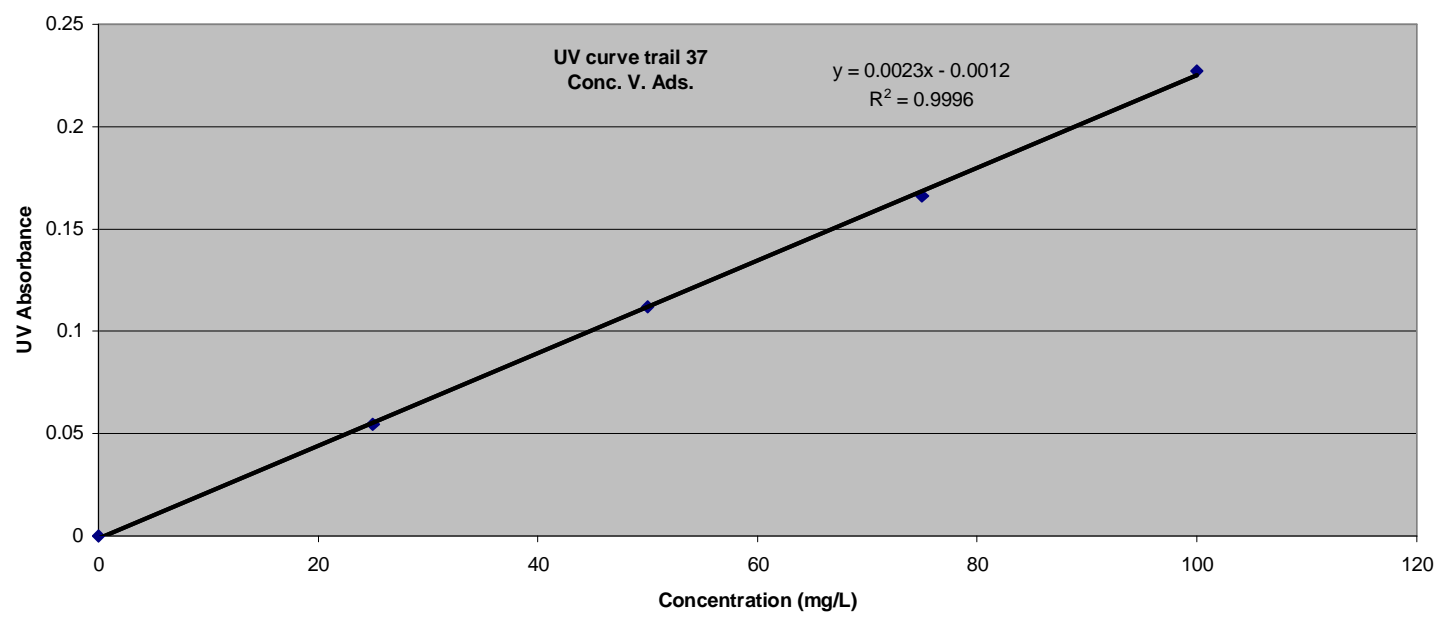

$\begin{array}{lr}\begin{array}{l}\text { UV Curve } \\ \text { Conc. } \\ \text { ppm }\end{array} & \begin{array}{l}\text { Trial } 37 \\ \text { Abs. }\end{array} \\ & \\ 100 & 0.227 \\ 75 & 0.166 \\ 50 & 0.112 \\ 25 & 0.0545 \\ 0 & 0\end{array}$




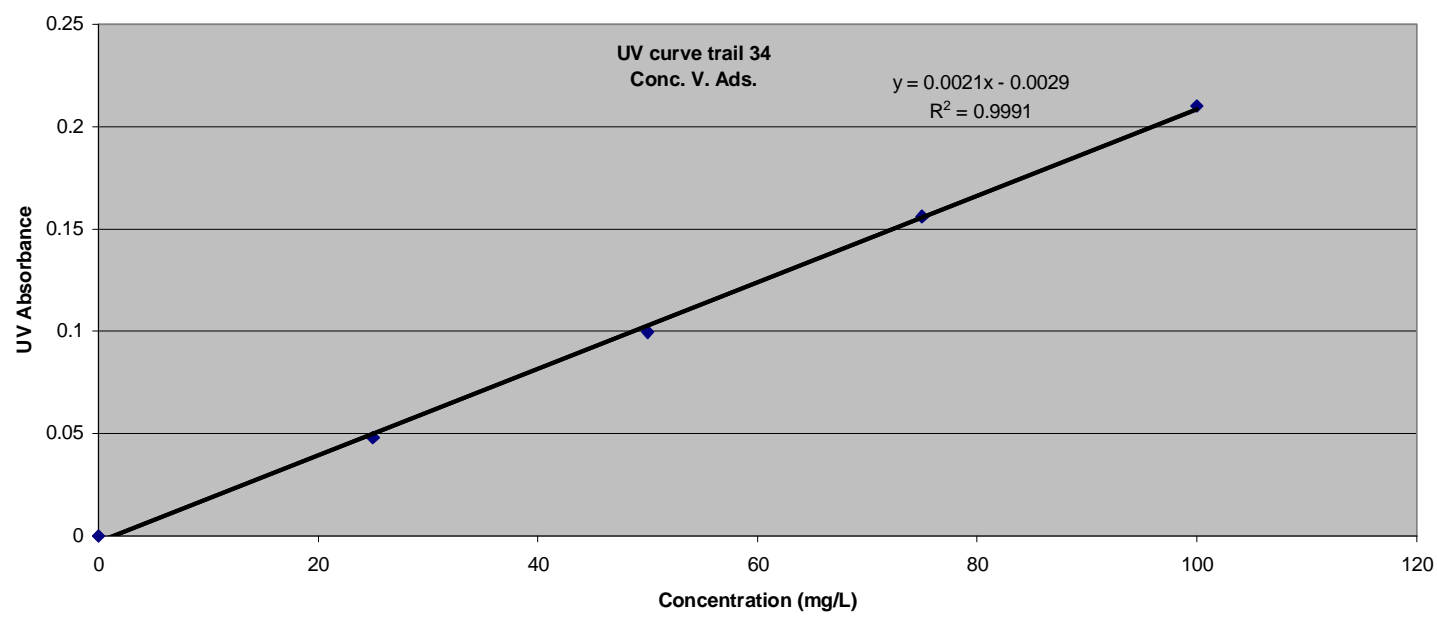

UV Curve Trial 34 Wavelength $=270 \mathrm{~nm}$

Conc. Abs. Max absorbance

ppm

$\begin{array}{rr}100 & 0.21 \\ 75 & 0.156 \\ 50 & 0.0995 \\ 25 & 0.048 \\ 0 & 0\end{array}$




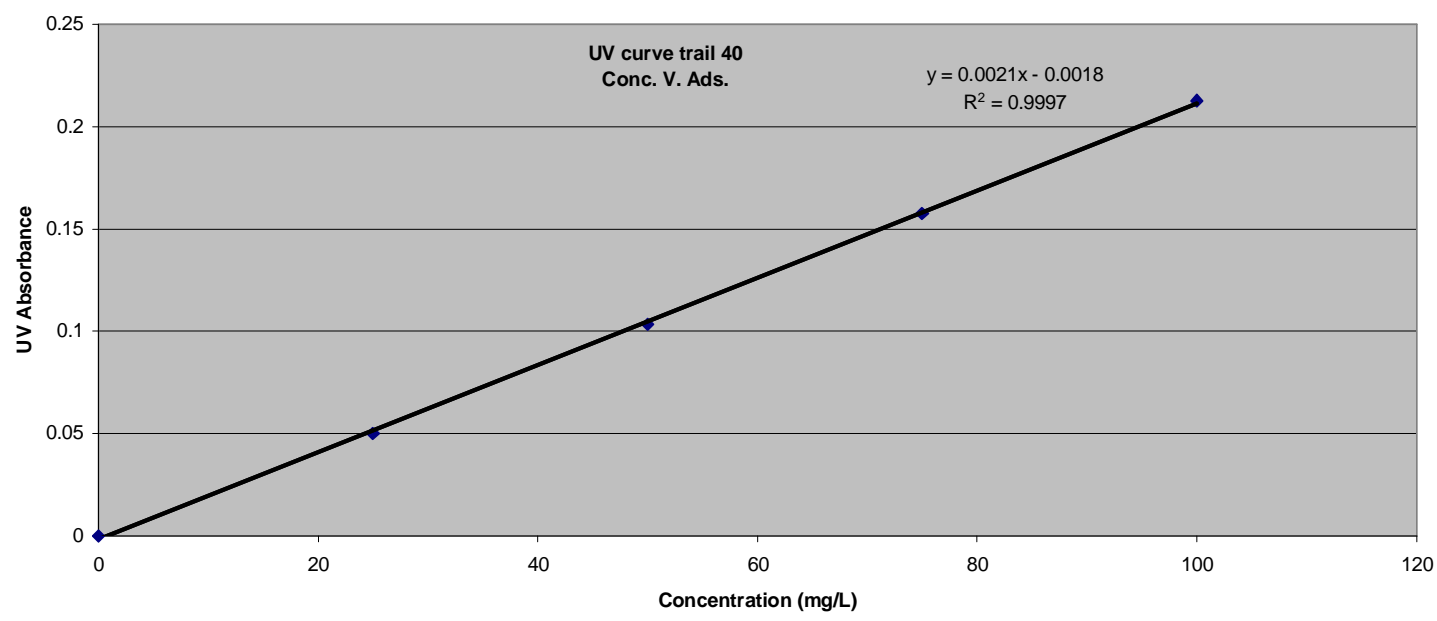

UV Curve Trial 40 Wavelength $=270 \mathrm{~nm}$

Conc. Abs. Max absorbance

ppm

$\begin{array}{rr}100 & 0.2125 \\ 75 & 0.1575 \\ 50 & 0.1035 \\ 25 & 0.05 \\ 0 & 0\end{array}$




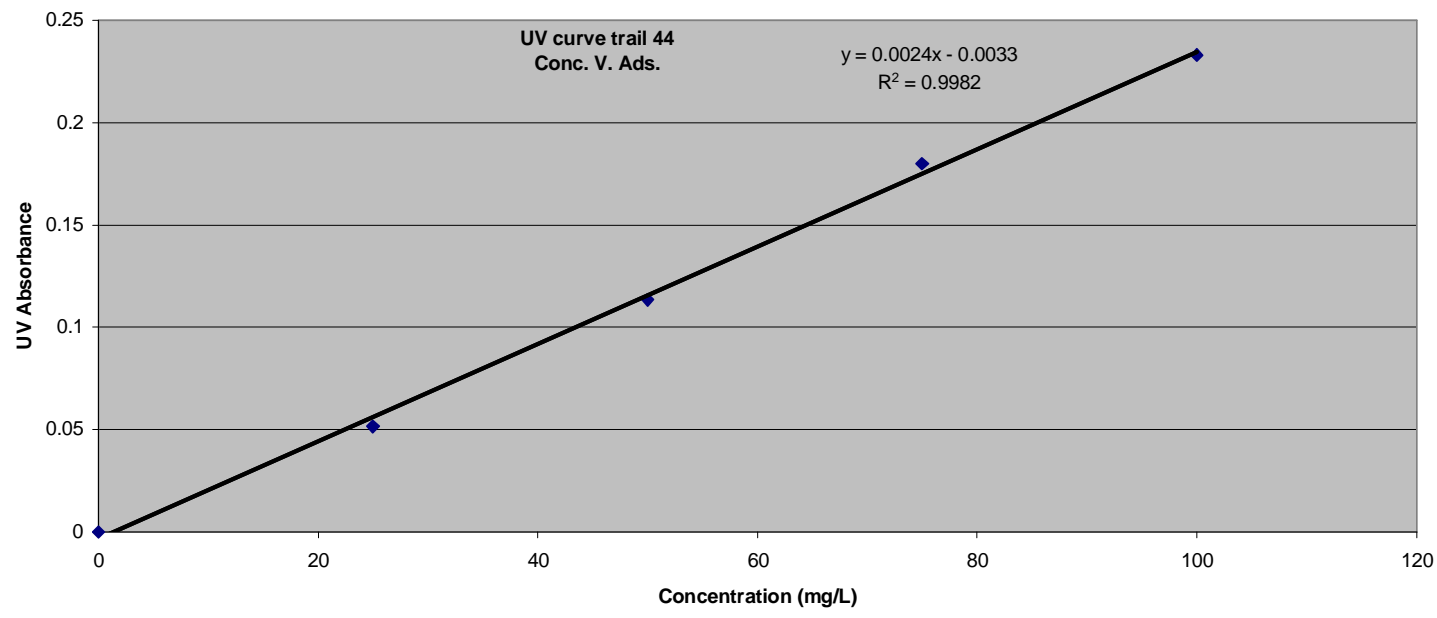

UV Curve Trial 44 Wavelength $=270 \mathrm{~nm}$

Conc. Abs. Max absorbance

ppm

$\begin{array}{rr}100 & 0.233 \\ 75 & 0.18 \\ 50 & 0.1135 \\ 25 & 0.0515 \\ 0 & 0\end{array}$




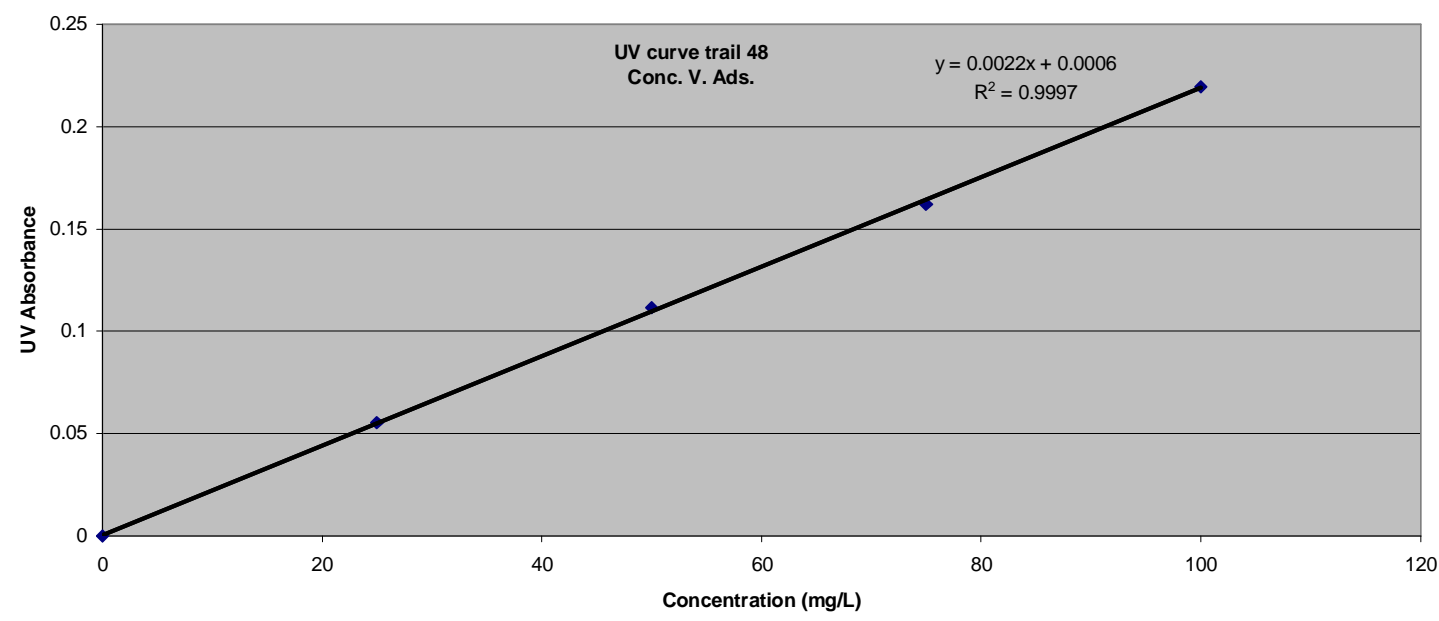

UV Curve Trial 48 Wavelength $=270 \mathrm{~nm}$

Conc. Abs. Max absorbance

ppm

$\begin{array}{rr}100 & 0.2195 \\ 75 & 0.162 \\ 50 & 0.1115 \\ 25 & 0.0555 \\ 0 & 0\end{array}$




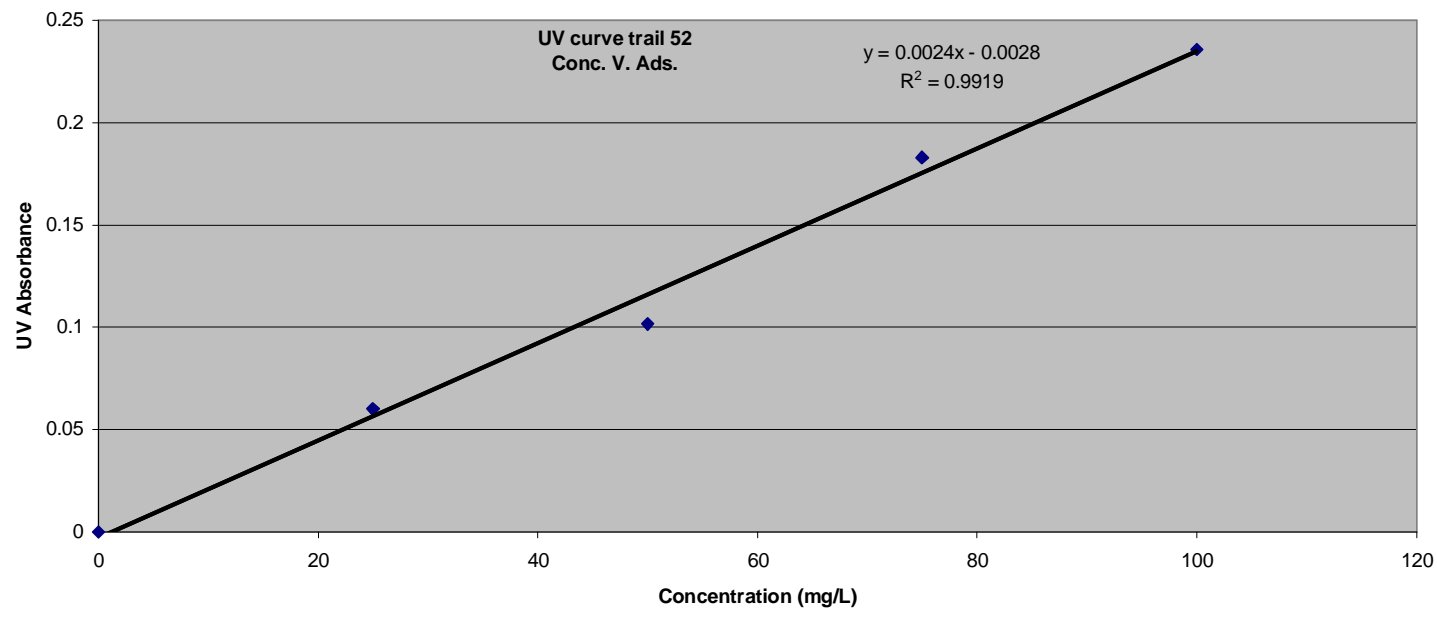

UV Curve Trial 52 Wavelength $=270 \mathrm{~nm}$

Conc. Abs. Max absorbance

ppm

$\begin{array}{rr}100 & 0.2355 \\ 75 & 0.183 \\ 50 & 0.1015 \\ 25 & 0.06 \\ 0 & 0\end{array}$




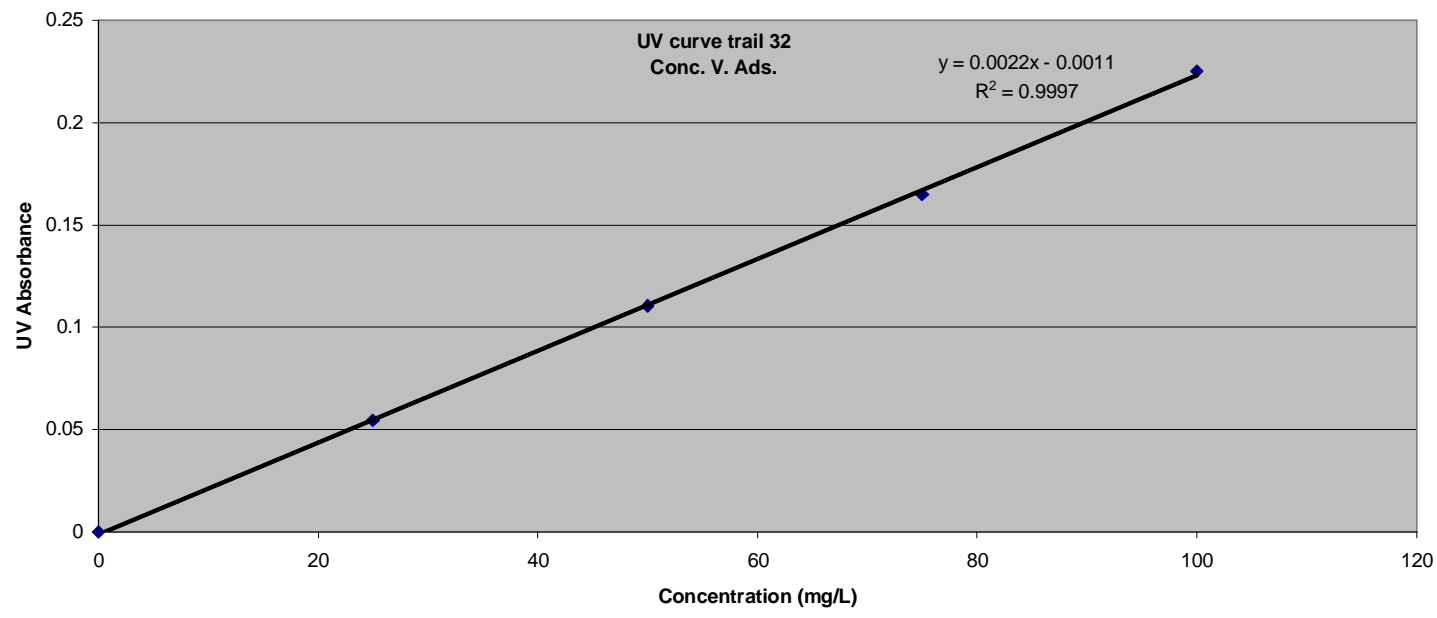

UV Curve Trial 32 Wavelength $=264 \mathrm{~nm}$

Conc. Abs. Max absorbance

ppm

$\begin{array}{rr}100 & 0.225 \\ 75 & 0.165 \\ 50 & 0.1105 \\ 25 & 0.0545 \\ 0 & 0\end{array}$




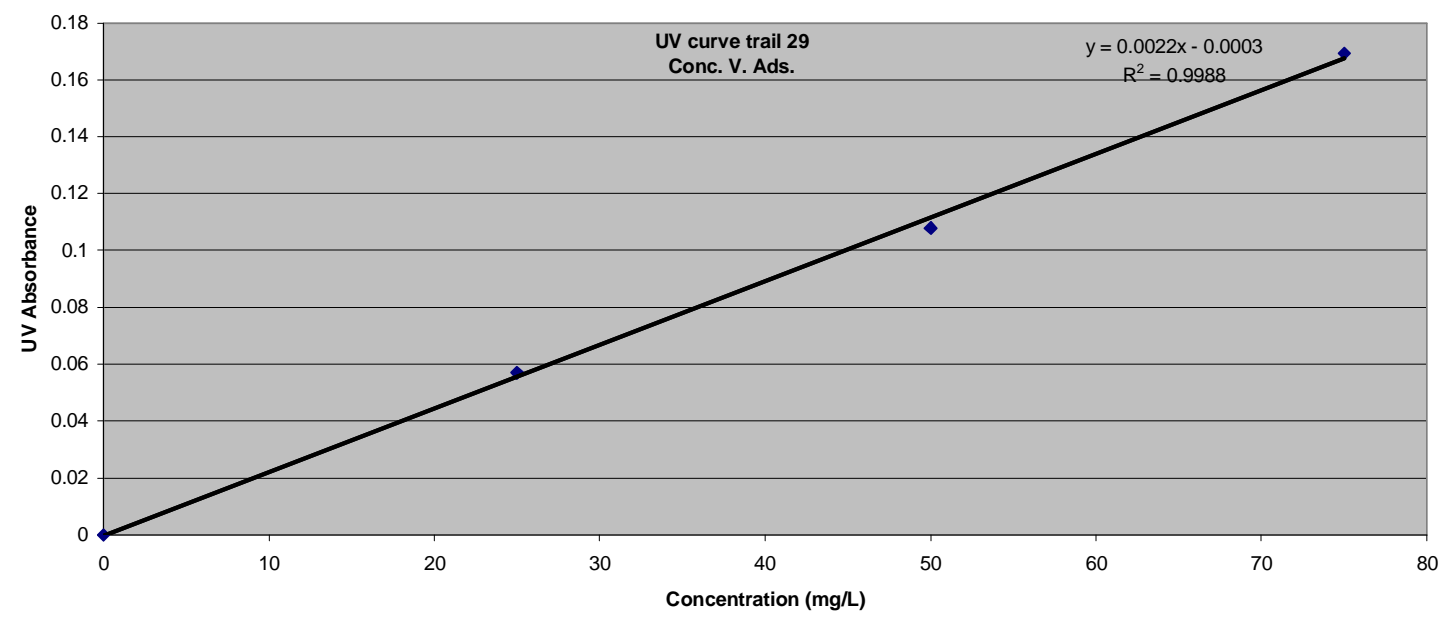

UV Curve Trial 29 Wavelength $=264 \mathrm{~nm}$

Conc. Abs. Max absorbance

ppm

$75 \quad 0.1695$

$50 \quad 0.108$

$25 \quad 0.057$

$0 \quad 0$ 


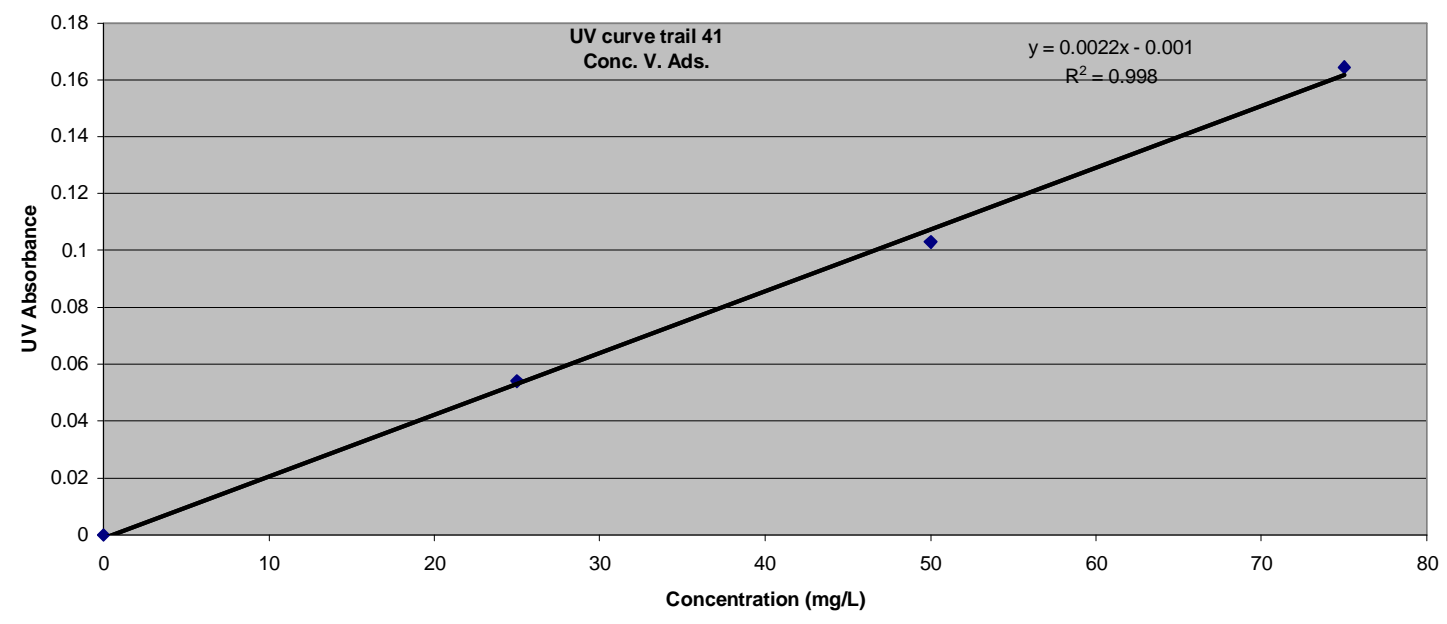

UV Curve Trial 41 Wavelength $=264 \mathrm{~nm}$

Conc. Abs. Max absorbance

ppm

$75 \quad 0.1645$

$50 \quad 0.103$

$25 \quad 0.054$

$0 \quad 0$ 


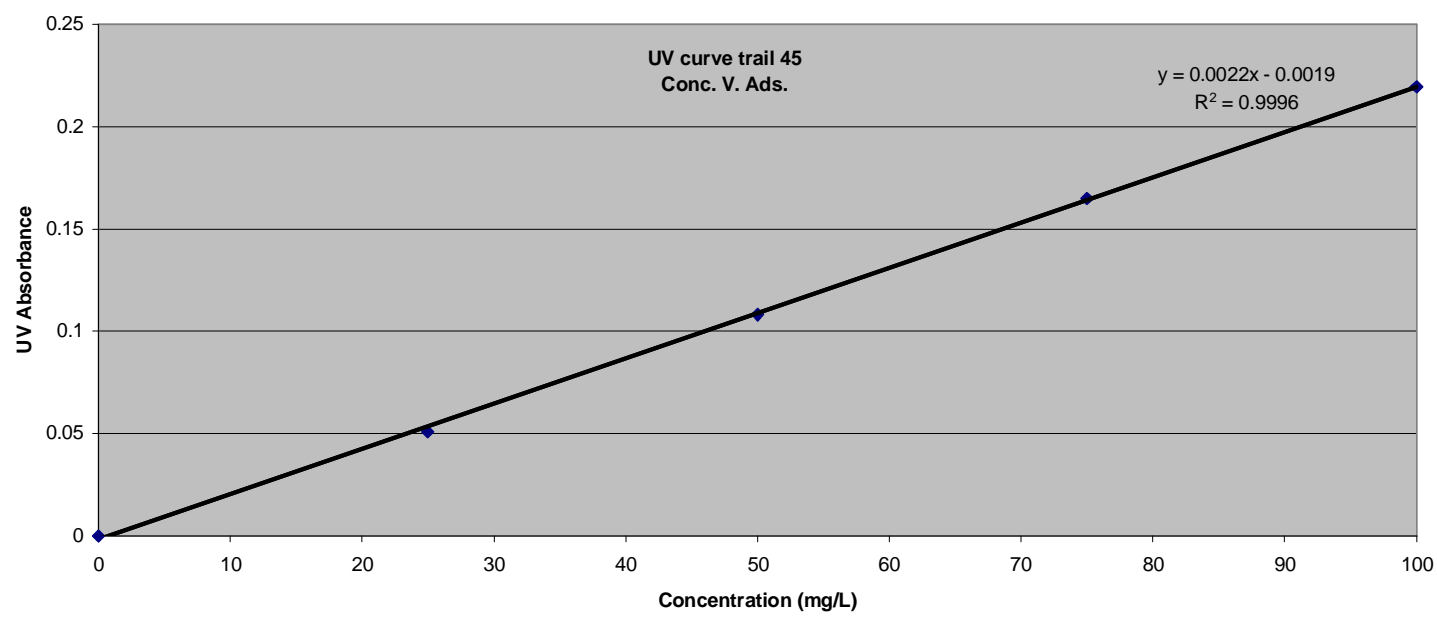

UV Curve Trial 45 Wavelength $=264 \mathrm{~nm}$

Conc. Abs. Max absorbance

ppm

$\begin{array}{rr}100 & 0.2195 \\ 75 & 0.165 \\ 50 & 0.108 \\ 25 & 0.051 \\ 0 & 0\end{array}$




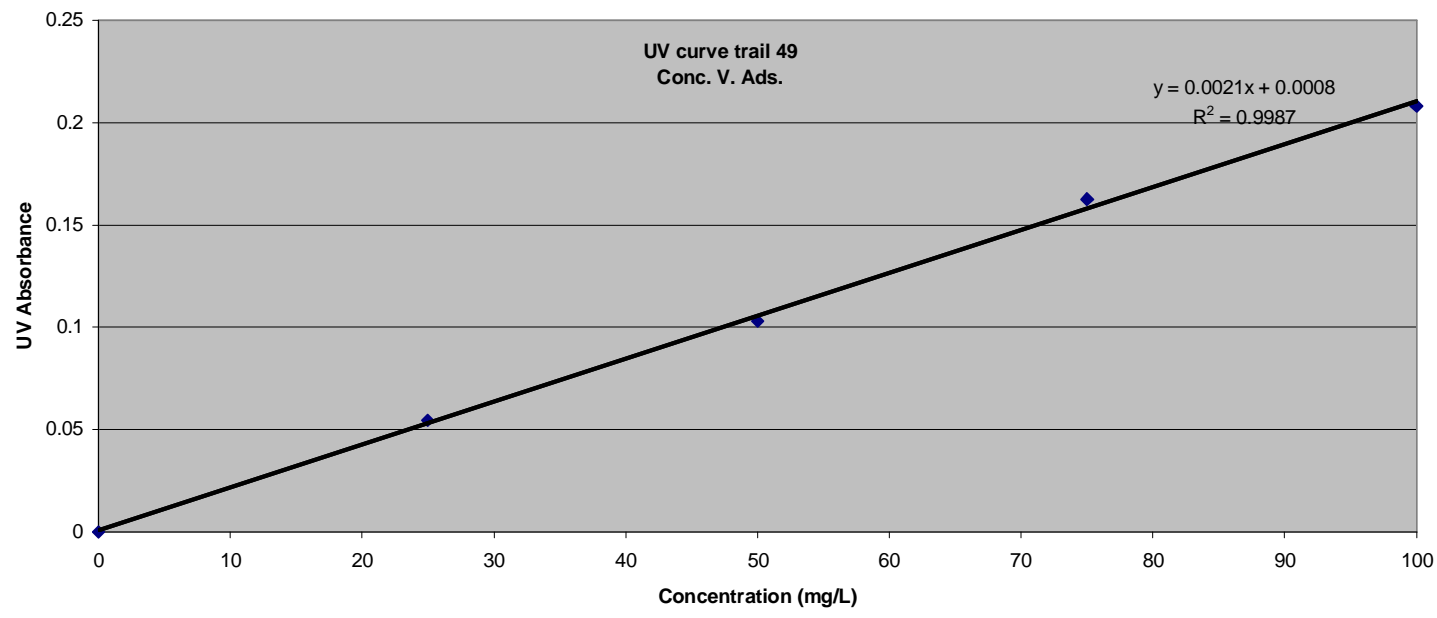

UV Curve Trial 49 Wavelength $=264 \mathrm{~nm}$

Conc. Abs. Max absorbance

ppm

$\begin{array}{rr}100 & 0.208 \\ 75 & 0.1625 \\ 50 & 0.103 \\ 25 & 0.0545 \\ 0 & 0\end{array}$




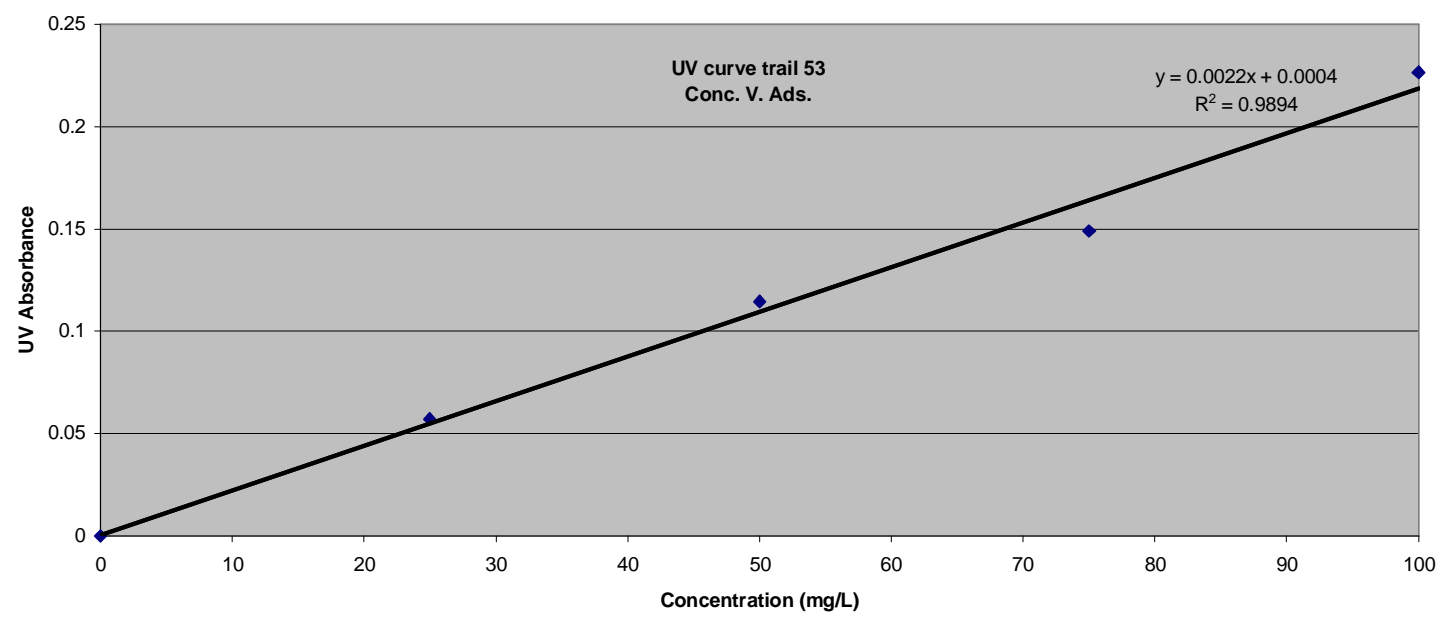

UV Curve Trial 53 Wavelength $=264 \mathrm{~nm}$

Conc. Abs. Max absorbance

ppm

$\begin{array}{rr}100 & 0.2265 \\ 75 & 0.149 \\ 50 & 0.1145 \\ 25 & 0.057 \\ 0 & 0\end{array}$

